\title{
Impacto do tratamento quimioterápico no estado nutricional e no comportamento alimentar de pacientes com neoplasia mamária e suas conseqüências na qualidade de vida
}

Sara Maria Moreira Lima Verde

Dissertação apresentada ao programa de Pós-Graduação em Saúde Pública da Faculdade de Saúde Pública da Universidade de São Paulo para obtenção do título de Mestre em Saúde Pública

Área de concentração: Nutrição

Orientadora: Profa. Dra. Nágila Raquel

Teixeira Damasceno

São Paulo 
..."Cada um de nós constrói a sua história.

E cada ser carrega em si o dom de ser capaz e ser feliz “...

Almir Sater/ Renato Teixeira 
Dedicatória 
Ao meu esposo Renato, por seu companheirismo e por seu carinho durante o tempo dedicado à realização deste trabalho; sua companhia e seu incentivo tornaram tudo mais fácil de ser conquistado;

Aos meus pais, Elmas e Joselila, por serem os que mais crêem nos meus sonhos;

Ao meu irmão João Victor, pelo exemplo de ser humano, pelos conselhos e pelas longas conversas;

À minha família Lima Verde, pela torcida organizada, sempre;

A Deus, por ter me proporcionado a oportunidade deste aprendizado profissional e humano e por me permitir ser alguém melhor. 
Agradecimentos 
À minha orientadora, Profa. Dra. Nágila Raquel Teixeira Damasceno, pelos exemplos de amor à arte da pesquisa, de dedicação com que realiza cada um de seus trabalhos, de carinho e forma especial de tratar cada uma de suas alunas; muito obrigada por todos os ensinamentos e por acreditar neste projeto;

Às amigas Ana Paula Mello, Karin Sarkis, Isis Tande e Letícia Sanches pelos momentos de descontração e pelo relacionamento que construímos nesse tempo de estudos;

A todas as alunas de iniciação científica, em especial Camila Barros e Bruna São Pedro que contribuíram diretamente para a realização deste trabalho; obrigada pelo cuidado e dedicação;

Ao Dr. Mário Mourão Netto, chefe do Departamento de Mastologia Hospital AC Camargo, por sua total receptividade e colaboração;

A Equipe do Departamento de Mastologia - Hospital AC Camargo pelo apoio durante o período de coleta;

A Equipe do Departamento de Nutrição - Hospital AC Camargo, em especial à Nutricionista Tatiana Oliveira pela disponibilidade e apoio;

A todas as pacientes que participaram deste estudo pelo tempo disponibilizado para a coleta de dados e pelo grande aprendizado sobre força e coragem;

Ao Conselho Nacional de Desenvolvimento Científico e Tecnológico CNPq e à Fundação de Amparo á Pesquisa - FAPESP, pelo apoio financeiro. 


\section{RESUMO}

VERDE SMML. Impacto do tratamento quimioterápico no estado nutricional e no comportamento alimentar de pacientes com neoplasia mamária e suas conseqüências na qualidade de vida [Dissertação de Mestrado]. São Paulo: Faculdade de Saúde Pública da USP; 2007.

Introdução: A neoplasia maligna da mama é o segundo tipo de câncer que mais atinge a população brasileira e a principal causa de morte entre as mulheres. Em pacientes com neoplasia mamária o tratamento quimioterápico adjuvante tem sido associado à alteração no estado nutricional, pois pode promover modificação no peso e na composição corporal, além de contribuir para o desenvolvimento de aversões alimentares e alterações na qualidade de vida. Objetivo: Avaliar o impacto do tratamento quimioterápico no estado nutricional e comportamento alimentar de pacientes com neoplasia mamária e suas conseqüências na qualidade de vida. Métodos: Participaram do estudo 25 pacientes, 46(9) anos, pré e pósmenopausadas, com diagnóstico de câncer de mama em estadiamento clínico (EC) I e II, atendidas no Departamento de Mastologia do Hospital AC Camargo - São Paulo, submetidas à cirurgia e ao tratamento quimioterápico adjuvante. As pacientes foram avaliadas em dois momentos: T0 - antes e T1 - após o tratamento quimioterápico. Foram realizadas: avaliação nutricional (peso, índice de massa corporal e composição corporal); avaliação de ingestão alimentar com 3 recordatórios de 24h (R24h); avaliação de aversão alimentar e avaliação de qualidade de vida. Resultados: Os resultados mostraram que o tratamento quimioterápico esteve associado ao aumento no peso das pacientes $(2,2 \mathrm{~kg} ; \mathrm{p}<0,0001)$. Essa variação refletiu as diferenças significativas observadas nos valores IMC $\left(1,0 \mathrm{~kg} / \mathrm{m}^{2} ; \mathrm{p}=0,00\right)$ e promoveu aumento no percentual de pacientes obesas $(4 \%)$ entre os momentos T0 e T1. Os percentuais de água, gordura e massa magra entre os dois momentos permaneceram inalterados. Ao contrário, o ângulo de fase mostrou redução $\left(-0,4^{0} ; p=0,00\right)$. A ingestão de nutrientes não apresentou alteração significativa após o tratamento. Entretanto, foi verificada redução 
significativa no consumo de alimentos do grupo das Frutas e Sucos $(p=0,03)$. Foram observadas aversões alimentares no grupo de bebidas (escore $=-5,04 ; p=0,00)$ e $52 \%$ das pacientes citaram pelo menos um alimento ou grupo como indicativo de aversão. Em relação à qualidade de vida foi verificada redução no aspecto de bem-estar físico (escore $=-3,47$; $p=0,00)$. $O$ estado nutricional não apresentou correlação significativa com qualidade de vida. Porém alguns aspectos do comportamento alimentar foram mutuamente correlacionados com a qualidade de vida Conclusões: $O$ tratamento quimioterápico em mulheres com câncer de mama promoveu ganho de peso associado à redução no ângulo de fase. Estas variáveis em associação às alterações no consumo alimentar e na qualidade de vida reduzida agravam os prognósticos clínico e social dessa população.

Descritores: Câncer de mama; Quimioterapia; Estado nutricional; Aversão alimentar; Qualidade de vida. 


\begin{abstract}
VERDE SMML. Impact of chemotherapy on nutritional status and eating patterns of breast cancer patients and their consequences on quality of life. [Dissertation]. São Paulo (BR): Faculdade de Saúde Pública da USP; 2007.
\end{abstract}

Introduction: The breast cancer is the second leading type of cancer in the Brazilian population and it is the leading cause of death between women. In breast cancer patients adjuvant chemotherapy has been linked to changes in nutritional status, because it can modify weight and corporal composition, besides contributing to development of food aversion and modification on quality of life. Objective: To assess the impact of chemotherapy on nutritional status and eating patterns of breast cancer patients and their consequences on quality of life. Methods: It were recruited from Departamento de Mastologia do Hospital AC Camargo - São Paulo, 25 patients, 46(9) years, pre and post-menopaused, with breast cancer diagnostic in I and II stage, submitted to surgery and adjuvant chemotherapy. Patients were assessed in two moments: T0 - before and T1 - after chemotherapy. Nutritional assessment (weight, body mass index, corporal composition); food intake assessment by three 24 hour recall (R24h); food aversion assessment and quality of life assessment were conducted. Results: The results showed that adjuvant chemotherapy was linked to increase on weight $(2.2 \mathrm{~kg} ; \mathrm{p}<0.00)$. This variation was confirmed by differences on BMI $\left(1.0 \mathrm{~kg} / \mathrm{m}^{2} ; p=0.00\right)$ and increase on percent of obese patients value (4\%), between T0 and T1. Water, fat and soft mass percent between two moments didn't change. In opposite, the phase angle showed reduction $\left(-0.4^{0} ; p=0.00\right)$. Results didn't show modification in nutrients intake, but the patients showed lower intake on fruit and juice group after treatment $(p=0.03)$. It was observed food aversion to drinks group (score $=-5.04 ; p=$ 0.00 ) and $52 \%$ patients cited just one food agreement with bed feel. In relation to quality of life we verified reduction on physic well be (score=-3.47; $\mathrm{p}=0.00$ ). Nutritional status didn't have correlation with quality of life, but some 
aspects of eating patterns showed correlations with quality of life variables. Conclusion: Chemotherapy treatment in breast cancer patients promoted increase weight linked to reduction on phase angle. Theses variables, associated with intake feed alterations and lower quality of life, to make worsen the clinic and social prognostic this population.

Descriptors: Breast cancer; Chemotherapy; Food aversion; Body composition; Quality of life. 


\section{ÍNDICE}

1. INTRODUÇÃO

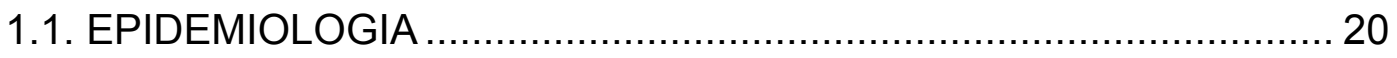

1.2 FISIOPATOLOGIA E ESTADIAMENTO DO CÂNCER DE MAMA..... 22

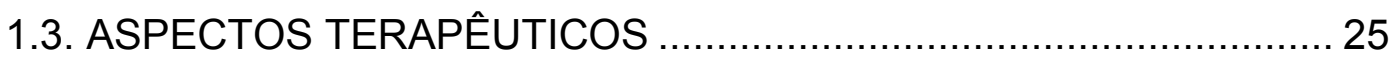

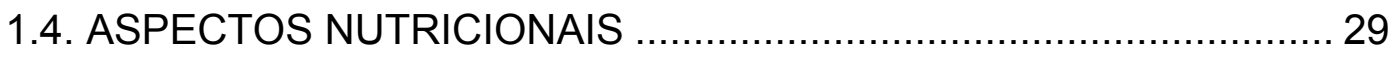

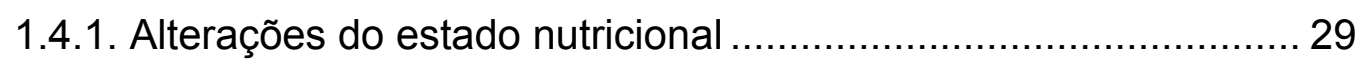

1.4.2. Alterações nas preferências alimentares ................................... 32

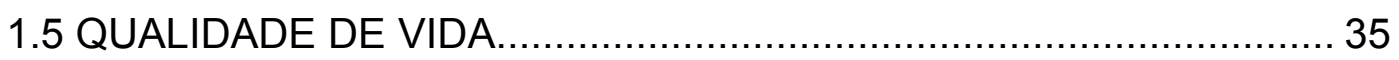

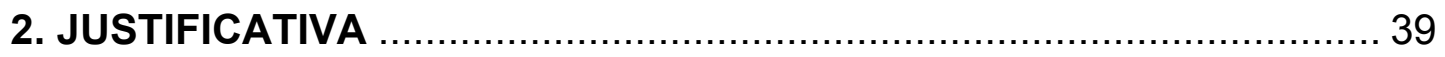

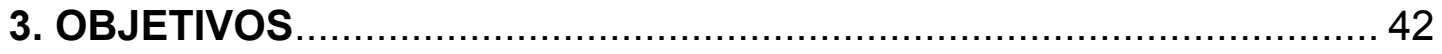

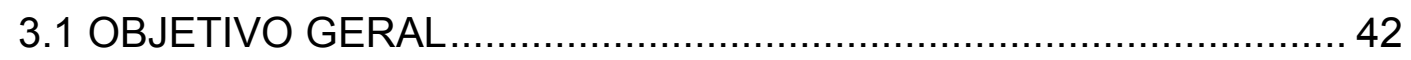

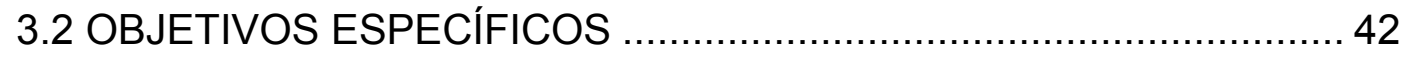

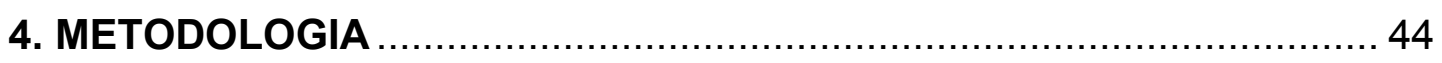

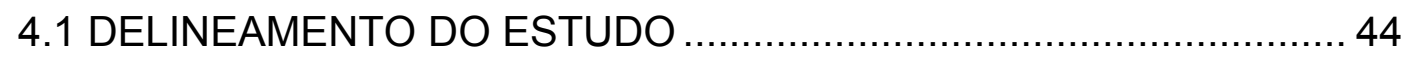

4.2 POPULAÇÃO E LOCAL DO ESTUDO ................................................ 44

4.3 CRITÉRIOS DE SELEÇÃO E EXCLUSÃO …….................................. 45

4.4. PERFIL SÓCIO-ECONÔMICO, CULTURAL E CLÍNICO .................. 47

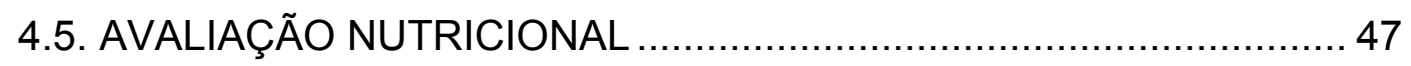

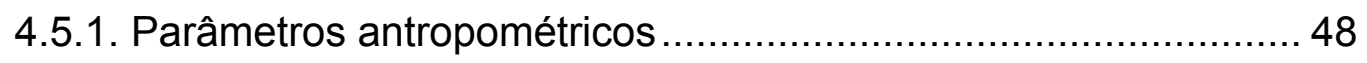

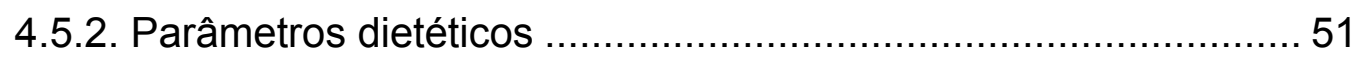

4.6. ANÁLISE DE AVERSÃO ALIMENTAR ........................................... 54

4.7. ANÁLISE DE QUALIDADE DE VIDA............................................... 55

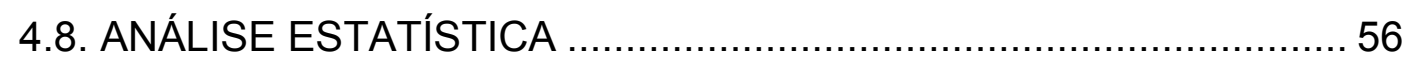

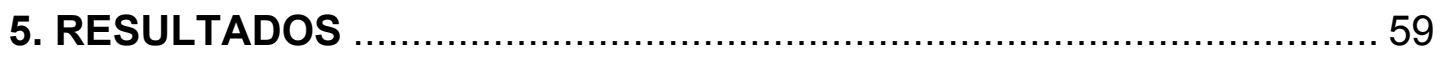

5.1 PERFIL SÓCIO-ECONÔMICO, CULTURAL E CLÍNICO .................... 59

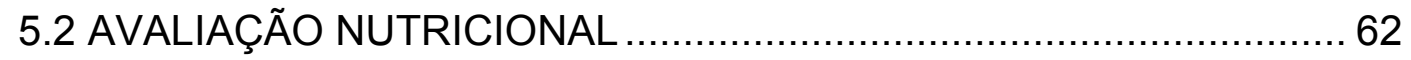

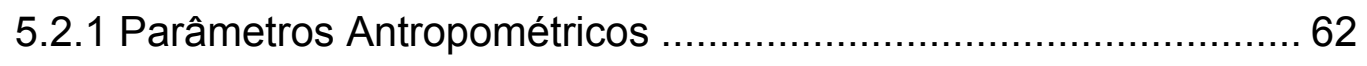

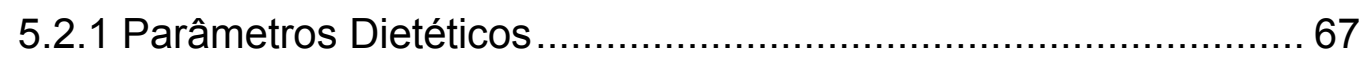

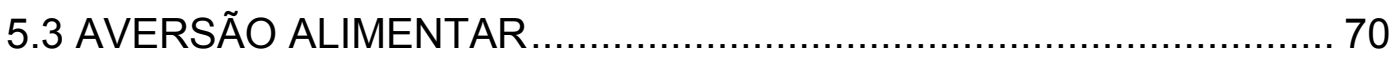

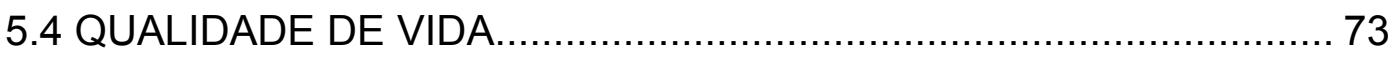

6. DISCUSSÃO 
7. CONCLUSÃO

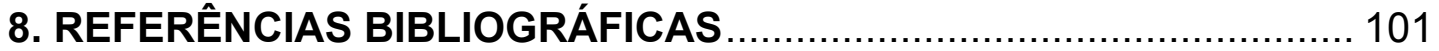

ANEXOS

ANEXO 1: Protocolos de Aprovação dos Comitês de Ética da Faculdade de Saúde Pública-USP e do Hospital do Câncer AC Camargo. ...................... 118

ANEXO 2 - Índice de performance de Karnofsky.................................... 122

ANEXO 3: Termo de consentimento ................................................... 123

ANEXO 4 - Protocolo de avaliação sócio-econômica cultural, clínica e

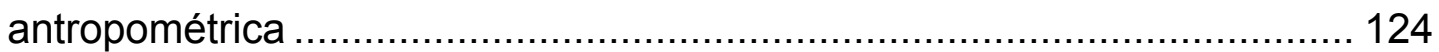

ANEXO 5 - Recordatório de 24 Horas.................................................. 125

ANEXO 6: Manual do Entrevistador ..................................................... 126

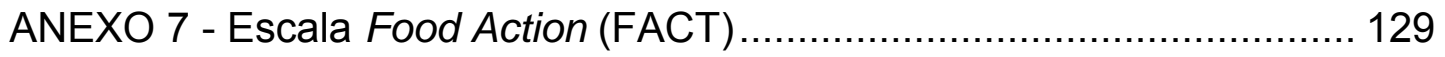

ANEXO 8 - Respostas para Escala de Aversão Alimentar (FACT) ........... 135

ANEXO 9 - Escala Functional Assessment Cancer Treatment -Breast

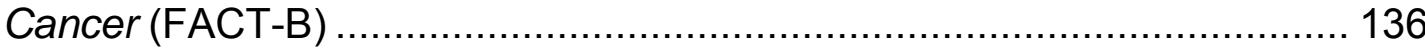




\section{LISTA DE FIGURAS E GRÁFICOS}

Figura 1. Esquema de seleção das pacientes inclusas no estudo, período de Outubro de 2005 a Abril de 2006. Hospital AC Camargo 45

Gráfico 1. Distribuição das pacientes de acordo com a classificação do estado nutricional, segundo a OMS (2000), baseada no IMC $\left(\mathrm{Kg} / \mathrm{m}^{2}\right)$, nos momentos T0 (A) e T1(B). Hospital AC Camargo. 63

Gráfico 2. Distribuição das pacientes de acordo com estado nutricional baseado no percentual de gordura nos momentos T0 (A) e T1 (B). Hospital AC Camargo.

Gráfico 3. Análise vetorial da correlação da diferença entre R/H (T1-T0) e Xc/H (T1-T0) em pacientes com câncer de mama. Hospital AC Camargo. São Paulo. 66

Gráfico 4. Distribuição das pacientes de acordo com ângulo de fase e faixa etária nos tempos T0 e T1. Hospital AC Camargo 67 


\section{LISTA DE QUADROS}

Quadro 1. Estadiamento dos tumores de mama

Quadro 2. Classificação do estado nutricional de adultos, segundo a Organização Mundial de Saúde (OMS, 2000).

Quadro 3. Classificação do estado nutricional, segundo o percentual de gordura corporal. 50

Quadro 4. Valores de referência de ângulo de fase para mulheres saudáveis, segundo faixa etária. 50 


\section{LISTA DE TABELAS}

Tabela 1. Descrição das pacientes de acordo com índice de Karnofsky. Hospital AC Camargo..

Tabela 2. Caracterização das pacientes de acordo com os perfis sócioeconômico e cultural. Hospital AC Camargo. 60

Tabela 3. Descrição das pacientes de acordo com o perfil clínico. Hospital AC Camargo..

Tabela 4. Parâmetros antropométricos das pacientes, nos momentos T0 e T1. Hospital do Câncer - AC Camargo.

Tabela 5. Valores de percentuais de gordura, de massa magra e de água das pacientes, nos momentos T0 e T1. Hospital AC Camargo. 64

Tabela 6. Correlação entre estado nutricional e composição corporal no momento T1. Hospital AC Camargo..

Tabela 7. Valores de correlação significantes das diferenças das variáveis entre os momentos T0 e T1. Hospital AC Camargo. 65

Tabela 8. Valores $\mathrm{R}$ e $\mathrm{Xc}$ das pacientes, nos momentos T0 e T1. Hospital AC Camargo. 66

Tabela 9. Valores de consumo de energia e nutrientes nos momentos T0 e T1. Hospital AC Camargo. 68

Tabela 10. Valores de consumo de micronutrientes nos momentos T0 e T1. Hospital- AC Camargo. 69 
Tabela 11. Valores de consumo de calorias por grupo de alimentos nos momentos T0 e T1. Hospital- AC Camargo.

Tabela 12. Escores de aversões alimentares obtidos pelas diferenças significativas entre os momentos T0 e T1. Hospital AC Camargo. 71

Tabela 13. Escores de aversões alimentares segundo os grupos de alimentos, nos momentos T0 e T1. Hospital AC Camargo. 72

Tabela 14. Escores de qualidade de vida relacionados com bem-estar físico, bem-estar social/familiar, bem-estar emocional, bem-estar funcional e preocupações adicionais. Hospital AC Camargo. 73

Tabela 15. Valores medianos de escores de qualidade de vida relacionados com bem-estar físico, bem-estar social/familiar, bem-estar emocional, bemestar funcional e preocupações adicionais. Hospital AC Camargo.

Tabela 16. Escores dos tópicos das sub-escalas de qualidade de vida bemestar físico, bem-estar social/familiar, bem-estar emocional, bem-estar funcional e preocupações adicionais. Hospital AC Camargo 75

Tabela 17. Correlação entre comportamento alimentar e qualidade de vida no momento T1. Hospital AC Camargo.. 


\section{ABREVIATURAS, SIGLAS E SÍMBOLOS}

AC

$\mathrm{AC}+\mathrm{T}$

BRCA

CMF

CNS

DNA

EC

FAC

FACT

FACT-B

FEC

IBGE

IGF

IMC

INCA

OMS

R24h

SAME

SHBG

TAC
Antracíclico, Ciclofosfamida

Antracíclico, Ciclofosfamida + Taxano

Gene do Câncer de Mama

Ciclofosfamida, Metotrexate, 5-Fluorouracil

Conselho Nacional de Saúde

Ácido desoxirribonucléico

Estadiamento Clínico

5-Fluorouracil, Antracíclico, Ciclofosfamida

Escala Food Action de Aversão Alimentar

Escala Functional Assessment Cancer Treatement Breast Cancer de Qualidade de Vida

5-Fluorouracil, Epirrubicina, Ciclofosfamida

Instituto Brasileiro de Geografia e Estatística

Fator de crescimento ligado à insulina

Índice de Massa Corporal

Instituto Nacional do Câncer

Organização Mundial da Saúde

Recordatório de 24h

Serviço de Arquivos Médicos e Estatísticos

Globulina ligante de hormônio sexual

Taxano, Antracíclico, Ciclofosfamida 
TACO

TBCAUSP

TNM

To

T1

UNIFESP

USDA

USP

WINS
Tabela Brasileira de Composição de Alimentos

Tabela de Composição de Alimentos - USP

Tamanho do tumor, Número de linfonodos e Metástase

Coleta antes do tratamento quimioterápico

Coleta após o tratamento quimioterápico

Universidade Federal de São Paulo

Nutrient Database for Standard Reference Release

Universidade de São Paulo

Women's Intervention Nutrition Study 
Introdução 


\section{INTRODUÇÃO}

\subsection{EPIDEMIOLOGIA}

A palavra câncer inclui muitas designações de doenças caracterizadas pelo desenvolvimento de células que perderam sua capacidade de crescimento normal e, assim, sofreram multiplicação e proliferam desordenadas, no local ou à distância (ROSENFELD et al., 2001).

O aumento no número de casos de neoplasia pode ser atribuído à urbanização, ao incremento na expectativa de vida e aos melhores diagnóstico (ROSENFELD et al., 2001). Desse modo, o câncer vem se convertendo, nas últimas décadas, em um evidente problema de saúde pública mundial (LOPES et al., 2002).

De acordo com o GLOBOCAN - Global Cancer Statistics (2002) aproximadamente 10,9 milhões de novos casos foram estimados e 6,7 milhões de mortes foram atribuídas ao câncer no ano de 2002, em todo o mundo. Entre as doenças crônicas não-transmissíveis, segundo Organização Mundial da Saúde - OMS (2006), o câncer é a segunda principal causa de morte, responsável por $33 \%$ delas e superado apenas pelas doenças cardiovasculares.

Entre os diferentes tipos de neoplasia, o câncer de mama representa, mundialmente, a segunda forma mais comum de câncer com estimativa anual de 1,15 milhões de novos casos e mais de 400 mil mortes (GLOBOCAN, 2002). As taxas de incidência desde 1990, de acordo com 
GLOBOCAN (2002) têm aumentado 0,5\% anualmente, sendo esperados, para o ano de 2010, 1,4 milhões de novos casos de neoplasia mamária.

No Brasil, desde 1930 o câncer se destaca como causa básica de morte e sua participação relativa subiu de $2,7 \%$ dos óbitos em 1930 para $11,2 \%$ em 1980, sendo superado pelos óbitos por doenças cardiovasculares, infecciosas e parasitárias. Em 1998, as neoplasias foram responsáveis por 11,8\% dos óbitos ocorridos no país (MIRRA et al., 2003).

Segundo o INCA - Instituto Nacional do Câncer (2005), a neoplasia maligna de mama é também o segundo tipo de câncer que mais atinge a população brasileira e a primeira causa de morte entre mulheres. Foram estimados para 2006 mais 237 mil novos casos de câncer no sexo feminino no Brasil, dos quais quase 50 mil era neoplasia mamária.

A incidência de câncer de mama na cidade de São Paulo no período de 1997-1999 foi de 95,1/100.000 habitantes (MIRRA et al., 2003). Para o ano de 2006 essa incidência foi estimada, de acordo com o INCA (2005) em $100,8 / 100.000$ habitantes, chegando a mais de 15 mil novos casos no Estado de São Paulo e mais de 6 mil na Capital. De acordo com PINHO e COUTINHO (2005), de 1980 a 2000, a mortalidade por câncer de mama aumentou de 6,14 para 9,64 por cem mil mulheres, resultando em um aumento relativo de $57 \%$ e, portanto, representando o maior problema de saúde pública para o país.

O prognóstico de um paciente com câncer, além das condições inerentes ao próprio hospedeiro, depende fundamentalmente, do diagnóstico precoce, planejamento terapêutico correto e seguimento cuidadoso (LOPES et al., 2002). Os dados mais recentes indicam taxas de cura da doença de $50 \%$, tornando assim o câncer, dentre as doenças crônicas, uma das mais preveníveis e curáveis (COELHO, 2000). 
O câncer de mama, apesar da alta incidência, apresenta relativo bom prognóstico e é, portanto, o mais prevalente câncer no mundo atualmente, com número estimado de 4,4 milhões de mulheres com diagnóstico de neoplasia maligna de mama há pelo menos 5 anos (GLOBOCAN, 2002). $\mathrm{Na}$ população mundial, a sobrevida média após cinco anos, para pacientes com câncer de mama, é de $61 \%$ (INCA, 2004).

Estudos epidemiológicos e pesquisas básicas têm identificado várias condições que predispõe mulheres ao câncer de mama. Idade e parentes em primeiro grau com câncer de mama são os principais fatores de risco para o desenvolvimento dessa neoplasia. Outros múltiplos fatores são também associados com o risco aumentado, tais como: menarca precoce, menopausa tardia, primeira gestação a termo após 30 anos, exposição a hormônios sexuais femininos, câncer de mama prévio, hiperplasia, nuliparidade, portadores de alteração no gene BRCA. Além destes, fatores ambientais como dieta e peso corpóreo têm sido extensivamente investigados como fatores promotores do câncer de mama (GIULIANO, 1997; WINER et al., 2001; PINHO e COUTINHO, 2005; GLOBOCAN, 2002).

\subsection{FISIOPATOLOGIA E ESTADIAMENTO DO CÂNCER DE MAMA}

As células mamárias, localizadas nos ductos ou lóbulos, a cada mês, em determinado momento do ciclo menstrual, recebem estímulos, por meio de estrógenos e progesterona, para iniciar o crescimento celular e se preparar para os períodos de gestação e lactação. Porém, se não ocorrer fecundação, as células recebem novo sinal e voltam ao seu tamanho normal. Esse processo ocorre desde a menarca até o climatério e, em algum momento, pode ocorrer um erro no processo de multiplicação celular devido 
ao crescimento rápido, permanente e repetitivo da célula (DIAZ e CONDEGARCIA, 2000; LANCHEROS et al., 2004).

Segundo MIRSHAHIDI e ABRAHAM (2005), vários subtipos histológicos de câncer de mama podem ser identificados: carcinoma ductal e lobular in situ, carcinoma ductal invasivo, carcinoma lobular invasivo, carcinoma de mamilo, sarcoma, linfoma e tumor phyllodes. Os mesmos autores afirmam que $80 \%$ dos cânceres de mama são carcinomas ductais invasivos.

A neoplasia de mama é classificada de acordo com tamanho do tumor $(\mathrm{T})$, linfonodos regionais $(\mathrm{N})$ e metástases à distância $(\mathrm{M})$, em estágios $0, \mathrm{I}$, II, III, IV, sendo essa nomenclatura, descrita no Quadro 1, e utilizada para comunicação entre investigadores e clínicos (INCA, 2004).

O estágio I (EC I - estadiamento clínico I) é descrito como aquele que apresenta as características T1N0; o estágio II (EC II) é subdividido em Ila e $\mathrm{Ilb}$, tendo o primeiro as características T0N1, T1N1 e T2N0, e o segundo, T2N1 e T3N0. O estágio III (EC III) é subdividido em IIla (TON2M0, T1N0M0, T2N2M0, T3N1M0, T3N2M0) e IIIb (T4 qualquer N M0; qualquer T N3 M0) (INCA, 2004).

O diagnóstico precoce de câncer de mama é de grande importância para o tratamento e cura. Mamografia e exame físico são responsáveis pela detecção de mais de $40 \%$ dos cânceres de mama em estágio inicial e a combinação desses com a biópsia tem sido a melhor alternativa tanto para o diagnóstico, quanto para o planejamento do tratamento (GIULIANO, 1997; NETTO et al., 2002). Dessa forma, nas últimas décadas, segundo BOÉR et al. (2003), em função das mais avançadas formas de diagnóstico, maior número de casos de neoplasia mamária têm sido registrados nos estágios iniciais da doença. 
Quadro 1 - Estadiamento dos tumores de mama

\begin{tabular}{|c|c|}
\hline CLASSIFICAÇÃO & DESCRIÇÃO \\
\hline TX & Tumor primário não pode ser avaliado \\
\hline T0 & Não há evidência de tumor primário \\
\hline Tis & Carcinoma in situ intraductal ou lobular, ou doença de Paget \\
\hline T1 & Tumor de $2 \mathrm{~cm}$ ou menos em sua maior dimensão \\
\hline T1 mic & Microinvasão de $0.1 \mathrm{~cm}$ ou menos \\
\hline T1a & Tumor de 0.1 a $0.5 \mathrm{~cm}$ \\
\hline T1b & Tumor de 0.5 a $1.0 \mathrm{~cm}$ \\
\hline T1c & Tumor de 1.0 a $2 \mathrm{~cm}$ \\
\hline T2 & Tumor de mais de $2 \mathrm{~cm}$ e menos de $5 \mathrm{~cm}$ em sua maior dimensão \\
\hline T3 & Tumor maior que $5 \mathrm{~cm}$ \\
\hline T4 & Tumor de qualquer dimensão, com extensão direta à parede torácica \\
\hline $\mathrm{T} 4 \mathrm{a}$ & Extensão à parede torácica \\
\hline $\mathrm{T} 4 \mathrm{~b}$ & Edema ou ulceração da pele mamária, ou nódulos satélites cutâneos \\
\hline $\mathrm{T} 4 \mathrm{c}$ & $T 4 a+T 4 b$ \\
\hline $\mathrm{T} 4 \mathrm{~d}$ & Carcinoma inflamatório \\
\hline NX & Não é possível avaliar os linfonodos regionais \\
\hline No & Ausência de metástase em linfonodos regionais \\
\hline N1 & Metástases em linfonodo(s) axilare(s) homolaterais móveis \\
\hline N2 & $\begin{array}{l}\text { Metástases em linfonodo(s) axilar(es) homolaterais fixos ou } \\
\text { linfonodos de cadeia mamária interna clinicamente suspeitos }\end{array}$ \\
\hline N2a & $\begin{array}{l}\text { Metástases em linfonodo(s) axilar(es) homolaterais fixos ou outras } \\
\text { estruturas }\end{array}$ \\
\hline $\mathrm{N} 2 \mathrm{~b}$ & Metástase em linfonodo de cadeia mamária \\
\hline N3 & $\begin{array}{l}\text { Metástase em linfonodo(s) supraclavicular(es) com ou sem } \\
\text { envolvimento de linfonodo(s) axilar(es) }\end{array}$ \\
\hline N3a & Metástase em linfonodo(s) intreclavicular(es) \\
\hline N3b & Metástase de cadeia mamária interna e linfonodo(s) axilar(es) \\
\hline N3c & Metástase em linfonodo supraclavicular \\
\hline MX & Presença de metástase não pode ser avaliada \\
\hline M0 & Ausência de metástase à distância \\
\hline M1 & Metástase à distância \\
\hline
\end{tabular}

Fonte: INCA (2004) 


\subsection{ASPECTOS TERAPÊUTICOS}

O tratamento de câncer é complexo e envolve o trabalho de diversos especialistas (OLIVEIRA e ANGELIS, 2003). A cada dia procuram-se formas de tratamento anti-neoplásico que sejam mais efetivas, menos mutilantes e, portanto, mais sociais (LOPES et al., 2002).

As armas disponíveis continuam sendo a cirurgia, radioterapia, quimioterapia, hormonioterapia e, mais recentemente, imunoterapia, cujos resultados são promissores (LOPES et al., 2002).

A cirurgia pode curar um número significante de casos em estágio inicial e fornecer uma avaliação mais segura da extensão da doença, permitindo um estadiamento mais adequado. Porém pode trazer riscos e/ ou morbidades significantes, ou ainda, deformidades ou perdas da função, além de não poder curar os casos com doença disseminada. Apesar das limitações deste procedimento, mais de $60 \%$ das pacientes com câncer são tratadas cirurgicamente, sendo este procedimento usado no diagnóstico e estadiamento de mais de $90 \%$ dos casos (LOPES et al., 2002).

Segundo NETTO e OLIVEIRA (2002), a escolha do tratamento cirúrgico para neoplasia mamária é dependente da localização e tamanho do tumor e, ainda, da análise da mamografia, tamanho da mama e da opção terapêutica da paciente. De acordo com MARQUES e BUZAID (2006) a cirurgia conservadora (quadrantectomia ou setorectomia), associada à dissecção axilar, deve ser considerada o tratamento padrão para todas as pacientes em estágios precoces.

A radioterapia tem papel fundamental no controle local do câncer. Estima-se que $60 \%$ dos pacientes com câncer necessitem de radioterapia, 
curativa ou paliativa, durante o curso de sua doença. As novas técnicas de radioterapia permitem a melhora dos resultados e menores danos a tecidos sadios (SALVAJOLI e SANTOS, 2002). A radioterapia é indicada para todas as pacientes com cirurgia conservadora e para as pacientes submetidas à mastectomia que preencham um dos seguintes critérios: (a) tumor maior que $5 \mathrm{~cm}$ ou que invade pele ou músculo; (b) mais que 3 linfonodos positivos ou; (c) linfonodos com extravasamento extracapsular (MARQUES e BUZAID, 2006).

CHU e DeVITA (2001) definiram quimioterapia como o tratamento anti-neoplásico sistêmico, sendo classificado em três grandes setores: neoadjuvante, terapêutica e adjuvante. A neoadjuvante caracteriza-se pelo uso de quimioterapia como tratamento inicial em pacientes que serão submetidos ao tratamento cirúrgico e/ ou radioterápico, utilizada quando há intenção de diminuir o tumor primário para tornar factível a cirurgia ou possibilitar menor mutilação do órgão no processo cirúrgico (ANELLI, 2002; GIMENEZ, 2003).

A quimioterapia terapêutica ocorre quando o tratamento principal é a submissão da paciente à quimioterapia. É a primeira opção para câncer avançado para o qual não existe tratamento alternativo. Pode ser curativa ou paliativa (CHU e DeVITA, 2001; ANELLI, 2002; GIMENEZ, 2003).

A quimioterapia adjuvante associa tratamento sistêmico e local. É utilizada após o tumor primário ter sido controlado por terapia cirúrgica ou radioterapia. Esta forma de quimioterapia atua no combate a processos de metástases no momento em que o tumor está em seu funcionamento mínimo ou inexistente, sem resistência, permitindo que a droga exerça seu efeito potencial (CHU e DeVITA, 2001). MARQUES e BUZAID (2006) afirmaram que a quimioterapia adjuvante aumenta a sobrevida em pacientes com câncer de mama, e que esquemas mais tóxicos produzem maior ganho. 
Em um estudo de revisão, PEREZ e MUSS (2005), afirmaram que o risco de recorrência do tumor é $23,5 \%$ menor nas pacientes que fazem uso da terapia anti-neoplásica e que a morte nessas pacientes é 15,3\% inferior do que naquelas que não recebem essa terapia. Porém, de acordo com MARQUES e BUZAID (2006) o benefício relativo da quimioterapia adjuvante diminui com a idade. Portanto, a opção pela quimioterapia adjuvante em pacientes maiores de 65 anos deve ser individualizada, devendo ser considerada a presença de complicações associadas.

Os importantes obstáculos encontrados no uso deste tratamento têm sido: a toxicidade para tecidos normais e o desenvolvimento de resistência celular aos agentes anti-neoplásicos (CHU e DeVITA, 2001).

GIMENEZ (2003) afirmou que cada quimioterápico tem seu perfil de toxicidade e os efeitos colaterais têm relação direta com a droga utilizada. Os efeitos colaterais mais comuns são: a mielotoxicidade, cistite, toxicidade pulmonar, cardiotoxicidade, mucosite, náuseas e vômitos. A combinação racional de drogas é importante para evitar o uso de anti-neoplásicos que se sobreponham, evitando assim efeitos colaterais cumulativos.

De acordo com CHU e DeVITA (2001), ANELLI (2002) e GIMENEZ (2003), os quimioterápicos podem ser classificados em:

-(a) Agentes alquilantes: capazes de quebrar a seqüência da molécula de DNA. São exemplos: ciclofosfamida, ifosfamida, melfalan, mitomicina.

-(b) Análogos da platina: interferem na replicação do DNA, atuam também na replicação do RNA e síntese de proteínas. São exemplos: cisplatina, carboplatina, oxaliplatina.

-(c) Antimetabólicos: classe de drogas antineoplásicas com maior espectro de ação na prática oncológica. São exemplos: metotrexate, 5-fluorouracil. 
-(d) Agentes que atuam na topoisomerase: inibem a topoisomerase I e II, impedindo a síntese de DNA. São exemplos: antracíclicos, epipodocilotoxinas, análogos da campitotecina, mitoxantrona.

-(e) Agentes que agem nos microtúbulos: atuam sobre os microtúbulos bloqueando a progressão do ciclo celular. São exemplos: alcalóides da vinca (vinblastina, vincristina, vindesina), taxanos (paclitaxel, docetaxel), extramustine.

No tratamento sistêmico adjuvante para câncer de mama, o protocolo de escolha depende do tamanho do tumor, da presença de comprometimento de linfonodos regionais e da positividade de receptores de estrógeno e progesterona (ANELLI et al., 2002). Depende ainda da idade da paciente, do estado de performance observado pelo índice de Karnofsky, estado nutricional (desnutrição ou obesidade), função orgânica e presença de comorbidades (WALSH et al., 1989; BUZZONI et al., 1991; SMITH e DESCH, 1991; BAKER et al., 1995; PERRY, 2001).

PEREZ e MUSS (2005) afirmaram que entre os agentes quimioterápicos associados que favorecem a melhor sobrevida estão os agentes alquilantes, principalmente a ciclofosfamida; antimetabólicos, como metrotexato e 5-fluorouracil; os antracíclicos, epirrubicina e doxorubicina e; mais recentemente os taxanos (paclitaxel e docetaxel). Baseando-se nesses agentes antineoplásicos, os esquemas quimioterápicos CMF (ciclofosfamida, metotrexate, 5-fluorouracil), FAC (5-fluorouracil, antracíclicos, ciclofosfamida), FEC (5-fluoruracil, epirrubicina, ciclofosfamida), AC (antracíclico, ciclofosfamida), AC+T e TAC têm mostrado benefício no tratamento de pacientes com neoplasia mamária (VENTURINI et al. 2005; PEREZ e MUSS, 2005). 


\subsection{ASPECTOS NUTRICIONAIS}

\subsubsection{Alterações do estado nutricional}

O comprometimento do estado nutricional é uma condição freqüente nos pacientes com câncer e está associado com maiores índices de mortalidade e morbidade, conforme afirmaram BERTERETCHE et al. (2004). KORNEK (2002) e TRINTIN (2003) afirmaram que a alteração do estado nutricional se desenvolve durante $\mathrm{o}$ progresso da neoplasia e também durante o tratamento, estando relacionado com maior tempo de hospitalização e menor resposta à quimioterapia e radioterapia, e sua maior conseqüência é o aumento do risco de complicações para o paciente.

O ganho de peso em pacientes com neoplasia mamária após o diagnóstico, durante e após tratamento quimioterápico é um fenômeno amplamente estudado. De acordo com COSTA et al. (2002) e MICHELLE et al. (2004), mulheres com câncer de mama, em tratamento quimioterápico adjuvante, apresentam tendência progressiva ao ganho de peso. Porém, segundo KUTYNEC et al. (1999) a causa desse ganho não é clara e pode ser associada com: ingestão alimentar aumentada, decréscimo da atividade física, alteração da taxa metabólica basal ou estado de menopausa.

Em estudo com 74 pacientes com câncer de mama em quimioterapia adjuvante, acompanhadas por 5 meses, COSTA et al. (2002) observaram que $81,1 \%$ delas apresentaram ganho de peso, e o ganho mensal médio foi de $0,91(1,19) \%$ do peso inicial. As pacientes de menor idade apresentaram maior ganho de peso. A quimioterapia adjuvante, segundo FREEDMAN et al. (2004), tem se mostrado um fator preditor desse ganho de peso, 
independente de variáveis como idade, ingestão calórica e índice de massa corporal.

CAMORIANO et al. (1990), em estudo com 545 mulheres em tratamento quimioterápico adjuvante, observaram ganho de peso de 3,6 kg para mulheres pós-menopausadas e de $5,9 \mathrm{~kg}$ para mulheres prémenopausadas. De acordo com os mesmos autores, o ganho de peso durante o tratamento quimioterápico adjuvante está relacionado com o maior índice de recidiva e a menor sobrevida dessas pacientes.

Segundo FREEDMAN et al. (2004), o ganho de peso ocorre entre 5096\% das pacientes com câncer de mama durante o tratamento com quimioterapia adjuvante. Esse ganho de peso varia de 2,5-6,2 kg, durante o tratamento, e se mantém por um período de até 1 ano $(2,0-4,0 \mathrm{~kg})$. Foi observada, no mesmo estudo, modificação na composição corpórea das pacientes, com aumento da gordura corpórea e diminuição da massa magra.

KUTYNEC et al. (1999), comparando mulheres pré-menopausadas com neoplasia mamária em estágio inicial, antes e após o tratamento quimioterápico, não verificaram diferença significante de peso entre os dois momentos, porém encontraram redução significante na massa magra e aumento no percentual de gordura.

O tipo de protocolo quimioterápico, segundo alguns autores, pode influenciar a modificação na composição corpórea das pacientes. $O$ tratamento com AC usa menos agentes anti-neoplásicos e tem menor duração do que o tratamento com CMF e está, portanto, associado com menor tendência ao ganho de peso. FREEDMAN et al. (2004) afirmaram que o tratamento com CMF (ciclofosfamida, metotrexato, fluorouracil) promove aumento de gordura e o AC (antracíclico, ciclofosfamida) promove perda de massa magra, o que aumenta o percentual de gordura corpórea. 
MICHELLE et al. (2004), também estudando mulheres com neoplasia mamária $(n=17)$ sob quimioterapia adjuvante (CMF e FEC - fluoruracil, epirrubicina, ciclofosfamida), verificaram ganho de peso durante $\mathrm{O}$ tratamento, ganho este que se estendeu ao longo de 1 ano $[5(3,8) \mathrm{kg}]$. Durante este período, o ganho de peso foi acompanhado de aumento da gordura corpórea e diminuição da massa magra.

De acordo com HEBER et al. (1996), o excesso de gordura associado à reduzida massa magra corpórea é denominado obesidade sarcopênica e tem sido observado em estudos realizados com mulheres em tratamento quimioterápico decorrentes de câncer de mama. Porém, os efeitos físicos ou metabólicos relacionados com as mudanças de composição corporal, observadas em mulheres com neoplasia mamária em tratamento quimioterápico adjuvante, ainda não estão bem esclarecidos (FREEDMAN et al., 2004).

A presença de fadiga é um efeito colateral comum em pacientes com câncer de mama em função do tratamento agressivo e prolongado envolvendo cirurgia, quimioterapia e radioterapia. A fadiga é citada como um dos mais freqüentes e desconfortáveis efeitos colaterais experimentados pelas pacientes e está associada com redução na atividade física e, dessa forma, pode atuar em sinergia com outros fatores, contribuindo para o ganho de peso e modificação na composição corpórea nessas pacientes (KUTYNEC et al., 1999).

De acordo com HERMAN et al. (2005) essa modificação no estado nutricional em função do ganho de peso pode colocar as pacientes em risco aumentado para recorrência da neoplasia e também para o aparecimento de outras doenças crônicas como doença cardiovascular e diabetes. COSTA et al. (2002) consideraram ainda que o ganho de peso adquirido durante $\circ$ tratamento do câncer tem magnitude suficiente para interferir na qualidade 
de vida da paciente, uma vez que representa um impacto negativo na imagem que ela tem de si mesma e em sua auto-estima.

\subsubsection{Alterações nas preferências alimentares}

FEUZ et al. (2005) definiram comportamento alimentar como a combinação de ações que incorporam aspectos de procura e aquisição do alimento, condições do ambiente onde as refeições ocorrem, e também quantidade e qualidade dos alimentos ingeridos bem como os fenômenos pré e pós-ingestão.

Neste contexto, a avaliação do consumo e das preferências alimentares em pacientes com câncer de mama, embora não caracterizando o comportamento alimentar num sentido mais amplo, contribui indicando que fatores emocionais e práticos, como o "cuidado alimentar" em função do diagnóstico e da terapia anti-neoplásica, podem influenciar nas escolhas alimentares e no estado nutricional dessa população.

Pacientes com câncer mostram redução do apetite e, conseqüente, redução na ingestão alimentar em conseqüência da localização do tumor ou efeitos colaterais da terapia anti-neoplásica (MERCADANTE, 1996; MEIJA et al. 1997; SMITH e SOUBA, 2001; OLIVEIRA e ANGELIS, 2003). COTRIM (2003) afirmou que os efeitos colaterais tóxicos mais comuns a agentes quimioterápicos relacionados à nutrição são: náuseas, vômitos, constipação, diarréia, anorexia, leucopenia, anemia, trombocitopenia, mielodepressão, disgeusia, fadiga, mal-estar, mialgias, febre, estomatite, mucosite, dor abdominal, ulceração de cólon. Esses efeitos colaterais são sempre 
dependentes da droga utilizada, da dose e se concomitante ou não à radioterapia.

KENNEDY e DIAMOND (1997), ANELLI (2002) e GIMENEZ (2003) verificaram que a mucosite oral é o efeito colateral mais freqüente no tratamento anti-neoplásico. A quimioterapia interfere no ciclo celular das células da mucosa, alterando sua integridade, modificando a microbiota oral, quantidade e composição salivar e maturação epitelial.

Náuseas e vômitos aparecem como uma das maiores preocupações das pacientes. Para êmese, são descritas três síndromes: a síndrome aguda (1-2h após o recebimento da quimioterapia); a tardia (9-18h após o recebimento da quimioterapia) e a síndrome antecipatória (antes de receber o tratamento). Como conseqüência, os pacientes em quimioterapia apresentam dor, disfagia e anorexia (KENNEDY e DIAMOND, 1997; ANELLI, 2002; GIMENEZ, 2003).

Esses fatores contribuem para a formação de aversões alimentares adquiridas (HOLMES, 1993). Essa condição alimentar é definida como aversão por alimentos após sua ingestão ter sido acompanhada de alguma doença ou sintoma, neste caso, mais freqüentemente, náuseas e vômitos (MATTES et al. 1987).

BERTERETCHE et al. (2004) afirmaram que as aversões alimentares adquiridas em pacientes com câncer resultam da associação entre sensação de mal-estar, que ocorre em conseqüência do tratamento anti-neoplásico, e o sabor do alimento simultaneamente consumido. O alimento é então interpretado como ruim e, conseqüentemente, evitado.

Uma outra hipótese para a presença das aversões alimentares adquiridas é o efeito das drogas anti-neoplásicas sobre o funcionamento das 
células sensoriais do paladar. Em indivíduos normais o turnover das células sensoriais do paladar é realizado continuamente e novas sinapses entre essas células e fibras nervosas acontecem permitindo o reconhecimento de sabores. Em pacientes submetidas ao tratamento anti-neoplásico, esse processo de renovação celular é diminuído durante o período em que a droga permanece ativa e isto pode reduzir a sensibilidade do paladar para alguns sabores (BERTERETCHE et al., 2004).

Aversões alimentares adquiridas, em geral, têm significante implicação nutricional, e a ausência de alguns alimentos pode afetar o estado nutricional e a qualidade de vida das pacientes. Em estudo realizado com 52 pacientes submetidas à quimioterapia, HOLMES (1993) mostrou que $82 \%$ delas apresentaram aversão alimentar após o início do tratamento. Os alimentos mais comuns no registro de aversão foram: café, chá, frutas cítricas, chocolate e carne vermelha.

SCHWARTS et al. (1996), em estudo com 40 pacientes, com diagnóstico de câncer de mama em EC I e II, submetidos à quimioterapia encontraram redução no consumo de bebidas presentes na dieta normal dessas pacientes, em conseqüência de aversão alimentar adquirida resultante do tratamento anti-neoplásico.

McELIGOT et al. (2000), em um estudo transversal, comparando mulheres com ou sem história de câncer de mama, encontraram no primeiro grupo aversão para alimentos como bolo, manteiga e produtos lácteos.

ROCK (2003) afirmou que mulheres com câncer de mama, submetidas ao tratamento quimioterápico e/ou radioterápico, podem apresentar alteração de curto período na ingestão alimentar devido aos efeitos adversos no apetite e nas funções gastrointestinais. 
Em estudo com mulheres com câncer de mama recebendo quimioterapia adjuvante, GRINDEL et al. (1993), encontraram modificações no sabor para alimentos como carne vermelha, aves, café e bolo, mas a aversão alimentar não foi considerada significante. Segundo HOLMES (1993) mesmo que a aversão alimentar presente em decorrência do tratamento quimioterápico não promova perdas nutricionais importantes, a exclusão de alguns alimentos pode afetar a qualidade de vida da paciente.

TRINTIN (2003) verificou que o fato da paciente ser portadora de uma neoplasia maligna, já a classifica como paciente de risco nutricional, em virtude de todas as alterações que esta patologia implica. A escolha adequada da intervenção e/ou acompanhamento nutricional deverão ser traçados de forma clara, a fim de minimizar o risco de depleção nutricional da paciente oncológica em tratamento quimioterápico.

\subsection{QUALIDADE DE VIDA}

A OMS (2000) define qualidade de vida como "a percepção do indivíduo sobre sua vida no contexto da cultura e sistemas de valores nos quais ele vive e em relação aos seus objetivos, expectativas, padrões e preocupações". A qualidade de vida se refere ainda à apreciação dos pacientes em relação a si mesmos e apresenta conceito amplo que aborda domínios como bem-estar físico, social e psicológico (CELLA e CHERIN, 1988; PANDEY et al., 2005). Pacientes com câncer de mama sofrem transtornos importantes na função física, saúde mental e bem-estar, o que leva a variabilidade na sua qualidade de vida.

MOLS et al. (2005), afirmaram que o número de pacientes com câncer de mama, sobreviventes após o diagnóstico, por um período de até 
cinco anos livre da doença, está aumentando rapidamente devido ao diagnóstico precoce e aos avanços no tratamento anti-neoplásico.

Esse aumento na sobrevida das pacientes conduz a maior preocupação com os efeitos colaterais decorrentes do diagnóstico e do tratamento anti-neoplásico. O diagnóstico e o tratamento para neoplasia mamária são difíceis de serem assimilados, causam seqüelas físicas e psicológicas sérias e, muitas vezes, permanentes e, desse modo, alteram a qualidade de vida das pacientes (WAPNIR et al., 1999; VACEK et al., 2003).

De acordo com VACEK et al. (2003), fatores como idade, relacionamento familiar, imagem corporal alterada em função da mastectomia, fadiga persistente e alteração de peso afetam diretamente a qualidade de vida das pacientes com neoplasia mamária. Diante disso, diversos estudos têm sido direcionados para avaliar a qualidade de vida de pacientes com neoplasia mamária, indicando a importância do estresse emocional no início e, também, no desenvolvimento da doença (SIMONTON et al., 1987).

ALBERT et al. (2004) confirmaram em estudo com 289 pacientes com câncer de mama que, independente das chances de sobrevivência, o transtorno psicológico está sempre presente nessas mulheres, sendo amenizado ao longo do tempo, mas persistindo acima do padrão em todas as pacientes que possuem a favorável chance de sobrevida por cinco anos.

O tratamento quimioterápico é caracterizado por inúmeros efeitos colaterais que, muitas vezes, são responsáveis pelos medos e recusas à terapia, mesmo quando indicado para melhora dos sintomas e com possibilidades de cura em alguns tipos de tumor. GANZ et al. (2002) e JANZ et al. (2005), encontraram que pacientes com câncer de mama que receberam quimioterapia adjuvante possuíam pior quadro de qualidade de 
vida, nos aspectos de bem-estar social, fadiga, imagem corporal e perspectivas em relação ao futuro, em comparação àquelas isentas do tratamento.

Alguns autores evidenciam a relação direta entre quimioterapia, mudanças nos hábitos alimentares e qualidade de vida. RHODES e McDANIEL (2001) observaram o fato de que alguns alimentos podem apresentar sabor diferente devido ao paladar alterado das pacientes com neoplasia mamária em tratamento quimioterápico.

Posteriormente, BERGVIST e WENGSTRÖM (2006), em estudo realizado com mulheres diagnosticadas com diferentes tipos de câncer e submetidas à quimioterapia, também identificaram odor e sabor alterados dos alimentos como um incômodo freqüente entre as pacientes. $O$ desconforto destas sensações somado a fatores decorrentes delas, tais como deficiências nutricionais, alteração de peso, desidratação e desequilíbrio eletrolítico, podem ser causadores de um considerável impacto negativo na qualidade de vida destas pacientes, afetando o funcionamento físico, cognitivo, social, emocional e geral. 
Justificativa 


\section{JUSTIFICATIVA}

O câncer tem sido visto como um problema de saúde pública em função da crescente incidência. Em particular, o câncer de mama tem merecido a atenção de importantes estudos por estar entre as principais causas de morte no sexo feminino, fato visto no mundo e no Brasil. No Estado de São, o cenário epidemiológico é similar, com o câncer de mama atingindo mais de 15 mil mulheres.

Paralelo ao aumento na incidência do câncer, novos tratamentos têm surgido e mostrado resultados interessantes em relação à neoplasia maligna de mama, promovendo o aumento da sobrevida e tornando essa neoplasia a de maior prevalência em todo o mundo.

Neste contexto, o ganho de peso em pacientes com câncer de mama submetidas ao tratamento quimioterápico adjuvante têm recebido atenção especial por diferentes estudos em todo o mundo em função da sua associação com recidiva do tumor e redução na sobrevida. Apesar dessas observações, no Brasil, são bastante reduzidos os estudos sobre o impacto da quimioterapia no estado nutricional das pacientes com câncer de mama. Além das modificações antropométricas, a presença de aversão alimentar adquirida é outro efeito colateral que pode promover alterações nutricionais importantes nessas pacientes.

O ganho de peso e a presença de aversões alimentares adquiridas são fatores que interagem com a auto-estima e o convívio social das pacientes e que, podem, de alguma forma, interferir na sua qualidade de vida. 
Portanto, considerando a crescente incidência de câncer $e$, particularmente, o aumento de câncer de mama, e ainda o impacto do tratamento anti-neoplásico nas condições físicas e psicológicas da paciente, torna-se indispensável avaliar em que grau esse tratamento afeta o estado nutricional e o comportamento alimentar e, ainda, as possíveis influências dessas variáveis na qualidade de vida dessas pacientes.

A partir desses resultados, orientações mais adequadas aos profissionais, pacientes e familiares poderão ser traçadas visando evitar, aceitar e controlar tais fatores. 
Objetivos 


\section{OBJETIVOS}

\subsection{OBJETIVO GERAL}

- Avaliar o impacto do tratamento quimioterápico no estado nutricional e no comportamento alimentar de pacientes com neoplasia mamária e suas conseqüências na qualidade de vida.

\subsection{OBJETIVOS ESPECÍFICOS}

- Caracterizar as condições sócio-econômicas e culturais das pacientes;

- Determinar o perfil clínico das pacientes;

- Avaliar o perfil antropométrico;

- Investigar o consumo alimentar;

-Monitorar a presença de aversões alimentares;

-Avaliar a qualidade de vida das pacientes;

-Investigar correlação entre estado nutricional, comportamento alimentar e qualidade de vida das pacientes. 
Metodologia 


\section{METODOLOGIA}

\subsection{DELINEAMENTO DO ESTUDO}

O estudo é um ensaio clínico do tipo "antes e depois", segundo FLETCHER et al. (1996). Foi realizado com pacientes com neoplasia mamária, submetidas ao tratamento quimioterápico adjuvante, com a coleta de dados realizada em dois momentos: T0 - após diagnóstico e cirurgia e antes do primeiro ciclo de quimioterapia e; T1 - ao término do último ciclo de quimioterapia, com intervalo médio de 5 meses ( $3-7$ meses) entre os dois momentos.

A coleta de dados teve início após a aprovação do projeto pelos Comitês de Ética da Faculdade de Saúde Pública - USP ( $N^{\circ}$ 140/05) e do Hospital AC Camargo - Fundação Antônio Prudente (Nº 687/05) (Anexo 1).

\subsection{POPULAÇÃO E LOCAL DO ESTUDO}

A partir de 377 prontuários de pacientes atendidas pelo Departamento de Mastologia, do Hospital AC Camargo (São Paulo, Brasil), no período de Outubro de 2005 a Abril de 2006, trinta e cinco (35) pacientes foram consideradas elegíveis. Dessas pacientes, cinco (5) recusaram participar do estudo, quatro (4) iniciaram o tratamento antes do primeiro contato (T0) e uma (1) desistiu após o tratamento quimioterápico (T1) (Figura 1). 
Neste sentido, a população de estudo foi constituída por vinte e cinco (25) pacientes, sexo feminino e a amostragem foi não-probabilística do tipo consecutivo, onde cada paciente foi admitida segundo os critérios de seleção, descritos no item 3.3.

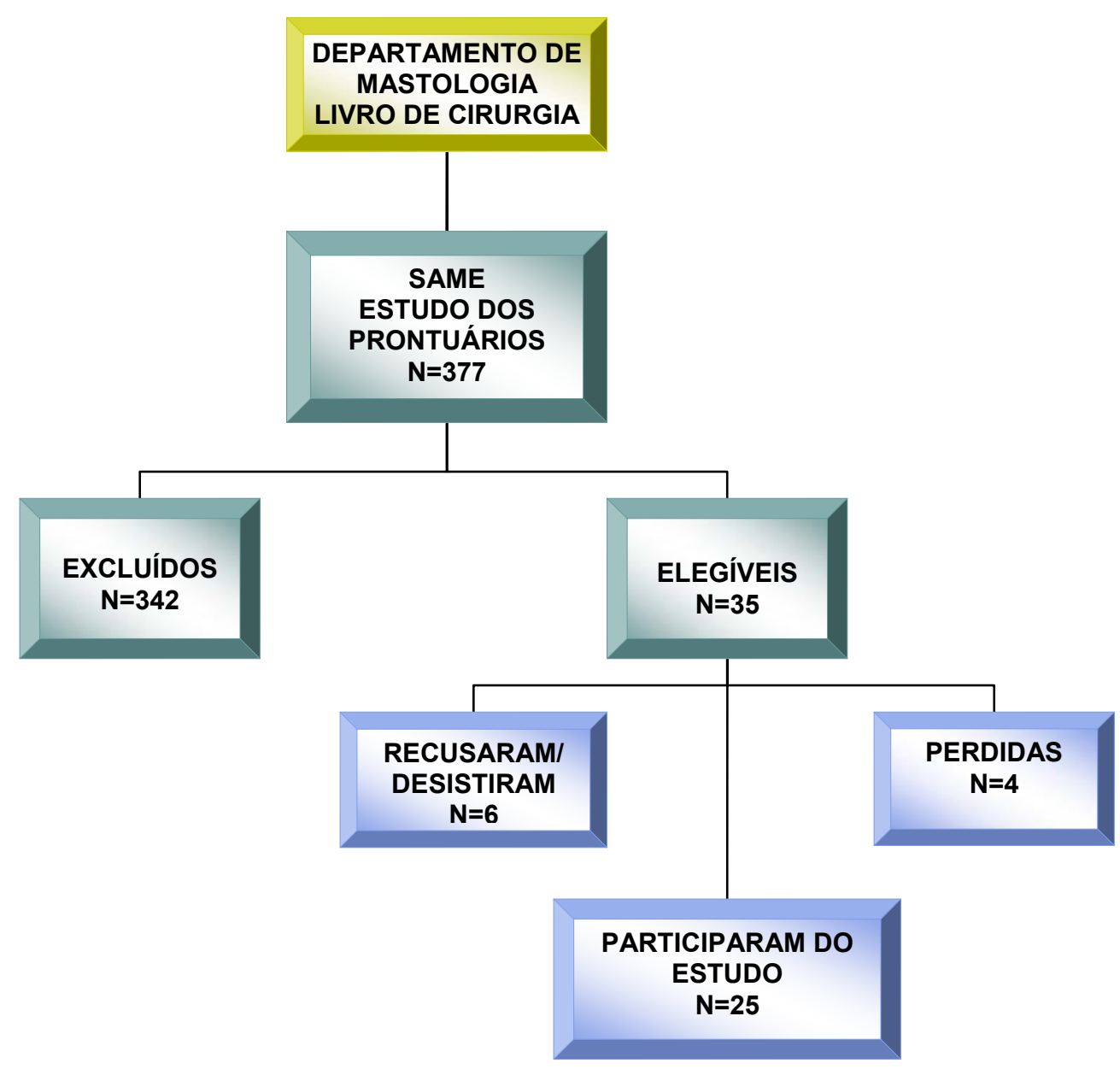

Figura 1 - Esquema de seleção das pacientes inclusas no estudo, período de Outubro de 2005 a Abril de 2006. Hospital AC Camargo, São Paulo.

\subsection{CRITÉRIOS DE SELEÇÃO E EXCLUSÃO}

Participaram do estudo pacientes com diagnóstico de câncer de mama, comprovado por exame anátomo-patológico, em estadiamento clínico 
I ou II e encaminhadas para o departamento de oncologia clínica do mesmo hospital, onde realizaram o tratamento quimioterápico adjuvante.

Para participar do estudo, as pacientes deveriam ter idade entre $18 \mathrm{e}$ 60 anos, pré ou pós-menopausadas e com índice de Karnofsky acima de 70 (Anexo 2). Este índice de performance classifica as pacientes, através da observação do entrevistador, de acordo com sua capacidade de realizar as atividades de rotina. Os valores do índice de Karnofsky variam de 20 (muito doente, hospitalização necessária, requer tratamento com suporte ativo) até 100 (normal).

Foram consideradas excluídas do estudo, pacientes que apresentaram um dos seguintes perfis clínicos: submetidas a tratamento quimioterápico anterior; submetidas à cirurgia nos últimos 12 meses, além da cirurgia da mama; submetidas à radioterapia associada ou tratamento radioterápico prévio; presença de neoplasia associada; presença de afecção crônica transmissível (HIV) ou não transmissível (dislipidemias, diabetes, insuficiência hepática ou renal); apresentavam problemas neurológicos ou psiquiátricos; tinham alguma disfunção gastrointestinal prévia ao tratamento (disfagia, colite, gastrite, úlcera duodenal e gástrica, hérnia de hiato e esofagite) ou que eram alcoolistas. Os critérios de exclusão foram reforçados por análises bioquímicas realizadas no hospital.

Uma vez selecionadas, as pacientes foram convidadas a participar do estudo. A coleta de dados teve início somente após as participantes terem sido esclarecidas sobre os objetivos da pesquisa e terem assinado o termo de consentimento (Anexo 3). O termo de consentimento foi estruturado, conforme resolução 196 do Conselho Nacional de Saúde - CNS (Brasil, 1996) seguindo o modelo da instituição onde o estudo foi desenvolvido. 


\subsection{PERFIL SÓCIO-ECONÔMICO, CULTURAL E CLÍNICO}

Os dados do perfil sócio-econômico e da história clínica das pacientes foram obtidos através de pesquisa dos prontuários e de entrevista direta com as pacientes, utilizando formulário apresentado no Anexo 4.

As variáveis sócio-econômicas e culturais: idade, estado civil, etnia, religião, grau de escolaridade, renda familiar e número de membros na família; e as variáveis clínicas: estado de menopausa, EC e presença de reações colaterais ao tratamento foram utilizadas para caracterizar a população.

Todas as faixas e classificação que descrevem as variáveis sócioeconômicas e culturais foram baseadas no Censo demográfico de 2000 realizado pelo Instituto Brasileiro de Geografia e Estatística (IBGE, 2002).

Essas variáveis foram organizadas com a ajuda do programa EPIDATA $^{\circledR}$, versão 3.1 (Epidata Association, 2005).

\subsection{AVALIAÇÃO NUTRICIONAL}

Neste estudo, a avaliação do perfil nutricional das pacientes foi realizada utilizando-se parâmetros antropométricos e parâmetros dietéticos. 


\subsubsection{Parâmetros antropométricos}

Os parâmetros antropométricos avaliados foram: peso atual, altura e composição corporal.

O peso atual foi obtido no momento da avaliação, através da medição em balança digital Control ${ }^{\circledR}$ (Plenna, São Paulo, Brasil), com capacidade de 150,0 kg e precisão de 100,0 g. Foi considerada modificação de peso, o aumento ou perda no T1 superior a $5 \%$ do peso obtido no baseline (T0), segundo recomendação de HARVIE et al. (2005).

A altura foi medida utilizando o estadiômetro do modelo AlturaExata ${ }^{\circledR}$ (TBW, São Paulo, Brasil) com limite de 2,10 m e precisão de $1,0 \mathrm{~mm}$. $O$ protocolo de obtenção das medidas de peso e altura seguiu a metodologia descrita por DUARTE e CASTELLANI (2002).

Para obtenção dos parâmetros bioelétricos de resistência (R), reactância $(\mathrm{Xc})$, ângulo de fase $(\Phi)$ e dados de composição corporal (percentuais de gordura, de água e de massa magra) foi realizada impedância bioelétrica (BIA), com o uso do aparelho tetrapolar Biodynamics $^{\circledR}$, modelo 450 (TBW, São Paulo, Brasil), através da aplicação de corrente de $800 \mu \mathrm{A}$ e freqüência de $50 \mathrm{KHz}$.

As medidas foram conduzidas por profissional treinado e realizadas com a paciente deitada na posição supina, do lado direito do corpo. Dois dispositivos presos por eletrodos foram fixados no dorso da mão direita e dois no dorso do pé direito, conforme protocolo recomendado pela Biodynamics ${ }^{\circledR}$ para realização da impedância bioelétrica. 
Para classificação das pacientes de acordo com o estado nutricional foram utilizados: índice de massa corporal (IMC) e percentual (\%) de gordura corporal.

O IMC foi calculado usando a fórmula abaixo e para determinação do estado nutricional adotou-se a classificação para adultos da Organização Mundial de Saúde (OMS, 2000) (Quadro 2).

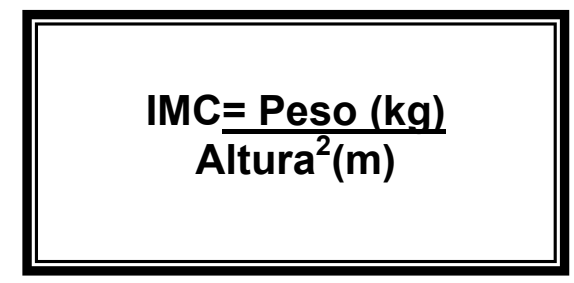

Quadro 2 - Classificação do estado nutricional de adultos, segundo a Organização Mundial de Saúde (OMS, 2000).

\begin{tabular}{|lcl|}
\hline \multicolumn{1}{|c}{ DIAGNÓSTICO } & \multicolumn{1}{c|}{$\begin{array}{c}\text { RISCO DE } \\
\text { NUTRICIONAL }\end{array}$} & \multicolumn{1}{c|}{ CO-MORBIDADES } \\
\hline Baixo peso & $<18,50$ & Baixo \\
Eutrófico & $18,50-24,99$ & Médio \\
Sobrepeso/ pré-obeso & $25,00-29,99$ & Aumentado \\
Obesidade grau I & $30,00-34,99$ & Moderado \\
Obesidade grau II & $35,00-39,99$ & Severo \\
Obesidade grau III & $\geq 40,00$ & Muito severo \\
\hline
\end{tabular}

Fonte: OMS (2000).

Para determinação do estado nutricional das pacientes de acordo com o percentual de gordura corporal adotou-se a classificação de LOHMAN e GOING (1998) (Quadro 3). 
Quadro 3 - Classificação do estado nutricional, segundo o percentual de gordura corporal.

\begin{tabular}{|cccc|}
\hline SEXO & IDADE & \% DE GORDURA & CLASSIFICAÇÃO \\
\hline \multirow{2}{*}{ FEMININO } & $\leq 40$ anos & $>35$ & Obesidade \\
& $41-60$ anos & $>38$ & Obesidade \\
\hline
\end{tabular}

Fonte: LOHMAN e GOING (1998)

De acordo com o método de análise vetorial pelo gráfico $\mathrm{RXc}$, as medidas de $\mathrm{R}$ e Xc foram padronizadas pela altura $(\mathrm{H})$ das pacientes $(\mathrm{R} / \mathrm{H}$ e $\mathrm{Xc} / \mathrm{H})$ e expressas em Ohms por metro $(\Omega / m)$. Para comparar as variáveis de impedância $(\mathrm{R} / \mathrm{H}$ e $\mathrm{Xc} / \mathrm{H})$ entre os tempos $\mathrm{T0}$ e $\mathrm{T} 1$, utilizamos o teste Hotelling's $\mathrm{T}^{2}$ e desenhamos elipses com 95\% de confiança com auxílio do programa Bivaconfidence file (BIVA ${ }^{\circledR}$ ) (PICCOLI e PASTORI, 2002).

O ângulo de fase $(\Phi)$ foi utilizado como preditor de prognóstico clínico, pois segundo SELBERG e SELBERG (2002) valores baixos de ângulo de fase sugerem morte ou diminuição da integridade celular e valores maiores indicam que a integridade das membranas está inalterada. Como parâmetro, foram utilizados os valores descritos por BARBOSA-SILVA (2002) (Quadro 4).

Quadro 4 - Valores de referência de ângulo de fase para mulheres saudáveis, segundo faixa etária.

\begin{tabular}{|cc|}
\hline FAIXA ETÁRIA (anos) & ÂNGULO DE FASE \\
\hline $18-20$ & 7,04 \\
$21-29$ & 6,98 \\
$30-39$ & 6,87 \\
$40-49$ & 6,91 \\
$50-59$ & 6,55 \\
$60-69$ & 5,97 \\
$\geq 70$ & 5,64 \\
\hline
\end{tabular}

Fonte: Barbosa-Silva (2002) 
Como variáveis antropométricas foram utilizadas: peso atual e IMC. A composição corporal incluiu as variáveis: percentuais de gordura, de água e de massa magra; e as variáveis de impedância elétrica foram: $R, X_{c}$ e $\Phi$. Todas essas variáveis foram organizadas com a ajuda do programa EPIDATA $^{\circledR}$, versão 3.1 (Epidata Association, 2005).

\subsubsection{Parâmetros dietéticos}

As informações relativas ao consumo alimentar foram obtidas utilizando-se o Recordatório de 24h (R24h) (Anexo 5).

Foram aplicados três R24h, em dias não consecutivos e sempre com um dia de final de semana ou feriado incluso, em cada período da coleta de dados (T0 e T1), com o objetivo de traduzir melhor o hábito alimentar da amostra em estudo.

A aplicação dos R24h foi feita por meio de entrevista por telefone. O registro dos alimentos foi feito por entrevistador treinado de acordo com manual elaborado exclusivamente para este fim (Anexo 6). O entrevistador conduzia as pacientes para que listassem todos os alimentos consumidos no dia anterior, desde a hora que acordaram até o momento que foram deitar-se, começando pelo primeiro alimento.

As pacientes não eram interrompidas até listarem o último alimento. Depois, o entrevistador conduzia o $\mathrm{R} 24 \mathrm{~h}$ revisando os itens citados e pedindo o relato do horário e local das refeições, quantidades consumidas, ingredientes das preparações e marca dos produtos. 
As entrevistadas foram questionadas sobre o número de pessoas que se serviam das preparações e, também, sobre a existência ou não de sobras. Foram orientadas para que se lembrassem de algum alimento que consumiram poderiam acrescentá-lo a qualquer momento durante a entrevista.

Os resultados obtidos a partir dos recordatórios de 24 horas foram analisados no programa NUTWIN ${ }^{\circledR}$, versão 1.5 (UNIFESP, 2002).

Para analisar os R24h, alguns alimentos ou preparações foram padronizados e adicionados ao programa. Foram utilizadas como referências para adição dos alimentos as tabelas de TOMITA e CARDOSO (2000), PINHEIRO et al. (2001), PHILLIPI (2002), Tabela Brasileira de Composição de Alimentos - TACO (2004), Nutrient Database for Standard Reference Release - USDA (2005) e Tabela de Composição de Alimentos Projeto Integrado de Composição de Alimentos Brasilfoods - TBCAUSP (2005) e ainda informações nutricionais obtidas dos rótulos de alimentos, quando se tratavam de marcas específicas.

As preparações citadas no $\mathrm{R} 24 \mathrm{~h}$, que não foram encontradas nas tabelas, foram analisadas no programa NutWin ${ }^{\circledR} 1.5$ (UNIFESP, 2002), tendo como base receitas caseiras. Nesse caso, foram utilizados os ingredientes do próprio programa e das fontes descritas acima.

Para avaliar o consumo alimentar foram utilizadas as seguintes variáveis: energia, proteínas, carboidratos, lipídeos, ácidos graxos saturados, ácidos graxos polinsaturados, ácidos graxos monoinsaturados, colesterol, fibras, vitamina $A$, vitamina $C$, vitamina $E$, folato, e zinco. $A$ escolha dessas variáveis seguiu a recomendação de REIS et al. (2004), que afirmaram que de um modo geral, os fármacos utilizados no tratamento quimioterápico promovem catabolismo protéico, aumento de triglicerídeos, 
colesterol e glicemia, depleção ou diminuição da absorção das vitaminas e minerais citados.

Os nutrientes foram submetidos à regressão linear para verificar possível correlação com a energia. Nesse teste, em cada um dos momentos (T0 e T1), o total de calorias ingeridas foi considerada variável independente e o valor absoluto do nutriente variável dependente. Todos os nutrientes que apresentaram coeficiente de correlação ( $r$ ) próximo de um e significância com $\mathrm{p}<0,05$ foram ajustados pelo método residual, proposto por WILLET e STAMPFER (1998) e MACKERRAS (1996), e avaliados após esse processamento estatístico.

Os nutrientes que não apresentaram correlação com a energia foram avaliados na sua forma bruta.

Além da avaliação do consumo de nutrientes, foram obtidas informações relacionadas ao consumo de alimentos e grupos de alimentos. Os alimentos citados pelas pacientes nos R24h (T0 e T1) foram agrupados seguindo a estrutura do formulário FACT (SCHUTZ, 1965) de preferências alimentares (Anexo 7) e inseridos nos grupos de alimentos (sopas, macarronada/lasanha, pizza/empada/kibe/coxinha etc), seguindo a contribuição calórica por cada $100 \mathrm{~g}$. Por exemplo, o caqui tem contribuição calórica semelhante a da banana, e, portanto, foi considerado como parte desse alimento.

Neste sentido, avaliou-se a variação (T1 - T0) no consumo de nutrientes, alimentos e grupos de alimentos em todas as pacientes inclusas no estudo. 


\subsection{ANÁLISE DE AVERSÃO ALIMENTAR}

A aversão alimentar foi avaliada usando a escala FACT desenvolvida por SCHUTZ (1965) (Anexo 7). As pacientes tinham nove opções de respostas: (a) como sempre que tenho oportunidade; (b) quase sempre; (c) frequentemente; (d) gosto muito e como de vez em quando; (e) como se estiver disponível, mas não deixo o que estou fazendo por causa desse alimento; (f) não gosto muito, mas como ocasionalmente; (g) quase nunca como; (h) somente se não houver outras opções de comida e; (i) somente se for forçada.

Para aplicação dessa ferramenta foi elaborado um guia com as opções de respostas para as pacientes. Cada resposta foi explicada individualmente e o entrevistador treinado pedia para que a paciente pensasse na sua relação emocional com o alimento, no quanto ela gostava ou não, para então escolher a resposta correta. Sempre que a paciente respondia diferente das opções descritas, era orientada a encaixar sua resposta nas opções disponíveis no guia (Anexo 8).

Cada uma das respostas tinha um escore determinado que variava de 1 a 9 , sendo o escore de menor valor para a opção "como somente de for forçada" e o escore de maior valor para "como sempre que tenho oportunidade". Dessa forma, escores maiores eram indicadores de preferência por determinado alimento/grupo e escores menores indicavam aversão alimentar.

Para avaliar aversão alimentar as variáveis consideradas foram os alimentos e grupos de alimentos e ainda as respostas à pergunta: "Há algum alimento que você não gosta e que comê-lo ou pensar nele faz você sentir- 
se desconfortável?". Foram consideradas como aversão adquirida somente para aqueles alimentos/grupos descritos a partir do tempo T1, mas tendo o tempo T0 como referência.

Essas variáveis foram agrupadas com a ajuda do programa EPIDATA $^{\circledR}$, versão 3.1 (Epidata Association, 2005).

\subsection{ANÁLISE DE QUALIDADE DE VIDA}

Para avaliar a qualidade de vida foi utilizado o questionário FACT-B, versão 4, em português, validado por BRADY et al. (1997) para pacientes com câncer de mama (Anexo 9).

Esse questionário foi auto-administrado após as pacientes terem sido esclarecidas sobre como funcionava a ferramenta. $O$ pesquisador treinado explicava que se tratava de um formulário que deveria ser preenchido pela paciente, considerando os últimos 7 dias, e que abordava diversos aspectos relacionados ao bem-estar físico, bem-estar emocional, relacionamento com o médico, bem-estar funcional, bem-estar social e familiar e questões de interesse adicional, específicas para pacientes com câncer de mama.

As pacientes foram orientadas a responder cada item de acordo com as opções apresentadas no questionário: não, pouco, às vezes, muito e sempre; escolhendo sempre a que mais se aplicava a sua situação atual.

O pesquisador estava sempre ao lado das pacientes para o esclarecimento de qualquer dúvida. 
As variáveis de qualidade de vida abordadas no FACT-B, foram organizadas com a ajuda do programa EPIDATA ${ }^{\circledR}$, versão 3.1 (Epidata Association, 2005).

De acordo com BRADY et al. (1997) os escores do FACT-B para bem-estar físico, social/familiar e funcional podem variar de 0 - 28. Para bem-estar emocional, 0 - 24 e, para preocupações adicionais, a variação pode ser de $0-36$.

A análise do total de escores foi baseada no guia de escores do FACT-B, disponível no site www.facit.org, onde em cada aspecto de qualidade de vida o valor do escore assinalado pelas pacientes é somado a zero ou subtraído de quatro, produzindo, dessa forma, diferentes pesos para cada uma das respostas. A soma de todos os escores indica o nível de qualidade de vida, ou seja, quanto mais alta a soma de escores, melhor a qualidade de vida do indivíduo.

Foram considerados na análise estatística, os escores obtidos em cada bloco, a somatória de escores de todos os blocos, além do escore médio referente às perguntas isolada presentes em cada bloco.

\subsection{ANÁLISE ESTATÍSTICA}

A análise descritiva da população do estudo e a análise comparativa das variáveis foram realizadas com auxílio dos programas $\mathrm{SPSS}^{\circledR}$, versão 13.0 (SPSS, 2000), SAS ${ }^{\circledR}$ versão 9.1 (SAS Institute, 2006) e MINITAB $^{\circledR}$ versão 14.1 (State College, 2003). 
O teste de Kolmogorov-Smirnov foi aplicado para verificar a normalidade de variáveis. Variáveis quantitativas com distribuição normal foram comparadas entre dois momentos pareados utilizando teste $t$-Student para amostras dependentes. Para as variáveis não paramétricas foi aplicado o teste dos postos assinalados de Wilcoxon. Análises de correlações lineares intra e entre os tempos (T0 e T1) foram efetuadas utilizando-se coeficiente de correlação linear de Pearson.

Todas as probabilidades de significância (p) apresentadas foram do tipo bilateral e foram considerados estatisticamente significantes os valores de $p<0,05$. 
Resultados 


\section{RESULTADOS}

\subsection{PERFIL SÓCIO-ECONÔMICO, CULTURAL E CLÍNICO}

A Tabela 1 mostra a descrição das pacientes, de acordo com o performance status classificadas pelo Índice de Karnofsky, onde a maioria (88\%) apresentou índice maior que 80.

Tabela 1. Descrição das pacientes de acordo com índice de Karnofsky. Hospital AC Camargo. São Paulo, 2005-2006.

\begin{tabular}{|c|c|}
\hline Índice de Karnofsky & Percentual (\%) e Quantidade (N) \\
\hline 100 & $4(1)$ \\
\hline 90 & $36(9)$ \\
\hline 80 & $48(12)$ \\
\hline 70 & $12(3)$ \\
\hline
\end{tabular}

O perfil sócio-econômico e cultural das pacientes, segundo as variáveis: idade, estado civil, religião, escolaridade, renda familiar e número de membros na família é apresentado na Tabela 2. No momento do diagnóstico, a maioria das pacientes estava nas faixas etárias de 31- 50 anos (56\%) e 51\} 70 anos (36\%), com idade média 46 (9) anos. Sessenta e quatro por cento $(64 \%)$ das pacientes eram casadas, $20 \%$ solteiras e $16 \%$ divorciadas e $80 \%$ classificou-se como da raça branca. A religião católica foi a predominante entre as participantes (48\%), seguida pela religião espírita (28\%). Com relação à escolaridade, $64 \%$ das pacientes tinham curso superior completo. A renda familiar foi superior a 7 salários mínimos (SM) em $88 \%$ das pacientes. Todos esses dados foram coletados apenas na primeira entrevista (T0). 
Tabela 2. Caracterização das pacientes de acordo com os perfis sócioeconômico e cultural. Hospital AC Camargo. São Paulo, 2005-2006.

\begin{tabular}{lc}
\hline \multicolumn{1}{c}{ Variáveis } & Percentual (\%) e Quantidade (N) \\
\hline Idade (anos) & \\
$11-30$ & $8(2)$ \\
$31-50$ & $56(14)$ \\
$51-70$ & $36(9)$ \\
$>70$ & - \\
Estado civil & $64(16)$ \\
Casada & $20(5)$ \\
Solteira & - \\
Viúva & $16(4)$ \\
Divorciada & - \\
Outros & \\
Etnia & $80(20)$ \\
Branco & $16(4)$ \\
Amarelo & - \\
Pardo & $4(1)$ \\
Negro & - \\
Indígena & \\
Religião & $48(12)$ \\
Católica & $8(2)$ \\
Evangélica & $28(7)$ \\
Espírita & $4(1)$ \\
Outras religiões & $12(3)$ \\
Não determinada & \\
Escolaridade & - \\
Ensino fundamental incompleto & $4(1)$ \\
Ensino fundamental completo & $8(2)$ \\
Ensino médio incompleto & $12(3)$ \\
Ensino médio completo & $12(3)$ \\
Superior incompleto & $64(16)$ \\
Superior completo & - \\
Renda familiar & $12(3)$ \\
<1 SM & $52(13)$ \\
$2-6$ SM & $36(9)$ \\
$7-10$ SM & $12(3)$ \\
$>10$ SM & $68(17)$ \\
Membros da família & $20(5)$ \\
2 & \\
$3-4$ & \\
$>4$ & \\
\hline \hline
\end{tabular}

A descrição do perfil clínico das pacientes é mostrada na Tabela 3.

De acordo com a localização, $96 \%$ das pacientes tinham neoplasia instalada nos ductos mamários (carcinoma ductal) e somente $4 \%$ nos lóbulos (carcinoma lobular). De acordo com estadiamento clínico (EC), 68\% das pacientes receberam diagnóstico de EC tipo II. Quanto ao estado de 
menopausa, 56\% apresentavam-se em estado de pré-menopausa no momento do diagnóstico e $44 \%$ eram pós-menopausadas.

Durante o curso do presente estudo as pacientes receberam quimioterapia intravenosa, com ciclos de 21 dias. A maioria das pacientes recebeu protocolo quimioterápico $A C$ - antracíclico e ciclofosamida (60\%), seguido de $A C+T$ - taxotere, TAC - docetaxel, doxorrubicina, ciclofosfamida (12\%), FEC (8\%) e CMF (4\%). A náusea foi o efeito colateral ao tratamento quimioterápico mais prevalente entre as pacientes estudadas, atingindo mais de $80 \%$ da população (Tabela 3 ).

Tabela 3. Descrição das pacientes de acordo com o perfil clínico. Hospital AC Camargo. São Paulo, 2005-2006.

\begin{tabular}{lc}
\multicolumn{1}{c}{ Variáveis } & Percentual (\%) e Quantidade (N) \\
\hline Localização & $4(1)$ \\
Carcinoma lobular & $96(24)$ \\
Carcinoma ductal & \\
Estadiamento clínico (EC) & $32(8)$ \\
EC I & $68(17)$ \\
EC II & \\
Estado de menopausa & $56(14)$ \\
Pré-menopausa & $44(11)$ \\
Pós-menopausa & \\
Protocolo quimioterápico & $60(15)$ \\
AC & $16(4)$ \\
AC + T & $12(3)$ \\
TAC & $8(2)$ \\
FEC & $4(1)$ \\
CMF & \\
Efeitos colaterais da quimioterapia & $60(15)$ \\
Constipação & $52(13)$ \\
Diarréia & $52(13)$ \\
Vômitos & $88(22)$ \\
Náusea & $56(14)$ \\
Lesões orais & $40(10)$ \\
Disfagia & $24(6)$ \\
Dificuldade de mastigação & $32(8)$ \\
Anorexia & \\
\hline & \\
\hline & \\
\hline &
\end{tabular}




\subsection{AVALIAÇÃO NUTRICIONAL}

\subsubsection{Parâmetros Antropométricos}

Podemos verificar através da Tabela 4 que as pacientes apresentaram aumento significativo de peso médio de $2,2 \mathrm{~kg}(\mathrm{p}=0,00)$ após $\mathrm{o}$ tratamento quimioterápico, que refletiu diretamente no aumento do IMC $(p=0,00)$.

Quarenta e quatro por cento (44\%) das pacientes apresentaram ganho de peso superior a $5 \%$ após o tratamento quimioterápico. Esse ganho foi de $4,5(1,2) \mathrm{kg}$ e variou entre $2,7-6,4 \mathrm{~kg}$.

Tabela 4. Parâmetros antropométricos das pacientes, nos momentos T0 e T1. Hospital do Câncer - AC Camargo. São Paulo, 2005-2006.

\begin{tabular}{cccccc}
\hline Variáveis & Tempo & $\mathbf{N}$ & Média & dp & $\mathbf{p}$ \\
\hline \multirow{2}{*}{ Peso $\mathbf{( k g )}$} & T0 & 25 & 64,1 & 13,3 & \\
& T1 & 25 & 66,5 & 13,5 & 0,00 \\
IMC $\left(\mathbf{k g} / \mathbf{m}^{2}\right)$ & T0 & 25 & 25 & 4,2 & \\
& T1 & 25 & 26 & 4,3 & 0,00 \\
\hline
\end{tabular}

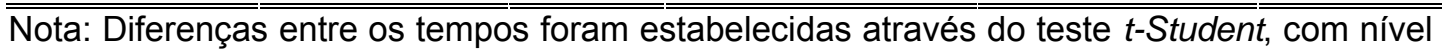
de significância de $p<0,05$.

O estado nutricional das pacientes, segundo o IMC, no momento T0 está descrito no Gráfico 1 - A. Podemos observar que $28 \%$ das pacientes encontravam-se com sobrepeso e $16 \%$ em estado de obesidade grau I. Após o tratamento quimioterápico (Gráfico 1 - B), o percentual de pacientes 
obesas aumentou em 4\% e dessas, $80 \%$ foram classificadas com obesidade grau I e $20 \%$ com obesidade grau II.

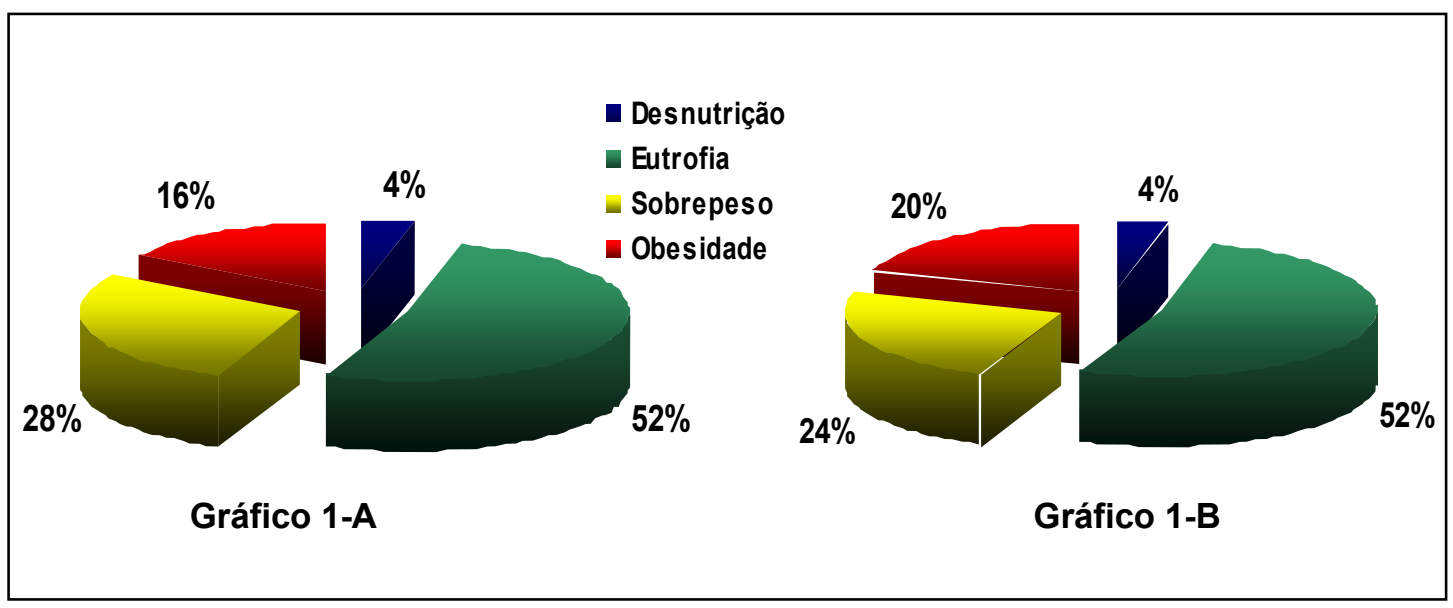

Gráfico 1. Distribuição das pacientes de acordo com a classificação do estado nutricional, segundo a OMS (2000), baseada no IMC $\left(\mathrm{Kg} / \mathrm{m}^{2}\right)$, nos momentos T0 (A) e T1(B). Hospital AC Camargo. São Paulo, 2005-2006.

Utilizando o percentual de gordura como parâmetro para determinação de obesidade, podemos observar no Gráfico 2 que houve aumento $(4 \%)$ no percentual de pacientes obesas entre os tempos T0 (Gráfico 2 - A) e T1 (Gráfico 2 - B).

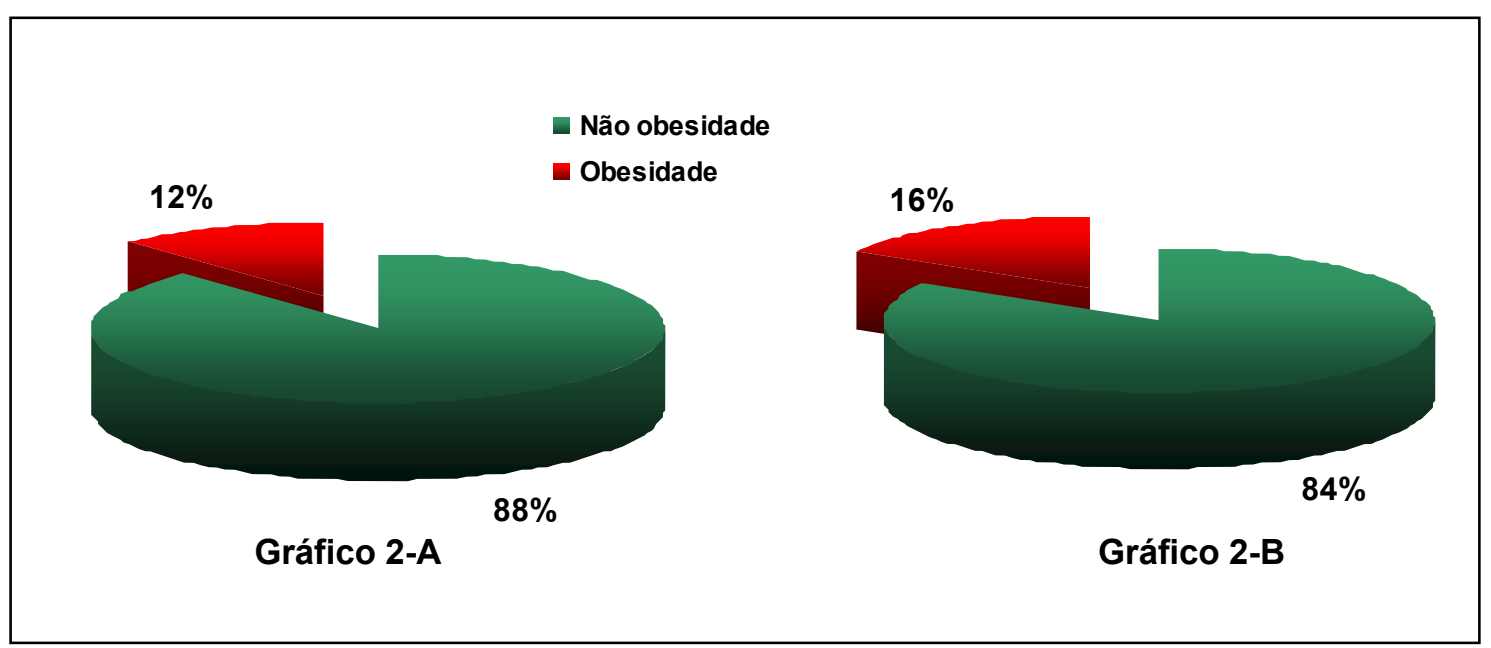

Gráfico 2. Distribuição das pacientes de acordo com estado nutricional baseado no percentual de gordura nos momentos T0 (A) e T1 (B). Hospital AC Camargo. São Paulo, 2005-2006. 
No que se refere à composição corporal não foram observadas diferenças significativas entre os momentos T0 e T1, quando avaliamos o percentual de gordura, percentual de massa magra e percentual de água corporal (Tabela 5).

Tabela 5. Valores de percentuais de gordura, de massa magra e de água das pacientes, nos momentos T0 e T1. Hospital AC Camargo. São Paulo, 2005-2006.

\begin{tabular}{cccccc}
\hline \hline Variáveis (\%) & Tempo & $\mathbf{N}$ & Média & dp & $\mathbf{p}$ \\
\hline \multirow{2}{*}{ Gordura } & T0 & 25 & 29,7 & 6,1 & 0,41 \\
& T1 & 25 & 29,2 & 6,6 & \\
Massa Magra & T0 & 25 & 70,3 & 6,1 & 0,78 \\
Água & T1 & 25 & 69,6 & 7,6 & \\
& T0 & 25 & 51,8 & 4,9 & 0,64 \\
\hline \hline
\end{tabular}

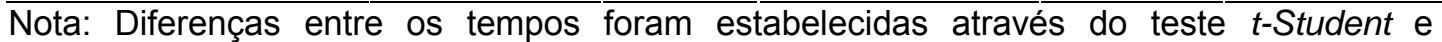
Wilcoxon com nível de significância de $p<0,05$.

Porém, observando individualmente as pacientes, observamos que $52 \%$ delas apresentaram redução no percentual de massa magra e aumento no percentual de gordura no momento T1.

Na Tabela 6 podemos verificar que, após a quimioterapia, o peso e o IMC apresentaram correlação significativa com percentual de gordura e massa magra. 
Tabela 6. Correlação entre estado nutricional e composição corporal no momento T1. Hospital AC Camargo. São Paulo, 2005-2006.

\begin{tabular}{|c|c|c|c|}
\hline Variável & Variável de correlação & $\mathbf{r}$ & $\mathbf{p}$ \\
\hline \multirow{2}{*}{ Peso } & Percentual de Gordura & 0,644 & 0,00 \\
\hline & Percentual de Massa Magra & $-0,532$ & 0,00 \\
\hline \multirow{2}{*}{ IMC } & Percentual de Gordura & 0,752 & 0,00 \\
\hline & Percentual de Massa Magra & $-0,604$ & 0,00 \\
\hline
\end{tabular}

$\overline{\text { Nota: (r) Coeficiente de correlação }} \overline{\text { de Pearson. O nível de significância }} \overline{\text { adotado de }} \overline{\overline{p<0,05} \text {. }}$

$\mathrm{Na}$ Tabela 7 foram estabelecidas correlações pelas diferenças correspondentes aos valores das variáveis antropométricas entre os dois momentos, ou seja, T1 - T0. Verificamos, portanto, que a diferença de peso encontrada entre os tempos T0 e T1 apresentou correlação significativa com o percentual de água $(r=-0,416 ; p=0,03)$.

Tabela 7. Valores de correlação significantes das diferenças das variáveis entre os momentos T0 e T1. Hospital AC Camargo. São Paulo, 2005-2006.

\begin{tabular}{|c|c|c|}
\hline \multirow{2}{*}{ Variáveis } & \multicolumn{2}{|c|}{$\Delta$ Percentual de Água } \\
\hline & $r$ & $p$ \\
\hline$\Delta$ Peso & $-0,416$ & 0,03 \\
\hline$\Delta \mathrm{IMC}$ & $-0,981$ & 0,04 \\
\hline$\Delta$ Percentual de Gordura & $-0,488$ & 0,01 \\
\hline$\Delta$ Percentual de Massa Magra & 0,947 & 0,00 \\
\hline
\end{tabular}

Nota: (r) Coeficiente de correlação de Pearson. O nível de significância de $p<0,05$.

$\mathrm{Na}$ Tabela 8 encontramos os valores de $\mathrm{R}$ e Xc brutos, onde verificamos redução significativa após o tratamento quimioterápico. 
Tabela 8. Valores $\mathrm{R}$ e $\mathrm{Xc}$ das pacientes, nos momentos $\mathrm{T} 0$ e $\mathrm{T} 1$. Hospital AC Camargo. São Paulo, 2005-2006.

\begin{tabular}{cccccc}
\hline Variáveis & Tempo & $\mathbf{N}$ & Média & $\mathbf{d p}$ & $\mathbf{p}$ \\
\hline \multirow{2}{*}{$\mathbf{R}$} & T0 & 25 & 563,95 & 69,74 & \multirow{2}{*}{0,00} \\
& T1 & 25 & 533,40 & 71,50 & \\
\multirow{2}{*}{ Xc } & T0 & 25 & 59,17 & 8,65 & \multirow{2}{*}{0,00} \\
& T1 & 25 & 52,39 & 9,72 & \\
\hline \hline
\end{tabular}

Nota: Diferenças entre os tempos foram $\overline{\text { estabelecidas através do teste t-Student e }}$ Wilcoxon com nível de significância de $p<0,05$

No Gráfico 3 essas variáveis são mostradas em elipses de $95 \%$ de confiança depois de ajustadas pela altura $(\mathrm{R} / \mathrm{H}$ e $\mathrm{Xc} / \mathrm{H})$. Podemos observar que após o tratamento quimioterápico os valores de $\mathrm{R} / \mathrm{H}$ e $\mathrm{Xc} / \mathrm{H}$ foram menores, mas, apesar da tendência à redução, não houve diferença significativa (Hotelling's $T^{2}=6,5 ; p=0,051$ ).

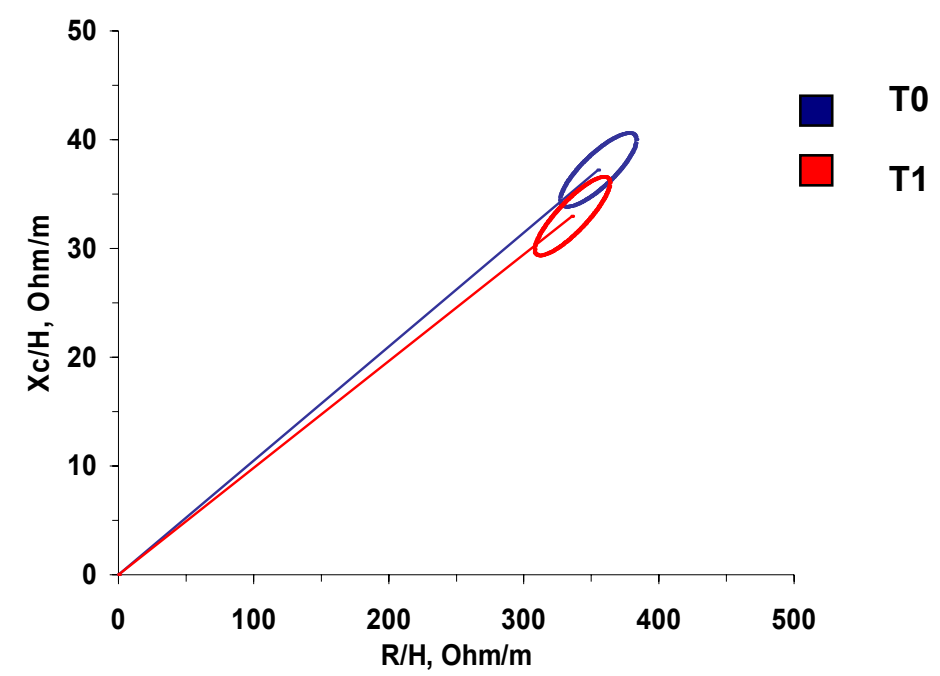

Gráfico 3. Análise vetorial da correlação da diferença entre R/H (T1-T0) e $\mathrm{XC} / \mathrm{H}$ (T1-T0) em pacientes com câncer de mama. Hospital AC Camargo. São Paulo, 2005-2006.

Os valores de ângulo de fase médio entre o T0 $\left[6,0\left(0,6^{0}\right)\right]$ e o T1 $\left[5,6\left(0,6^{0}\right)\right]$ apresentaram redução significativa (T1-T0 $\left.=-0,4^{0} ; p=0,00\right)$. Essa redução pode ser observada no Gráfico 3, onde o ângulo de fase, formado pela relação entre $\mathrm{R} / \mathrm{H}$ e $\mathrm{Xc} / \mathrm{H}$, diminuiu no segundo momento (T1). 
No Gráfico 4 podemos observar que tanto antes, quanto após o tratamento quimioterápico os valores de ângulo de fase encontram-se abaixo dos valores de referência, independente da idade.

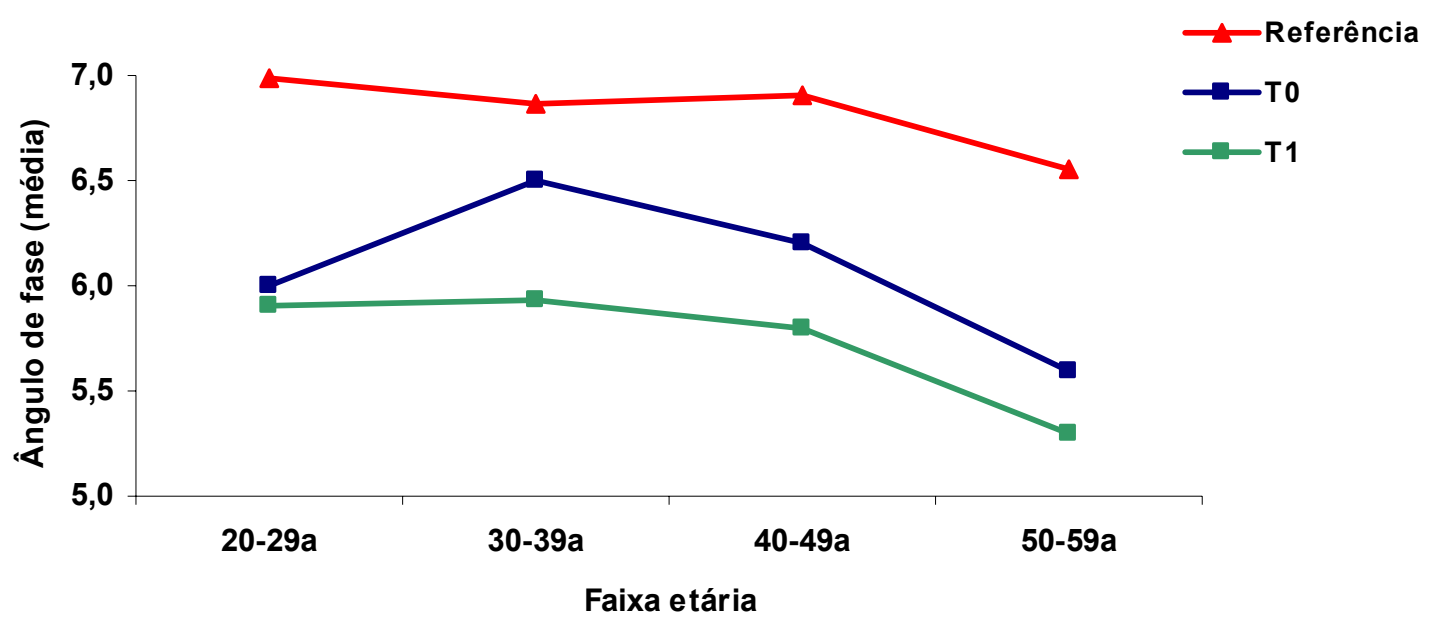

Gráfico 4. Distribuição das pacientes de acordo com ângulo de fase e faixa etária nos tempos T0 e T1. Hospital AC Camargo. São Paulo, 2005-2006.

\subsubsection{Parâmetros Dietéticos}

Os macronutrientes (carboidratos, proteínas, lipídeos totais, ácidos graxos saturados, monoinsaturados e polinsaturados) e micronutrientes (zinco e folato) apresentaram correlação com a ingestão de calorias nos momentos T0 e T1. O consumo de fibras sofreu influência das calorias somente após o tratamento quimioterápico. Todos esses nutrientes foram ajustados através do "método residual" e com esse procedimento houve manutenção do seu consumo médio e diminuição do desvio padrão dentro da população estudada. 
As vitaminas $A$ e $E$ não tiveram correlação com a energia e a vitamina C apresentou distribuição não-paramétrica, não sendo possível ajustá-los pela ingestão de energia. Portanto, esses nutrientes foram avaliados na sua forma bruta.

Nas Tabelas 9 e 10 estão descritos os consumos de macronutrientes, fibras e micronutrientes pela população estudada. Quando analisados, os dados de consumo desses nutrientes não foram observadas diferenças significativas entre as médias dos dois tempos (T1-T0).

Tabela 9. Valores de consumo de energia e nutrientes nos momentos T0 e T1. Hospital AC Camargo. São Paulo, 2005-2006.

\begin{tabular}{|c|c|c|c|c|c|}
\hline Variáveis & Tempo & $\mathbf{N}$ & Média & Dp & $p$ \\
\hline \multirow{2}{*}{ Energia (kcal) } & T0 & 25 & 1648,05 & 534,48 & \multirow{2}{*}{0,68} \\
\hline & T1 & 25 & 1599,55 & 336,80 & \\
\hline \multirow{2}{*}{ Carboidratos (g) } & T0 & 25 & 218,23 & 26,82 & \multirow{2}{*}{0,46} \\
\hline & T1 & 25 & 206,83 & 38,07 & \\
\hline \multirow{2}{*}{ Proteínas (g) } & T0 & 25 & 67,90 & 13,54 & \multirow{2}{*}{0,55} \\
\hline & T1 & 25 & 64,18 & 16,60 & \\
\hline \multirow{2}{*}{ Lipídios (g) } & T0 & 25 & 56,77 & 8,47 & \multirow{2}{*}{0,69} \\
\hline & $\mathrm{T} 1$ & 25 & 59,22 & 15,94 & \\
\hline \multirow{2}{*}{ Colesterol (mg) } & T0 & 25 & 201,18 & 68,70 & \multirow{2}{*}{0,79} \\
\hline & T1 & 25 & 208,89 & 67,80 & \\
\hline \multirow{2}{*}{ AGS (g) } & TO & 25 & 19,70 & 4,54 & \multirow{2}{*}{0,33} \\
\hline & T1 & 25 & 21,79 & 6,05 & \\
\hline \multirow{2}{*}{ AGM (g) } & T0 & 25 & 18,56 & 4,61 & \multirow{2}{*}{0,20} \\
\hline & $\mathrm{T} 1$ & 25 & 21,91 & 7,12 & \\
\hline \multirow{2}{*}{ AGP (g) } & T0 & 25 & 11,07 & 4,55 & \multirow{2}{*}{0,90} \\
\hline & T1 & 25 & 10,88 & 4,58 & \\
\hline \multirow{2}{*}{ Fibras (g) } & T0 & 25 & 13,70 & 6,25 & \multirow{2}{*}{0,18} \\
\hline & T1 & 25 & 11,72 & 4,87 & \\
\hline
\end{tabular}

Nota: AGS - ácidos graxos saturados; AGM - ácidos graxos monoinsaturados; AGP ácidos graxos polinsaturados. Diferenças entre os tempos foram estabelecidas através dos testes $t$-Student e Wilcoxon, com nível de significância de $p<0,05$. 
Tabela 10. Valores de consumo de micronutrientes nos momentos T0 e T1. Hospital- AC Camargo. São Paulo, 2005-2006.

\begin{tabular}{|c|c|c|c|c|c|}
\hline Variáveis & Tempo & $\mathbf{N}$ & Média & $\mathrm{Dp}$ & $\mathbf{p}$ \\
\hline \multirow{2}{*}{ Zinco (mg) } & TO & 25 & 6,65 & 2,27 & \multirow{2}{*}{0,74} \\
\hline & $\mathrm{T} 1$ & 25 & 6,44 & 1,88 & \\
\hline \multirow{2}{*}{ Vitamina C (mg) } & T0 & 25 & 255,32 & 651,11 & \multirow{2}{*}{0,17} \\
\hline & T1 & 25 & 203,88 & 362,33 & \\
\hline \multirow{2}{*}{ Vitamina E (mg) } & T0 & 25 & 6,77 & 2,80 & \multirow{2}{*}{0,79} \\
\hline & $\mathrm{T} 1$ & 25 & 6,99 & 3,51 & \\
\hline \multirow{2}{*}{ Folato $(\mu \mathrm{g})$} & TO & 25 & 207,30 & 93,93 & \multirow{2}{*}{0,31} \\
\hline & T1 & 25 & 183,00 & 55,62 & \\
\hline \multirow{2}{*}{ Vitamina $A(\mu g R E)$} & TO & 25 & 912,61 & 1194,40 & \multirow{2}{*}{0,52} \\
\hline & T1 & 25 & 896,51 & 701,42 & \\
\hline
\end{tabular}

$\overline{\text { Nota: Diferenças entre os tempos foram estabelecidas através }} \overline{\overline{\text { do teste t-Student e }}}$ Wilcoxon, onde o nível de significância adotado foi de $p<0,05$.

Com relação ao consumo de alimentos (sopas, macarronada/ lasanha, peixe frito, etc.) não foram observadas diferenças entre os momentos T0 e T1. Entretanto, quando realizamos a análise entre os grupos de alimentos (sopas e massas, carnes e peixes, arroz e tubérculos, etc.) (Tabela 11), verificamos que houve redução significativa no consumo do grupo de Frutas e Sucos $(p=0,03)$ após o tratamento quimioterápico.

Tabela 11. Valores de consumo de calorias por grupo de alimentos nos momentos T0 e T1. Hospital- AC Camargo. São Paulo, 2005-2006.

\begin{tabular}{lccccc}
\hline \multicolumn{1}{c}{ Variáveis } & Tempo & $\mathbf{N}$ & Média & $\mathbf{d p}$ & $\mathbf{p}$ \\
\hline \multirow{2}{*}{ Sopas e massas } & T0 & 25 & 192,07 & 219,09 & \multirow{2}{*}{ Carnes e peixes } \\
T1 & T0 & 25 & 254,76 & 130,66 & \\
\multirow{2}{*}{ Leguminosas e ovo } & T1 & 25 & 246,16 & 182,86 & \\
& T0 & 25 & 62,25 & 71,66 & \multirow{2}{*}{ Arroz e tubérculos } \\
T1 & T0 & 25 & 48,60 & 40,71 & \\
& T1 & 25 & 165,92 & 141,24 & \\
& T1 & 131,76 & 79,13 & 0,32
\end{tabular}


Tabela 11. Valores de consumo de calorias por grupo de alimentos nos momentos T0 e T1. Hospital- AC Camargo. São Paulo, 2005-2006.

\begin{tabular}{|c|c|c|c|c|c|}
\hline & & & & \multicolumn{2}{|c|}{ continuação } \\
\hline Variáveis & Tempo & $\mathbf{N}$ & Média & dp & $\mathbf{p}$ \\
\hline \multirow{2}{*}{$\begin{array}{l}\text { Leite/ derivados e } \\
\text { cereais }\end{array}$} & T0 & 25 & 217,67 & 203,66 & \multirow{2}{*}{0,56} \\
\hline & $\mathrm{T} 1$ & 25 & 196,17 & 137,96 & \\
\hline \multirow{2}{*}{ Vegetais } & T0 & 25 & 29,89 & 36,24 & \multirow{2}{*}{0,47} \\
\hline & $\mathrm{T} 1$ & 25 & 23,43 & 20,83 & \\
\hline \multirow{2}{*}{ Molhos } & T0 & 25 & 61,31 & 51,93 & \multirow{2}{*}{0,23} \\
\hline & $\mathrm{T} 1$ & 25 & 83,37 & 97,09 & \\
\hline \multirow{2}{*}{ Frutas e sucos } & T0 & 25 & 163,95 & 110,59 & \multirow{2}{*}{0,03} \\
\hline & $\mathrm{T} 1$ & 25 & 120,88 & 70,48 & \\
\hline \multirow{2}{*}{ Pães e biscoitos } & T0 & 25 & 192,89 & 110,23 & \multirow{2}{*}{0,25} \\
\hline & $\mathrm{T} 1$ & 25 & 222,93 & 89,24 & \\
\hline \multirow{2}{*}{ Bebidas } & T0 & 25 & 28,05 & 42,51 & \multirow{2}{*}{0,70} \\
\hline & $\mathrm{T} 1$ & 25 & 60,28 & 193,04 & \\
\hline \multirow{2}{*}{$\begin{array}{l}\text { Doces, sobremesas e } \\
\text { aperitivos }\end{array}$} & T0 & 25 & 280,78 & 236,99 & \multirow{2}{*}{0,64} \\
\hline & $\mathrm{T} 1$ & 25 & 257,77 & 170,36 & \\
\hline
\end{tabular}

Nota: Diferenças entre os tempos foram estabelecidas através do teste t-Student e Wilcoxon, onde o nível de significância adotado foi de $p<0,05$

\subsection{AVERSÃO ALIMENTAR}

$\mathrm{Na}$ Tabela 12 estão descritos os alimentos cujas preferências apresentaram diferenças significantivas entre os dois momentos. O café preto apresentou contagem de escores menor no momento T1 que no momento T0. Para os demais alimentos apresentados, os valores dos escores foram maiores após o tratamento quimioterápico. Os outros alimentos avaliados não apresentaram diferença significativa entre os momentos T0 e T1. 
Tabela 12. Escores de aversões alimentares obtidos pelas diferenças significativas entre os momentos T0 e T1. Hospital AC Camargo. São Paulo, 2005-2006.

\begin{tabular}{lccccc}
\hline \multicolumn{1}{c}{ Variáveis } & Tempo & N & Média & dp & p \\
\hline Carne bovina (cozida, assada, & T0 & 25 & 5,56 & 2,65 & \multirow{2}{*}{0,04} \\
grelhada ou churrasco) & T1 & 25 & 6,24 & 2,31 & \\
Arroz branco & T0 & 25 & 7,28 & 1,88 & 0,02 \\
Laranja e mexerica & T1 & 25 & 7,88 & 1,67 & \\
& T0 & 25 & 7,04 & 1,65 & \multirow{2}{*}{ Mamão } \\
Biscoito salgado/ biscoito doce & T1 & 25 & 7,64 & 1,73 & \\
sem recheio & T0 & 25 & 7,24 & 1,98 & \multirow{2}{*}{0,04} \\
Café preto & T1 & 25 & 7,72 & 1,77 & \\
& T1 & 25 & 5,44 & 2,33 & 0,03 \\
Sorvete & T0 & 25 & 7,36 & 1,98 & \multirow{2}{*}{0,01} \\
& T1 & 25 & 5,80 & 3,00 & \\
\hline \hline
\end{tabular}

Nota: Diferenças entre os tempos foram estabelecidas através do teste t-Student e Wilcoxon, com nível de significância de $p<0,05$.

Os escores de aversão para grupos de alimentos estão descritos na Tabela 13. Observamos redução significativa nos escores do grupo de bebidas [escore $=-5,04(7,39) ; p=0,00]$ que engloba bebidas alcoólicas, chá, café preto e adoçante, entre os tempos T0 e T1. Os demais grupos de alimentos avaliados permaneceram estatisticamente semelhantes entre os dois tempos. Porém, pôde ser observada tendência ao aumento nos escores do grupo de arroz e tubérculos (arroz branco, batata, mandioca, inhame, abóbora, cuscuz, angu, farofa, farinha de mandioca); essa tendência não mostrou diferença significante [escore $=3,56(8,79) ; p=0,05$ ] entre os dois momentos em função da elevada dispersão dos valores entre as pacientes. 
Tabela 13. Escores de aversões alimentares segundo os grupos de alimentos, nos momentos T0 e T1. Hospital AC Camargo. São Paulo, 20052006.

\begin{tabular}{|c|c|c|c|c|c|}
\hline Variáveis & Tempo & $\mathbf{N}$ & Média & $d p$ & $p$ \\
\hline \multirow{2}{*}{ Sopas e massas } & T0 & 25 & 19,84 & 4,17 & \multirow{2}{*}{0,92} \\
\hline & T1 & 25 & 19,76 & 2,83 & \\
\hline \multirow{2}{*}{ Carnes e peixes } & T0 & 25 & 49,48 & 12,22 & \multirow{2}{*}{0,49} \\
\hline & $\mathrm{T} 1$ & 25 & 50,44 & 12,99 & \\
\hline \multirow{2}{*}{ Leguminosas e ovo } & T0 & 25 & 20,44 & 3,34 & \multirow{2}{*}{0,39} \\
\hline & T1 & 25 & 19,76 & 3,42 & \\
\hline \multirow{2}{*}{ Arroz e tubérculos } & TO & 25 & 40,12 & 11,23 & \multirow{2}{*}{0,05} \\
\hline & $\mathrm{T} 1$ & 25 & 43,68 & 11,46 & \\
\hline \multirow{2}{*}{$\begin{array}{l}\text { Leite/ derivados e } \\
\text { cereais }\end{array}$} & T0 & 25 & 35,52 & 11,31 & \multirow{2}{*}{0,57} \\
\hline & T1 & 25 & 36,56 & 11,31 & \\
\hline \multirow{2}{*}{ Vegetais } & T0 & 25 & 44,28 & 7,04 & \multirow{2}{*}{0,86} \\
\hline & $\mathrm{T} 1$ & 25 & 43,56 & 8,27 & \\
\hline \multirow{2}{*}{ Molhos } & T0 & 25 & 15,80 & 3,75 & \multirow{2}{*}{0,07} \\
\hline & $\mathrm{T} 1$ & 25 & 16,32 & 4,85 & \\
\hline \multirow{2}{*}{ Frutas e sucos } & TO & 25 & 68,64 & 11,27 & \multirow{2}{*}{0,29} \\
\hline & $\mathrm{T} 1$ & 25 & 70,60 & 11,98 & \\
\hline \multirow{2}{*}{ Pães e biscoitos } & TO & 25 & 29,16 & 6,52 & \multirow{2}{*}{0,48} \\
\hline & T1 & 25 & 30,04 & 5,88 & \\
\hline \multirow{2}{*}{ Bebidas } & T0 & 25 & 23,76 & 6,48 & \multirow{2}{*}{$0,00^{*}$} \\
\hline & $\mathrm{T} 1$ & 25 & 18,72 & 6,79 & \\
\hline \multirow{2}{*}{$\begin{array}{l}\text { Doces, sobremesas e } \\
\text { aperitivos }\end{array}$} & T0 & 25 & 29,48 & 6,76 & \multirow{2}{*}{0,97} \\
\hline & $\mathrm{T} 1$ & 25 & 29,52 & 6,75 & \\
\hline \multirow{2}{*}{ Total de escores } & T0 & 25 & 376,52 & 46,51 & \multirow{2}{*}{0,73} \\
\hline & T1 & 25 & 378,96 & 49,65 & \\
\hline
\end{tabular}

Nota: Diferenças entre os tempos foram estabelecidas através do teste $t$-Student e Wilcoxon, com nível de significância de $p<0,05$.

Para a pergunta "há algum alimento que você não gosta e que comêlo ou pensar nele faz você sentir-se desconfortável?", verificamos que no momento $\mathrm{T} 1,52 \%$ das pacientes citaram pelo menos um alimento ou grupo. Portanto, desenvolveram novas aversões alimentares subseqüentes ao 
tratamento. Entre os mais citados estão os alimentos gordurosos (38\%), seguido pelo grupo de leite e derivados (23\%). Foram citados ainda café preto $(15 \%)$, chá $(15 \%)$, chocolate $(7 \%)$ e carne vermelha $(7 \%)$.

\subsection{QUALIDADE DE VIDA}

Na Tabela 14 estão descritas as variáveis de qualidade de vidas e seus escores antes e após o tratamento quimioterápico. Houve diferença significativa para o aspecto de bem-estar físico (escore $=-3,47 ; p=0,00$ ) que engloba questões associadas à presença de dor, capacidade de atender às necessidades da família, sensação de fraqueza e náuseas e incômodo pelos efeitos colaterais do tratamento quimioterápico. Para as demais variáveis não houve alterações significativas entre os tempos T0 e T1.

Tabela 14. Escores de qualidade de vida relacionados com bem-estar físico, bem-estar social/familiar, bem-estar emocional, bem-estar funcional e preocupações adicionais. Hospital AC Camargo. São Paulo, 2005-2006.

\begin{tabular}{lccccc}
\hline \multicolumn{1}{c}{ Variáveis } & Tempo & $\mathbf{N}$ & Média & $\mathbf{d p}$ & $\mathbf{p}$ \\
\hline Bem-estar físico & T0 & 25 & 22,23 & 4,88 & \multirow{2}{*}{0,00} \\
& T1 & 25 & 18,76 & 5,02 & \\
Bem-estar social/ familiar & T0 & 25 & 16,10 & 4,13 & 0 \\
& T1 & 25 & 16,88 & 2,39 & \\
Bem-estar emocional & T0 & 25 & 16,53 & 4,87 & \multirow{2}{*}{0,52} \\
Bem-estar funcional & T1 & 25 & 16,94 & 4,01 & \\
Preocupações adicionais & T0 & 25 & 17,24 & 5,81 & 0,56 \\
& T1 & 25 & 18,07 & 6,30 & \\
Total de escores & T0 & 25 & 21,42 & 5,05 & \multirow{2}{*}{0,11} \\
& T1 & 25 & 19,48 & 5,13 & \\
\hline \hline
\end{tabular}


Nota: Diferenças entre os tempos foram estabelecidas através do teste $t$-Student e Wilcoxon, com nível de significância de $p<0,05$.

Os valores medianos dos escores para bem-estar físico, bem-estar social/familiar, bem-estar emocional, bem-estar funcional e preocupações adicionais são mostrados na Tabela 15 e apresentaram-se acima da mediana recomendada (bem-estar físico, bem-estar social/familiar, bemestar funcional - 14 escores; bem-estar emocional - 12 escores; bem-estar funcional e preocupações adicionais - 18 escores nos dois momentos (T0 e T1).

Tabela 15. Valores medianos de escores de qualidade de vida relacionados com bem-estar físico, bem-estar social/familiar, bem-estar emocional, bemestar funcional e preocupações adicionais. Hospital AC Camargo. São Paulo, 2005-2006.

\begin{tabular}{lccc}
\hline \multicolumn{1}{c}{ Variáveis } & Tempo & N & Mediana \\
\hline Bem-estar físico & T0 & 25 & 24 \\
& T1 & 25 & 18 \\
Bem-estar social/ familiar & T0 & 25 & 17 \\
Bem-estar emocional & T1 & 25 & 17 \\
Bem-estar funcional & T0 & 25 & 17 \\
Preocupações adicionais & T1 & 25 & 17 \\
Total de escores & T0 & 25 & 17 \\
& T1 & 25 & 18 \\
\hline \hline
\end{tabular}

Visando uma análise mais detalhada sobre qualidade de vida, avaliamos os escores obtidos em cada um dos tópicos que fazia parte das sub-escalas bem-estar físico, bem-estar social/familiar, bem-estar emocional, bem-estar funcional e preocupações adicionais. Verificamos redução significativa nos escores relacionados aos incômodos com efeitos colaterais do tratamento $(p=0,00)$ e presença de náuseas $(p=0,00)$ e no 
escore relacionado à atividade sexual $(p=0,00)$ após $o$ tratamento quimioterápico (Tabela 16).

Observamos ainda que entre os aspectos relacionados com o bloco de preocupações adicionais, somente aquele que avalia faltar de ar mostrou redução significativa no T1 $(p=0,03)$ (Tabela 16). Os demais parâmetros avaliados não apresentaram alterações significativas.

Tabela 16. Escores dos tópicos das sub-escalas de qualidade de vida bemestar físico, bem-estar social/familiar, bem-estar emocional, bem-estar funcional e preocupações adicionais. Hospital AC Camargo. São Paulo, 2005-2006.

\begin{tabular}{llccc}
\hline \multicolumn{1}{c}{ Variáveis } & Tempo & N & Diferença & p \\
\hline Sente-se fraca? & T0-T1 & 25 & 0,39 & 0,00 \\
Tem náuseas? & T0-T1 & 25 & 3,36 & 0,00 \\
Está incomodada com os & & & & \\
efeitos colaterais do & T0-T1 & 25 & 0,84 & 0,00 \\
tratamento? & & & & \\
Tem sido sexualmente ativa & & & & \\
no último ano? Se sim, está & T0-T1 & 25 & 0,60 & 0,00 \\
satisfeita? & & & & \\
Tem tido falta de ar? & T0-T1 & 25 & 2,183 & 0,03 \\
\hline \hline
\end{tabular}

Nota:Diferenças entre os tempos foram estabelecidas através do teste $t$-student e wilcoxon, com nível de significância de $p<0,05$

\subsection{CORRELAÇÕES}


Considerando que os objetivos desse estudo se ampliam a fim de verificar a influência do estado nutricional e comportamento alimentar na qualidade de vida das pacientes verificamos as possíveis correlações entre essas variáveis.

No que se refere ao impacto do estado nutricional na qualidade de vida das pacientes, os resultados encontrados não mostraram correlações significativas.

Entretanto, na Tabela 17, podemos observar correlações significativas entre variáveis de comportamento alimentar e variáveis de qualidade de vida, após o tratamento quimioterápico. Essas correlações não existiam no momento TO.

Tabela 17. Correlação entre comportamento alimentar e qualidade de vida no momento T1. Hospital AC Camargo. São Paulo, 2005-2006.

\begin{tabular}{llcc}
\hline \multicolumn{1}{c}{ Variável } & Variável de correlação & $\mathbf{r}$ & $\mathbf{p}$ \\
\hline Carboidratos $\mathbf{( g )}$ & $\quad$ Nutrientes & $-0,434$ & 0,03 \\
Proteínas $(\mathbf{g})$ & Bem-estar funcional & 0,472 & 0,01 \\
& Bem-estar emocional & & \\
Leite/ derivados e cereais & Grupos de alimentos & $-0,309$ & 0,06 \\
Vegetais & Bem-estar social & $-0,44$ & 0,01 \\
Frutas e sucos & Bem-estar funcional & 0,368 & 0,03 \\
& Bem-estar social & $-0,442$ & 0,01 \\
Pães e biscoitos & Bem-estar funcional & $-0,356$ & 0,04 \\
Bebidas & QIA & $-0,380$ & 0,03 \\
& Bem-estar funcional & & \\
Arroz e tubérculos & Grupos de aversões alimentares & 0,514 & 0,00 \\
& Bem-estar físico & 0,556 & 0,00 \\
Leite e derivados & Bem-estar funcional & 0,468 & 0,01 \\
Sopas e massas & Bem-estar emocional & 0,552 & 0,00 \\
& Bem-estar funcional & 0,534 & 0,00
\end{tabular}




$\begin{array}{llll}\text { Carnes e peixes } & \text { Bem-estar funcional } & 0,415 & 0,04 \\ \text { Vegetais } & \text { Preocupações adicionais } & 0,422 & 0,03\end{array}$

Nota: (r) Coeficiente de correlação de Pearson. O nível de significância adotado de $p<0,05$. 


\section{DISCUSSÃO}

O presente estudo é a mais longa investigação científica conduzida no Brasil se considerarmos os parâmetros de estado nutricional, composição corporal, consumo alimentar e qualidade de vida monitorados em pacientes com câncer de mama operável submetidas ao tratamento quimioterápico.

Neste sentido, o objetivo principal desse estudo foi avaliar o impacto do tratamento quimioterápico no estado nutricional e no comportamento alimentar de pacientes com neoplasia mamária atendidas no Hospital AC Camargo - São Paulo e suas conseqüências na qualidade de vida.

Com os avanços no diagnóstico e na terapia, o câncer de mama tem sido identificado em EC iniciais e os tratamentos anti-neoplásicos se tornado mais específicos. Neste sentido, o número de sobreviventes e o tempo de sobrevida pós-diagnóstico têm aumentado. Diante disso, a atenção à paciente com neoplasia mamária, visando minimizar o risco de recidiva do tumor e promover sobrevida livre da doença e com boa qualidade de vida, tem merecido atenção especial.

De acordo com DeL RIO et al. (2002) a maioria das pacientes com câncer de mama em EC I e I| recebe quimioterapia associada à cirurgia ou à radioterapia como forma de prevenir a recorrência do tumor. Porém, apesar dos benefícios do tratamento quimioterápico adjuvante em melhorar a sobrevida, os efeitos colaterais são freqüentes e considerados importantes. 
Neste contexto, o ganho de peso é um efeito colateral comum entre as pacientes com câncer de mama que recebem quimioterapia adjuvante. Foi descrito pela primeira vez por DIXON et al. (1978), sendo considerado contraditório devido às náuseas, vômitos e mucosites associadas ao tratamento antineoplásico e que deveriam ter maior relação com a perda de peso e, conseqüente, desnutrição nestas pacientes.

O aumento de peso em paciente pós-diagnóstico de neoplasia mamária não tem causa determinada e pode estar relacionado com diferentes fatores, sendo a quimioterapia adjuvante responsável direta ou indireta por este aumento (CAMORIANO et al., 1990). De acordo com MICHAEL (1985), ASLANI et al. (1999) e KROENKE et al. (2005) a redução na atividade física em função da fadiga e conseqüente diminuição na taxa metabólica basal, associadas com aumento na ingestão alimentar, contribuem diretamente para o ganho de peso. Fatores hormonais, como falência ovariana promovida pelo tratamento quimioterápico, resultam em mudanças na distribuição da gordura corporal (ASLANI et al., 1999). De acordo com DeL RIO et al. (2002) o tipo de protocolo quimioterápico, drogas utilizadas e duração do tratamento podem influenciar o ganho de peso.

De acordo com DeL RIO et al. (2002) de $50-90 \%$ das pacientes em tratamento quimioterápico adjuvante apresentam algum ganho de peso. Esse número foi confirmado em nosso estudo, onde $84 \%$ das pacientes aumentaram o peso após o tratamento anti-neoplásico (T1). Apesar disso, somente $44 \%$ das pacientes apresentaram aumento superior a $5 \%$ no $\mathrm{T} 1 \mathrm{em}$ comparação com o T0.

É interessante observar que esse ganho de peso aconteceu em paralelo com outros efeitos colaterais que poderiam levar ao quadro de desnutrição, pois verificamos que $88 \%$ das pacientes apresentaram náuseas 
durante o tratamento quimioterápico e mais de $50 \%$ delas tiveram quadro de mucosite e vômitos.

INGRAM e BROWN (2004) afirmaram que o ganho de peso em mulheres com câncer de mama é em média $4,4 \mathrm{Kg}$ durante o tratamento antineoplásico. ASLANI et al. (1999) quando avaliaram 25 mulheres em regime de quimioterapia, observaram ganho de 2,3kg. DeL RIO et al. (2002) observaram ganho de peso médio de 2,8kg (2 - 5,5kg) em mulheres menopausadas. Em nosso estudo encontramos valores semelhantes aos de ASLANI et al. (1999) e DeL RIO et al. (2002), com ganho médio de 2,2kg $(p=0,00)$ e com variação de $0,2-6,4 \mathrm{Kg}$, independente do estado de menopausa.

De acordo com diversos estudos, mulheres pré-menopausadas apresentam maior tendência ao ganho de peso durante o tratamento quimioterápico, provavelmente devido à amenorréia precoce causada pelo tratamento quimioterápico adjuvante (ASLANI et al., 1999; DEMARKWAHNEFRIED et al., 2001; DeL RIO et al., 2002). Em nosso estudo, porém, verificamos que as mulheres pré-menopausadas ganharam menos peso $(2,6 \mathrm{~kg})$ que as pacientes pós-menopausadas $(3,9 \mathrm{~kg})$. Entretanto, $100 \%$ das pacientes pré-menopausadas apresentaram aumento de peso, comparado com $66 \%$ das pacientes pós-menopausadas após o tratamento quimioterápico. Portanto, em concordância com CAMORIANO et al. (1990), em nosso estudo encontramos que as pacientes pré-menopausadas apresentam maior tendência ao ganho de peso, porém a intensidade desse ganho é maior nas mulheres pós-menopausadas.

BROWN et al. (2003) afirmaram que existe um corpo de evidências solidamente comprovado de que o sobrepeso e a obesidade são fatores de risco para o aparecimento e recorrência de vários tipos de neoplasia. 
Em pacientes com câncer de mama, a obesidade está relacionada com diagnósticos em estágios mais avançados da doença e maior tamanho do tumor, ambos importantes preditores da sobrevida. O sobrepeso e a obesidade podem interferir na sobrevida através do aumento dos níveis de insulina e de fatores do crescimento ligados à insulina (IGF), por aumento da conversão do estrógeno no tecido adiposo, redução na síntese da globulina ligante de hormônio sexual (SHBG), redução na eficácia do tratamento e por estarem associadas ao menor nível sócio-econômico (DeL RIO et al., 2002; KROENKE et al., 2005). CAMORIANO et al. (1990) em uma coorte com 665 mulheres demonstraram que ganho de peso maior que $5,9 \mathrm{~kg}$ envolveu aumento de 1,5 no risco de recorrência do tumor e também aumento de 1,6 no risco de morte.

Portanto, a obesidade tem sido mostrada como uma variável de risco para o surgimento do câncer de mama, primário ou secundário. Em nosso estudo, em função da alteração de peso, verificamos aumento significativo no IMC médio da população pós-tratamento $\left(26 \mathrm{~kg} / \mathrm{m}^{2}\right)$. Verificamos ainda que o total de pacientes com obesidade grau I aumentou para $20 \%$ da população total. É importante destacar que esse aumento foi em função da diminuição do percentual de pacientes com sobrepeso, ou seja, aquelas pacientes que antes do tratamento apresentavam IMC entre $25-29,9 \mathrm{~kg} /$ $\mathrm{m}^{2}$, ganharam peso e migraram para a classificação de estado nutricional de obesidade. Dessa forma, pacientes que após diagnóstico e antes de iniciar o tratamento apresentam sobrepeso devem ser orientadas sobre os riscos do ganho de peso que o tratamento quimioterápico oferece e sobre as opções de orientação alimentar disponíveis para o bom andamento do tratamento e também manutenção do estado nutricional de eutrofia.

Além do ganho de peso e presença de obesidade, DEMARKWAHNEFRIED et al. (2001) afirmaram que mudanças na composição corporal em função da idade são claramente aceleradas pelo tratamento quimioterápico. Porém, apesar do aumento significativo de peso e 
modificação do estado nutricional da população, nosso estudo não foi capaz de identificar mudanças significativas na composição corporal dessas pacientes após a quimioterapia. Entretanto, observamos que $53 \%$ das pacientes apresentaram aumento no percentual de gordura e redução no percentual de massa magra, o que pode caracterizar um ganho de peso atípico, presente na maioria das pacientes com câncer de mama inclusas em nosso estudo.

No momento $\mathrm{T} 1$ verificamos ainda correlação negativa $(r=-0,53$; $p=0,00$ ) entre peso e percentual de massa magra e correlação positiva $(r=0,64 ; p=0,00)$ entre peso e percentual de gordura. Esses dados confirmam que o aumento de peso nas pacientes do nosso estudo, após o tratamento quimioterápico, está relacionado à mudança de composição corporal, com aumento de gordura e redução de massa magra.

Foram verificadas também correlações negativas entre as diferenças $(\Delta)$ de peso e IMC e a diferença $(\Delta)$ de percentual de água entre os momentos T0 e T1. Esse dado indica que o ganho de peso ocorrido em função do tratamento quimioterápico não foi relacionado com aumento de água corporal. Se considerarmos que a diferença $(\Delta)$ no percentual de água mostrou correlação negativa com a diferença $(\Delta)$ no percentual de gordura podemos reforçar que o ganho de peso observado nestas pacientes, alterado em função do tratamento quimioterápico, foi de massa gordurosa.

Ganho de peso típico se caracteriza, segundo DEMARKWAHNEFRIED et al. (2001), por aumento no tecido adiposo e no tecido muscular. $\mathrm{O}$ tratamento quimioterápico, porém, parece induzir ganho de peso atípico, com ausência do ganho de massa magra. Esse perfil denomina-se, obesidade sarcopênica e, fisiologicamente, aparece com o avançar da idade e com a chegada da menopausa. Provavelmente, a menopausa precoce ocasionada pelo tratamento quimioterápico seja 
responsável pelo aparecimento desse quadro de obesidade que está associado ao aumentado risco de câncer de mama (HEBER et al., 1996).

A tendência ao ganho de peso atípico verificada em nosso estudo foi também descrita por FREEDMAN et al. (2004) onde pacientes avaliadas após 6 meses de tratamento quimioterápico apresentaram tendência ao aumento de gordura e diminuição de massa magra. O quadro de obesidade sarcopênica pode ser tratado com programas de atividade física aeróbica e treinos de resistência que promovam ganho de massa magra e aumento da taxa metabólica basal (HEBER et al., 1996; DEMARK-WAHNEFRIED et al., 2001).

O impacto do ganho de peso nos benefícios de sobrevida obtidos com o tratamento quimioterápico adjuvante apresenta dados contraditórios na literatura, porém, esse ganho afeta o bem-estar psicossocial da paciente (ASLANI et al., 1999). Mesmo que reduzido, em termos absolutos, o aumento de peso pode promover grandes implicações na saúde das pacientes no momento em que está diretamente associado com o desenvolvimento de outras doenças crônicas não-transmissíveis como: hipertensão, diabetes e doença cardiovascular, secundárias ao acúmulo de gordura visceral observado após a quimioterapia (ASLANI et al., 1999; DeL RIO et al., 2002).

As pacientes avaliadas foram submetidas a diferentes protocolos quimioterápicos ( $\mathrm{AC}, \mathrm{AC}+\mathrm{T}$, TAC, $\mathrm{FEC}, \mathrm{CMF}$ ), de acordo com o $\mathrm{EC}$, diagnóstico anátomo-patológico e idade. FREEDMAN et al. (2004) e MICHELLE et al. (2004) afirmaram que o tipo de quimioterápico utilizado na terapia anti-neoplásica pode promover ganho de peso em intensidade diferente e com maior ganho de gordura e perda de massa magra. Em nosso trabalho não foi possível avaliar o impacto do tipo de protocolo 
quimioterápico no ganho de peso e na qualidade desse ganho, em função do número de pacientes inclusas no estudo.

Outro fator avaliado em nosso estudo que tem relação com o prognóstico clínico foi o ângulo de fase. Segundo BARBOSA-SILVA (2005), o ângulo de fase é considerado o parâmetro de impedância que melhor estabelece o diagnóstico de má nutrição e também é visto como um bom preditor de prognóstico clínico. Está associado com a integridade das membranas celulares e com alterações no balanço fluídico e, portanto, é capaz de expressar quantidade e qualidade de massa tecidual mole.

SELBERG e SELBERG (2002) afirmaram que valores baixos de ângulo de fase sugerem morte ou diminuição da integridade celular e valores maiores indicam que a integridade das membranas está inalterada. Considerando a redução observada em nosso estudo (T1-T0 $=-0,4^{0}$; $p=0,0002$ ), podemos afirmar que nossas pacientes apresentaram tendência a um pior prognóstico clínico em função do ângulo de fase e que associado ao ganho de peso pode indicar maior risco de recidiva ou de pior sobrevida.

No que se refere ao consumo alimentar, CHLEBOWSKY et al. (1986) e DEMARK-WAHNEFRIED et al. (2001) afirmaram que as pacientes em tratamento quimioterápico podem apresentar quadro de hiperfagia e aumentar a freqüência de ingestão de alimentos a fim de diminuir o aparecimento de náuseas. Dessa forma ocorre aumento na ingestão de energia que contribui para o ganho de peso.

Assim como DeL RIO et al. (2002), em nosso estudo não verificamos aumento significativo no consumo de calorias e macronutrientes entre os dois momentos (T1-T0). No momento T1, os R24h foram aplicados em média 21 (9 - 41) dias após a infusão da última dose de quimioterápico. Essa diferença de tempo certamente influencia na alimentação, pois 
imediatamente após a infusão do quimioterápico há alteração no paladar e os efeitos colaterais das drogas (mucosites, náuseas e vômitos) apresentam-se de forma mais intensa, possivelmente interferindo diretamente nas escolhas alimentares tanto em quantidade, quanto em qualidade.

O tempo existente entre o T0 e T1, que foi em média de 5 meses (37 meses) pode ter contribuído para variação no tipo de alimento consumido, se considerarmos a sazonalidade, e se considerarmos ainda que, na cidade de São Paulo, as estações do ano são também definidas por tipos específicos de alimentos disponíveis. Por exemplo, no inverno há maior disponibilidade de frutas como morango, enquanto na estação seguinte é época de frutas como pêssego. Disponibilidade de alimentos diferentes, ricos em distintos tipos de nutrientes pode ter contribuído para a inexistência de diferença no consumo antes e após o tratamento quimioterápico.

Apesar dessa possibilidade, a análise do consumo de alimentos, conforme apresentado no item 5.2.1, indicou que não houve diferença entre os alimentos ingeridos nos dois momentos do estudo. Deste modo, o viés da sazonalidade, apesar de possível, não influenciou os resultados apresentados em nosso estudo.

Verificamos, entre as pacientes avaliadas, redução no consumo de frutas e sucos, promovendo redução no consumo de fibras e de nutrientes antioxidantes. A redução no consumo de fibras pode contribuir para pior prognóstico clínico. De acordo com McEGLIOT et al. (2006), ao avaliarem 516 pacientes, o risco de morte após diagnóstico de câncer de mama pode ser reduzido em $40-50 \%$ em função da elevada ingestão de vegetais e fibras. Dessa forma, dieta rica em fibras melhora a sobrevida após o diagnóstico de neoplasia mamária. 
Além do consumo de macronutrientes e fibras que apresentam implicação direta sobre o ganho de peso, alguns micronutrientes têm sido estudados em função da sua relação com câncer de mama. De acordo com THOMSON et al. (2005) um dos mecanismos pelo qual a dieta pode ajudar a prevenir o câncer é através da modulação dos danos ao DNA e da peroxidação lipídica.

De acordo com CONKLIN (2004), administração de determinados agentes anti-neoplásicos pode resultar na produção de espécies reativas de oxigênio em pacientes submetidos ao tratamento quimioterápico, sendo os radicais livres formados associados à redução na efetividade do tratamento e aumento na recidiva do tumor.

Nesse contexto, o consumo de nutrientes antioxidantes poderia ter efeito positivo na prevenção das modificações biológicas associadas ao estresse oxidativo.

Considerando que as pacientes avaliadas em nosso estudo foram submetidas ao tratamento cirúrgico, seguido de quimioterapia adjuvante, podemos afirmar que esse grupo apresentou fatores que levam ao aumento do estresse oxidativo, o qual promove o surgimento de novas alterações neoplásicas. Portanto, a presença de nutrientes antioxidantes, que minimizem a ação dos radicais livres pode colaborar para uma maior sobrevida livre da doença nessas pacientes.

Em coorte com pacientes com câncer de mama $(n=678)$ JAIN et al. (1994) observaram maior risco de morte por recidiva nos menores quartis de consumo de vitaminas $\mathrm{C}$ e carotenóides e, concordando com esse estudo, McELIGOT et al. (2006), constataram associação entre redução no risco de morte (33-50\%) após diagnóstico de câncer de mama e consumo desses nutrientes antioxidantes. 
McELIGOT et al. (2005) avaliando a vitamina C afirmaram que o mecanismo antioxidante desse nutriente ocorre via redução dos radicais altamente reativos tais como radical hidroxil, peroxil e superóxido e também oxigênio singlet, os quais são gerados por processos metabólicos internos. Nesse processo há a formação de radical ascorbil não-reativo e dessa forma há redução no dano ao DNA e, possivelmente, redução do risco de câncer de mama.

Estudos mais recentes têm demonstrado a habilidade do ácido ascórbico como fator regulador que pode influenciar a expressão gênica, a apoptose e outras funções celulares (PUSKAS et al., 2002; CARCAMO et al., 2004).

Considerando que vitamina $A$ é composta pelos carotenóides com atividade de pró-vitamina e pela vitamina A pré-formada (retinol e ésteres de retinil), $\mathrm{CHO}$ et al. (2003), em estudo de coorte com 116 mil mulheres do Nurses' Healthy Study II, sugeriram que a relação inversa entre a ingestão de vitamina A e o risco de câncer de mama torna fundamental a orientação sobre o consumo de alimentos ricos nesse nutriente, pois pode contribuir positivamente na redução da recorrência do tumor.

De acordo com ALTUCCI e GRONEMEYER (2001) a vitamina A tem sido associada com reduzido risco de câncer de mama através de diferentes mecanismos: (a) seus metabólitos regulam crescimento, diferenciação e morte celular e (b) pela atividade antioxidante dos carotenóides ( $\beta$-caroteno, $\beta$-criptoxantina e $\gamma$-caroteno).

Os carotenóides têm como principal mecanismo de ação antioxidante sua capacidade para neutralizar o oxigênio singlet. Os carotenóides são capazes de interagir com radicais livres como peroxil e alcoxil, agir como 
doadores de elétrons, reduzir esses radicais a espécies não-reativas e dessa forma minimizar os danos ao DNA e conseqüentes alterações neoplásicas (McELIGOT et al., 2005).

Esses nutrientes são encontrados em frutas e vegetais, o que justifica a maioria dos trabalhos encontrados associar o baixo consumo de frutas e vegetais com o surgimento de câncer. Em meta-análise conduzida por ROCK e DEMARK-WAHNEFRIED (2002) três estudos prospectivos que avaliaram a relação entre consumo de frutas e vegetais e efeito protetor após diagnóstico de câncer de mama, constataram associação inversa com o risco de morte, com redução de $20 \%$ - $90 \%$ desse risco.

Apesar da redução no consumo de frutas e sucos observada em nosso estudo é importante destacar que o uso de suplementes e medicamentos com ação antioxidante pelas pacientes não foi avaliado. Segundo McELIGOT et al. (2006), os nutrientes antioxidantes provenientes de alimentos estão associados com uma melhor sobrevida, conferindo maior efeito protetor, após o diagnóstico de câncer de mama, que os nutrientes provenientes de suplementos. Portanto, a atenção à adequação de nutrientes deve fazer parte do tratamento de pacientes com câncer de mama, independentemente do uso ou não de suplementos ou fármacos fontes de desses micronutrientes.

Ainda que os efeitos da suplementação não sejam conhecidos, os benefícios destes nutrientes, sobretudo sobre o perfil oxidativo, suportam a contribuição que uma orientação nutricional adequada poderia resultar na melhoria do prognóstico e na qualidade de vida dos pacientes oncológicos, a partir do aumento no consumo de alimentos ricos nesses nutrientes.

É importante destacar que a ausência de dados sobre a composição centesimal de muitos alimentos, tanto nos rótulos como nas tabelas 
nutricionais, dificulta a mensuração do consumo real, subestimando o que é de fato foi ingerido pelos indivíduos. Portanto, a utilização de tabelas eventualmente incompletas pode ser apontada como viés de estudos que buscam avaliar o consumo de nutrientes. Porém, por serem, na maioria dos casos a única fonte de consulta disponível, sua utilização tornou-se indispensável. Entretanto, acreditamos que este pode ser considerado um possível viés para a inexistência de diferenças de consumo entre os momentos T0 e T1 no nosso estudo.

Além das alterações metabólicas que promovem estresse oxidativo, contribuem para o ganho de peso e modificam a composição corporal das pacientes, alguns autores evidenciam uma relação direta entre o tratamento quimioterápico e mudanças nos hábitos alimentares. Neste contexto, BETERETCHE et al. (2004) e RAVASCO (2005) constataram que pacientes tratadas com quimioterapia apresentavam redução temporária na sensibilidade ao sabor e essa alteração poderia levar ao aparecimento de aversões alimentares.

Náuseas e vômitos constituem efeitos colaterais comuns em pacientes em tratamento quimioterápico, também são responsáveis pelo aparecimento das alterações nos hábitos alimentares, conhecidas como aversões alimentares adquiridas (BETERETCHE et al., 2004). Percentuais importantes das pacientes em nosso estudo apresentaram náuseas (88\%) e vômitos $(52 \%)$ durante o período de tratamento quimioterápico e mais de $50 \%$ delas citaram pelo menos um alimento ou grupo como causador de desconforto após a terapia anti-neoplásica.

Em nosso estudo, o grande percentual de pacientes apresentando efeitos colaterais à quimioterapia adjuvante (88 \%), esteve associado ao aparecimento de aversões alimentares. Este fato foi observado na análise das preferências alimentares relacionadas ao grupo das bebidas (bebidas 
alcoólicas, chá, café preto e adoçante), cujo consumo apresentou redução significativa $(p=0,002)$ no total de escores no T1. Acreditamos que a presença de bebidas alcoólicas neste grupo de alimentos teve forte contribuição para redução no total de escores.

MATTES et al. (1987) verificaram que pacientes com câncer mama em EC iniciais apresentam menores níveis de aversões alimentares adquiridas $(p=0,014)$ que pacientes com doença avançada. JACOBSEN et al. (1993) encontraram que as aversões alimentares adquiridas diminuem com a continuidade do tratamento. É provável que devido nossas pacientes apresentarem EC I e II, as diferenças entre os escores de preferências alimentares não tenham sido significativas entre os dois momentos (T1-T0), exceto para o grupo das bebidas. Consideramos ainda que a falta de aversões observada após o último ciclo de quimioterapia, para a maioria dos alimentos, possa indicar que tais modificações nas escolhas alimentares, potencialmente ocorridas durante o tratamento, foram transitórias.

Porém, quando consideramos os alimentos individualmente, verificamos redução significativa no escore de preferências para o café preto ( $p=0,011$ ), que foi também citado por $15 \%$ das pacientes como preparação que trazia sensação de desconforto. $\mathrm{O}$ chá e o chocolate foram alimentos igualmente mencionados por $15 \%$ e $7 \%$ das pacientes, respectivamente, desse estudo como rejeitados após a terapia anti-neoplásica adjuvante. Esse dado foi também verificado por HOLMES (1993) que mostrou serem café, chá e chocolate alimentos comuns no registro de aversão, assim como frutas cítricas e carne vermelha.

Diferente do estudo de HOLMES (1993), em nosso estudo as frutas não foram referidas como alimentos rejeitados após o tratamento quimioterápico. É importante enfatizar que verificamos aumento significativo no escore de preferências para o consumo de laranja/mexerica $(p=0,04)$ e 
mamão $(p=0,04)$, que pode indicar aumento no consumo de vitaminas antioxidantes, principalmente carotenóides.

Destacamos que o aumento na preferência por alguns tipos de frutas e o fato desses alimentos não terem sido rejeitados depois do tratamento é contrário à redução no consumo do grupo alimentar frutas e sucos. Essas observações revelam a complexidade do monitoramento do comportamento alimentar e reforçam os dados de GARCIA (1997), que observou que as escolhas alimentares podem ser orientadas pela busca da satisfação do paladar, pelo que "se deseja comer" ou pelo que "se deve comer", ou seja, pelo hedonismo ou pela disciplina.

Com relação ao consumo de carne vermelha, verificamos que somente $7 \%$ das pacientes fizeram referência a este alimento como relacionado à sensação de desconforto. Entre os alimentos do grupo das carnes constatamos aumento significativo no escore de preferências para carne bovina (cozida, assada, grelhada ou churrasco) $(p=0,04)$. Esse percentual é inferior ao encontrado por MATTES et al. (1992), onde 26,4\% dos pacientes com câncer em tratamento quimioterápico apresentaram aversão à carne. Porém, os pacientes avaliados no estudo de MATTES et al. (1992) tinham câncer de diferentes tipos e EC. É provável que esses fatores, associados aos diferentes perfis de tratamento tenham contribuído para os resultados encontrados por estes autores.

Ainda com relação aos escores de preferências alimentares, observamos que houve aumento significativo na preferência por sorvete $(p=0,00)$. Considerando que o Serviço de Nutrição Clínica do Hospital AC Camargo orienta todos os pacientes no primeiro dia de quimioterapia seguindo "Manual de alimentação para pacientes em quimioterapia" (IKEMORI e COTRIM, 2006), verificamos que no tópico que aborda "O que fazer em caso de mucosite?" há a recomendação para consumir flans, 
sorvetes e gelatinas. Em nosso estudo verificamos que mais de $50 \%$ das pacientes referiram presença de mucosite e, portanto, acreditamos que o aumento no escore de preferência por sorvete possa ser explicado pela adesão à orientação dada pelo Serviço de Nutrição Clínica do hospital.

McELIGOT et al. (2000), verificaram em pacientes com câncer de mama presença de aversão alimentar pós-quimioterapia para produtos lácteos. Esse dado foi confirmado também em nosso estudo, onde verificamos que apesar de não ter havido modificação significativa no escore de preferências para este grupo de alimentos, $23 \%$ das pacientes citaram leite e derivados como sendo associado a incômodo no T1.

Arroz branco $(p=0,04)$ e biscoito salgado/biscoito doce sem recheio $(p=0,03)$ foram alimentos que também apresentaram aumento significativo no escore de preferências alimentares após o tratamento quimioterápico. Ao contrário, $38 \%$ das pacientes avaliadas associavam alimentos gordurosos, no T1, com sensação de incômodo e mal-estar.

De acordo com GARCIA (1997) o conjunto de elementos que orientam o comportamento alimentar não é coordenado, necessariamente pela coerência, mas ocorre circunstancialmente imposto por uma dada situação. Portanto, os achados do nosso estudo nos levam a afirmar que as escolhas alimentares das pacientes com neoplasia mamária em tratamento adjuvante ultrapassam as barreiras do que é correto ou do que é desejado e, em função de diferentes efeitos colaterais, podem ser regidas pela simples aceitação.

Pacientes com câncer de mama apresentam baixa qualidade de vida em função do diagnóstico, da mastectomia e também em função dos efeitos do tratamento anti-neoplásico (BAUCOM et al., 2006). Em nosso estudo, entre os aspectos de qualidade de vida avaliados, houve redução 
significativa no escore de bem-estar físico $(p=0,00)$ após o tratamento quimioterápico. Confirmando esses resultados de piora na qualidade de vida em relação ao bem-estar físico, verificamos modificação significativa no escores relacionados a náuseas $(p=0,00)$ e incômodo com efeitos colaterais do tratamento $(p=0,00)$. Essa alteração de escores pode ser justificada pelo percentual importante das pacientes com pelo menos um efeito colateral ao tratamento quimioterápico, sendo a náusea o mais prevalente $(88 \%)$.

TANGNEY et al. (2002) e WAYNE et al. (2006) afirmaram que a qualidade de vida tem se tornado importante foco de pesquisas em pacientes sobreviventes de câncer de mama, entretanto poucos estudos têm avaliado a relação entre a qualidade de vida e a qualidade da dieta. De acordo com VAN DEN BRANDT et al. (1999) alterações no comportamento alimentar, associadas à presença de aversões alimentares em função dos efeitos colaterais do tratamento quimioterápico podem ter implicações nutricionais importantes, como redução na ingestão alimentar e perda de peso, o que pode indicar depleção clínica, associada com o quadro de caquexia, na maioria dos pacientes com câncer. Apesar dessas observações, em pacientes com câncer de mama, onde o ganho de peso em função da quimioterapia tem sido comprovado, a presença de aversões alimentares tem uma implicação de caráter social e um impacto emocional mais forte. Segundo RHODES e McDANIEL (2001), essas alterações alimentares, dependendo da intensidade e freqüência, constituem causas adicionais que interferem na qualidade de vida das pacientes.

Em sintonia com os autores acima, nossos resultados nos permite afirmar que as modificações no estado nutricional e alterações alimentares decorrentes do tratamento anti-neoplásico em pacientes com câncer de mama têm impacto direto sobre o prognóstico clínico e podem comprometer a qualidade de vida no momento que modificam seu convívio social. Portanto é essencial investigar se os aspectos do estado nutricional e quali- 
quantitativos da dieta podem ser associados com a qualidade de vida e também com a mortalidade nessas pacientes.

TANGNEY et al. (2002), avaliaram 212 pacientes com história de câncer de mama e verificaram que os escores de depressão parecem ser os mais fortes determinantes da qualidade da dieta e podem indicar que o estado emocional das pacientes interfere fortemente nas suas escolhas alimentares. Neste contexto, acreditamos que o estado nutricional, o consumo e escolhas alimentares influenciam e também são influenciados pela qualidade de vida atual das pacientes.

Considerando as diversas variáveis monitoradas, as possíveis interações entre os parâmetros antropométricos, alimentares e de qualidade de vida foram investigadas visando confirmar prévias observações citadas na literatura de modo isolado.

DeL RIO et al. (2002) afirmaram que o ganho de peso tem impacto psicológico negativo em mulheres que já sofrem de imagem corporal e autoestima alterada. Entretanto, em nosso estudo, apesar do aumento do peso em $84 \%$ da população e da conseqüente modificação do estado nutricional não verificamos correlação entre essas variáveis e a qualidade de vida das pacientes.

Neste sentido, observamos que a diferença (T1-T0) no consumo de carboidratos foi correlacionada com importantes aspectos da qualidade de vida das pacientes, tais como: bem-estar funcional, bem-estar físico e preocupações adicionais, sendo esse último composto por itens que caracterizam especificamente a qualidade de vida de pacientes com câncer de mama. O consumo de proteínas também apresentou correlação com bem-estar funcional. Verificamos ainda que após 0 tratamento quimioterápico (T1), o aspecto de bem-estar funcional foi correlacionado 
com consumo de carboidratos $(r=-0,43 ; p=0,03)$, enquanto bem-estar emocional foi correlacionado positivamente com consumo de proteínas $(r=0,50 ; p=0,01)$.

Constatamos também correlações significativas entre o consumo de alguns grupos de alimentos e diferentes aspectos de qualidade de vida. Entre esses achados destacamos as correlações significativas entre o consumo de do grupo de Frutas e Sucos e os aspectos de bem-estar social $(r=0,368 ; p=0,03)$ e bem-estar funcional $(r=-0,442 ; p=0,01)$. Portanto, se considerarmos que o consumo de Frutas e Sucos apresentou redução significante após a quimioterapia podemos inferir que essa modificação pode ter implicação direta na qualidade de vida das pacientes dessa amostra.

Diante desses resultados podemos concordar com RHODES e McDANIEL (2001) e afirmar que qualidade de vida e consumo alimentar são aspectos interligados em pacientes com câncer de mama em função da alteração emocional e física a qual estão submetidas.

No momento $T 1$, no que se refere às preferências alimentares, correlações significativas positivas com alguns aspectos de qualidade de vida foram encontrados: preferência por arroz e tubérculos e bem-estar físico ( $r=0,514 ; p=0,00)$; preferência por leite e derivados e bem-estar emocional $(r=0,468 ; p=0,02)$; preferência por sopas e massas $(r=0,534$; $p=0,00)$, carnes e peixes $(r=0,415 ; p=0,04)$, arroz e tubérculos $(r=0,556$; $p=0,00)$ e leite e derivados $(r=0,552 ; p=0,00)$ e bem-estar funcional; preferência por vegetais e preocupações adicionais $(r=0,422 ; p=0,03)$. Essas correlações concordam com os resultados de BERTERETCHE et al. (2004) que avaliaram 110 pacientes com câncer, comparados com 170 controles e constataram que a presença de aversão alimentar tem impacto negativo na qualidade de vida desses indivíduos. Portanto, em nosso estudo, as pacientes mostraram após o tratamento quimioterápico que melhores escores em preferências alimentares indicaram melhores escores de qualidade de vida. 
Apesar da significância das correlações entre as variáveis de qualidade de vida e de consumo observadas em nosso estudo, destacamos que possíveis mecanismos neuro-endócrino podem justificar tais relações e que estudos mais específicos devem ser realizados visando comprovar nossas observações, assim como identificar possíveis nutrientes envolvidos nesses processos.

Mais recentemente, WAYNE et al. (2006) demonstraram que a qualidade da alimentação após o diagnóstico afeta o funcionamento físico e mental das pacientes e que aquelas com alimentação mais saudável apresentam melhores escores de qualidade de vida. Portanto, alimentação e qualidade de vida são aspectos fortemente interligados, que devem ser trabalhados em paralelo nas pacientes sobreviventes de câncer de mama com o objetivo de minimizar o ganho de peso, melhorar a oferta de nutrientes e promover uma sobrevida de melhor qualidade.

Deste modo, os dados encontrados em nosso estudo confirmam as investigações prévias realizadas em outros países, onde o tratamento quimioterápico induz ganho de peso e ainda que as pacientes após o diagnóstico de neoplasia mamária podem apresentar consumo inadequado de nutrientes, devido as modificações nas suas escolhas alimentares, importantes para a manutenção do adequado estado nutricional e melhor resposta ao tratamento. 
Conclusão 


\section{CONCLUSÃO}

Considerando que o diagnóstico precoce do câncer de mama, associado às formas de tratamento menos invasivas têm contribuído para melhorar o prognóstico e a sobrevida das pacientes, os resultados apresentados em nosso estudo tornam-se importantes para a qualidade de vida pós-diagnóstico de neoplasia mamária. Deste modo, os resultados encontrados nesta amostra nos permitem concluir que:

I - O tratamento quimioterápico favoreceu o ganho de peso e este foi correlacionado com as alterações na composição corporal;

II - O consumo alimentar, apesar de não ter apresentado correlação significativa com a modificação de peso e de estado nutricional, mostrou alterações importantes no que se refere à ingestão de alimentos que compõem o grupo das Frutas e Sucos;

III - A qualidade de vida das pacientes após o tratamento quimioterápico apresentou redução nos aspectos relacionados ao bem-estar físico e aos efeitos colaterais do tratamento, e; 


$$
\text { IV - Qualidade de vida e preferências alimentares são }
$$

mutuamente correlacionados.

Portanto, as pacientes com diagnóstico de câncer de mama, submetidas ao tratamento quimioterápico necessitam de suporte multidisciplinar e, sobretudo nutricional, de modo a minimizar os efeitos colaterais do tratamento, como o ganho de peso, associado positivamente com a recidiva do tumor e piora na qualidade de vida. Neste sentido, orientações que promovam um conhecimento mais amplo da relação Nutrição - Qualidade de vida - Prognóstico clínico devem ser inclusas nos protocolos de tratamento. 


\section{REFERÊNCIAS BIBLIOGRÁFICAS}

Albert US, Koller M, Wagner U, Schultz KD. Survival chances and psychological aspects of quality of life in patients with localized early stage breast cancer. Inflamm Res. 2004; 53 (2S): 136-41.

Altucci L, Gronemeyer H. The promise of retinoids to fight against câncer. Nat Rev Cancer. 2001; 1:181-193.

Anelli A. Tratamento sistêmico do câncer. In: Kowaslki LP, Anelli A, Salvajoli JV, Lopes LF. Manual de condutas diagnósticas e terapêuticas em oncologia. $2^{\mathrm{a}}$ ed. São Paulo: Âmbito Editores Ltda; 2002. p.100-111.

Anelli A, Gadelha AP, Gimenes DL. Câncer de mama: tratamento sistêmico adjuvante. In: Kowaslki LP, Anelli A, Salvajoli JV, Lopes LF. Manual de condutas diagnósticas e terapêuticas em oncologia. $2^{\mathrm{a}}$ ed. São Paulo: Âmbito Editores Ltda; 2002. p.651-653. 
Aslani A, Smith RC, Allen BJ, Pavlakis N, Levi JA. Change in bory composition during breast cancer chemotherapy with the CMF-regimen. Breast Cancer Res Treat. 1999; 57:285-290.

Baker DS, Grochow LB, Donehower RC. Should anticancer drug dose be adjusted in the obese patient? J Natl Cancer Inst. 1995; 87:333-334.

Barbosa-Silva MCG, Barros AJD, Wang J, Heymsfield SB, Pierson Jr RN. Bioelectrical impedance analysis: population reference values for phase angle by age and sex. Clin Nutr. 2005; 82:49-52.

Baucom DH, Porter LS, Kirby JS, Gremore TM, Keefe FJ. Psychosocial issues confronting young women with breast cancer. Breast Dis. 2006; 23:103-13.

Bergvist K, Wengström Y. Symptom experiences during chemotherapy treatment-with focus on nausea and vomiting. Eur J Onc Nurs.2006; 10:21-9.

Bertereche MV, Dalix AM, Cesar d'Ornaro AM, Bellisle F, Khayat D, Faurion A. Decreased taste sensitivity in cancer patients under chemotherapy. Support Care Cancer. 2004; 12:571-576.

Boér K, Láng I, Juhos E, Pintér T, Szánto J. Adjuvant therapy of breast câncer with docetaxel-containing combination (TAC): a Hungrian experience in the BCIRG 001 trial. Pathol Oncol Res. 2003; 9(3): 166-169.

Brady MJ, Cella DF, Mo F, Bonome AE, Tulsky DS, Lloyd SR et al. Reliability and validity of the Functional Assessment of Cancer TherapyBreast quality-of-life instrument. J Clin Oncol. 1997; 15(3):974-86. 
Brown JK, Byers T, Doyle C, Courneya KS, Demark-Wahnefried W et al. Nutrition and physical activity during and after cancer treatment: an american cancer society guide for informed choices. CA Cancer Journal Clinicians. 2003; 53:268-291.

Buzzoni R, Bonadonna G, Valagussa P, et al:Adjuvant chemotherapy with doxorubicin plus cyclophosphamide, methotrexate, and fluorouacil in the treatment of respectable breast cancer with more than three positive nodes.J Clin Oncol. 1991; 9:2134-2140.

Camoriano JK, Loprinzi CL, Ingle JN, Therneau TM, Krook JE, Veeder MH. Weight change in women treated with adjuvant therapy or observed following mastectomy for node-positive breast cancer. J Clin Oncol. 1990; 8(8): 132734.

Carcamo JM, Pedraza A, Borquez-Ojeda O, Zhang B, Sanches R, Golde DW. Vitamin $C$ is a kinase inhibitor: dehydroascorbic acid inhibits IkBa kinase B. Mol Cell Biol. 2004; 24:6645-52.

Cella DF, Cherin EA. Quality of life during and after cancer treatment. Compr Ther. 1988; 14:69-75.

Chlebowsky RT, Weiner JM, Reynolds R, Luce J, Bulcavage L, Bateman JL. Long term survival following relapse after 5-FU but not CMF adjuvant breast cancer therapy. Breast Cancer Research Treatment. 1986; 7:23-29.

Cho E, Spiegelman D, Hunter DJ, Chen WY, Zhang SM, Colditz GA et al. Premenopausal intakes of vitamins $\mathrm{A}, \mathrm{C}$ and $\mathrm{E}$, folate and carotenoids, and risk of breast cancer. Cancer Epidemiol Biomarkers Prev. 2003; 12: 713-720. 
Chu E, DeVita VTJ. Principles of cancer management: chemotherapy. In: DeVita VTJ; Hellmans S; Rosember SA. Cancer: principles e practice of oncology. $6^{a}$ ed. Philadelphia: Lippincott Willians \& Wilkins; 2001. p.289-306.

Coelho FRG. Câncer: manual de orientação para pacientes interessados. $2^{\mathrm{a}}$ ed. São Paulo: Robe Editorial; 2000.

Conklin KA. Chemotherapy-associated oxidative stress: impact on chemotherapeutic effectiveness. Integr Cancer Ther. 2004; 3(4): 294-300.

Costa LJM, Varella PCS, Giglio AD. Weight changes during chemotherapy for breast cancer. Med J. 2002; 120(4): 113-7.

Cotrim TH. Acompanhamento nutricional de pacientes em radioterapia e quimioterapia. In: Ikemori EHA, Oliveira T, Serralheiro IFD, Shibuya E, Cotrim TH, Trintin LA et al. Nutrição em oncologia. $1^{\text {a }}$ ed. São Paulo: Lemar; 2003. p.205-18.

Del Rio G, Zironi S, Valeriani L, Menozzi R, Bondi M, Bertolini M, et al. Weight gain in women with breast câncer treated with adjuvant cyclophosphomide, methotrexate and 5-fluorouracil. Analysis of resting energy expenditure and body composition. Breast Cancer Res. 2002; 73:267-273.

Demark-Wahnefried W, Peterson BL, Winer EP, Marks L, Aziz N, Marcom PK, Blackwell K, Rimer BK. Changes in weight, body composition, and factors influencing energy balance among premenopausal breast cancer patients receiving adjuvant chemotherapy. J Clin Oncol. 2001; 19(9): 2381-9.

Diaz J, Conde-Garcia J. Oncologia Clínica Básica. Madrid: Aran Ediciones. 2000. 
Dixon JK, Moritz DA, Baker FL. Breast cancer and weight gain: an unexpected finding. Oncol Nurs Forum. 1978; 5(3): 5-7.

Duarte AC, Castellani FR. Semiologia nutricional. [s.ed.]. Rio de Janeiro: Axcel Books do Brasil Editora; 2002.

Epidata, versão 3.1 [software na internet]. Denmark: Epidata Association; 2005 [acesso em setembro de 2005]. Disponível em: http://www.epidata.com.br.

Feuz AS, Assis MAA, Passos AACF. Métodos de inquéritos alimentares com abordagens do comportamento alimentar. In: Fisberg RM, Slater B, Marchioni DML, Martini LA. Inquéritos alimentares: métodos e bases científicos. $1^{\text {a }}$ ed. São Paulo: Editora Manole; 2005.

Fletcher RH, Fletcher SW, Wagner EH. Epidemiologia Clínica: elementos essenciais. 3a ed. Porto Alegre: Artes Médicas, 1996.

Freedman RJ, Aziz N, Albanes D, Hartman T, Danforth D, Hill S, Sebring N, Reynolds JC, Yanovski JA. Weight and body composition changes during and after adjuvant chemotherapy in women with breast cancer. J Clin Endocrinol Metab. 2004; 89(5): 2249-53.

Ganz PA, Desmond KA, Leedham B et al. Quality of life in breast cancer survivors. J Natl Cancer Inst. 2002; 94: 39-49.

Garcia RWD. Práticas e comportamento alimentar no meio urbano: um estudo no centro da cidade de São Paulo. Cad Saúde Públ. 1997; 13(3): 455-467. 
Gimenez DL. Quimioterapia. In: Ikemori EHA, Oliveira T, Serralheiro IFD, Shibuya E, Cotrim TH, Trintin LA et al. Nutrição em oncologia. $1^{a}$ ed. São Paulo: Lemar; 2003. p.179-88.

Giuliano AE. Breast. In: Tierney LMJ, McPhee SJ, Papadakis MA. Current: medical diagnosis \& treatment. $36^{a}$ ed. United States: Appleton \& Lange; 1997. p.644-77.

GLOBOCAN - Global Cancer Statistics. [homepage na internet]. França: Interantional Agency for Research on Cancer. [acesso em 21 janeiro 2007]. Disponível em: http://www.iarc.fr.

Grindel CG, Cahil CA, Walker M. Food intake of women with breast cancer during their first six month of chemotheraphy. Support Care Cancer.1993; 1 : 326-30.

Harvie M, Howell A, Vierkant RA, Kumar N, Cerhan JR, Kelemen LE, et al. Association of gain and loss of weight before and after menopause with risk of postmenopausal breast cancer in the lowa women's health study. Cancer Epidemiol Biomarkers Prev; 2005. 14(3): 656-661.

Heber D, Ingles S, Ashley JM, et al. Clinical detection of sarcopenic obesity by bioelectrical impedance analysis. Am J Clin Nutr. 1996; 64(S): 472-477.

Herman DR, Ganz PA, Petersen L, Greendale GA. Obesity and cardiovascular risk factors in younger breast cancer survivors: the cancer and menopause study (CAMS). Breast Cancer Res Treat. 2005; 93: 13-23.

Holmes S. Food avoidance in patients undergoing cancer chemotherapy. Support Care Cancer. 1993; 1:3230. 
Ikemori, EHA, Cotrim, TH. Manual de alimentação para pacientes em quimioterapia. 2006. 19p.

INCA - Instituto Nacional do Câncer. TNM: Classificação de tumores malignos. $6^{a}$ ed. Rio de Janeiro: INCA, 2004. 254p.

INCA - Instituto Nacional do Câncer. Coordenação de Prevenção e Vigilância. Estimativa 2006: Incidência de câncer no Brasil. Rio de Janeiro: INCA, 2005. 94p.

Ingram C, Brown J. Patterns of weight and body composition change in premenopausal woman with early stage breast cancer. Cancer Nurs. 2004; 27(6): 483-490.

Instituto Brasileiro de Geografia e Estatística (IBGE). Ministério do planejamento, orçamento e gestão. Censo demográfico. 2002.

Jacobsen PB, Bovbjerg DH, Schwartz MD, Andrykowski MA, Futterman D, Gilewski $T$ et al. Formation of food aversion in cancer patients receiving repeated infusions of chemotherapy. Behav Res Ther. 1993; 31(8):738-748.

Jain M, Miller AB, To T. Premorbid diet and prognosis of women with breast cancer. J Natl Cancer Inst. 1994; 86(18): 1390-7.

Janz NK, Mujahid M, Lantz PM, Fagerlin A, Salem B, Morrow M et al. Population-based study of the relationship of treatment and sociodemographics on quality of life for early stage breast cancer. Quality of Life Research. 2005; 14: 1467-79.

Kennedy L, Diamond J. Assessement and management of chemotherapyinduced mucositis in children. J Pediatr Oncol Nurs. 1997; 14:164-74. 
Kornek G. Nutrition for cancer patients - are there specific recomendations. Onkologie. 2002; 2: 575-577.

Kroenke $\mathrm{CH}$, Chen WY, Rosner B, Holmes MD. Weight, weight gain, and survival after breast cancer diagnosis. J Clin Oncol. 2005; 23: 1370-1378.

Kutynec CL, McCargar L, Barr SI, Hislop TG. Energy balance in women with breast cancer during adjuvant treatment. J Am Diet Assoc. 1999; 99(10): 1222-27.

Lancheros L, Gamba M, González H, Sánchez R. Characterization of the evolution of the nutritional condition of patients with breast câncer on chemotherapy. Rev Colomb Cancerolo. 2004; 8(2): 11-22.

Lohman T, Going S. Assesment of body composition and energy balance. In: Lamb D, Murray R. Perspectives in exercise science and sports medicine. Cooper Publishing Group: Carmel; 1998. p. 61-105.

Lopes A, et al. Oncologia cirúrgica. In: Kowaslki LP, Anelli A, Salvajoli JV, Lopes LF. Manual de condutas diagnósticas e terapêuticas em oncologia. $2^{\mathrm{a}}$ ed. São Paulo: Âmbito Editores Ltda; 2002. p.81-91.

Mackerras, D. Energy adjustment: the concepts underlying the debate. J Clin Epidemiol. 1996; 49(9): 957-962.

Marques R, Buzaid AC. Câncer de mama: tratamento adjuvante. Manual de oncologia clínica. $5^{\mathrm{a}}$ ed. Rio de Janeiro: Reichmann \& Affonso Editores; 2006. p. 1-9.

Mattes RD, Arnold C, Boraas M. Learned food aversion among cancer chemotherapy patients: incidence, nature, and clinical implications. Cancer. 1987; 60: 2576-2580. 
Mattes RD, Curran Jr WJ, Alavi J, Powlis W, Whittington R. Clinical implications of learned food aversions in patients with cancer treated with chemotherapy or radiation therapy. Cancer. 1992; 70(1):192-200.

McEligot AJ, Rock CL, Sobo EJ, Flatt SW. Food avoidance by women at risk for recurrence of breast cancer. J Cancer Educ. 2000; 15(3):151-5.

McEligot AJ, Yang S, Meyskens Jr FL. Redox regulation by intrinsic species and extrinsic nutrients in normal and cancer cells. Annu Rev Nutr. 2005; 25:261-295.

McEligot AJ, Largent J, Ziogas A, Peel D, Anton-Culver H. Dietary fat, fiber, vegetable, and micronutrients are associated with overall survival in postmenopausal women diagnosed with breast cancer. Nutr Cancer. 2006; 55(2): 132-140.

Mercadante S. Nutrition in cancer patients. Support Care Cancer. 1997; 4:1020.

Meija A J M et al. Nutritional state alterations in children with acute lymphoblastic leukemia during induction and consolidation of chemotherapy. Arch Med Res. 1997; 28:273-79.

Michael O. Huntington MD. Weight gain in patients receiving adjuvant chemotherapy for carcinoma of the breast. Cancer. 1985; 56: 472-74.

Michelle NH, Campbell IT, Baildam A, Howell A. Energy balance in early cancer patients receiving adjuvant chemotherapy. Breast Cancer Res Treat. 2004; 83: 201-10. 
Mirra AP, Latorre MRDO, Veneziano DB. Aspectos epidemiológicos do câncer no município de São Paulo: fatores de risco. São Paulo: TOMGRAF Editora Ind. Gráfica Ltda.,2003. 64p.

Minitab Statistical [software em CD-ROM]. Versão 14. State College, Pa: Minitab Inc, 2003.http://www.minitab.com.

Mirshahidi H R, Abraham J. Breast Cancer. In: Abraham J, Allegra CJ, Gulley J. Handbook of Clinical Oncology. 2a ed. Philadelphia, PA: Lippincott William \& Wilkins; 2005. p. 155-172.

Mols F, Vingerhoets Ad J J M, Coebergh J W et al. Quality of life among long-term breast cancer survivors: a systematic review. Eur J Cancer. 2005;41:2613-19.

Netto MM, lyeyasu H, Maia MAC. Câncer de mama localmente avançado. In: Kowaslki LP, Anelli A, Salvajoli JV, Lopes LF. Manual de condutas diagnósticas e terapêuticas em oncologia. $2^{\mathrm{a}}$ ed. São Paulo: Âmbito Editores Ltda; 2002. p.649-50.

Netto MM, Oliveira AGC. Câncer de mama feminino. In: Kowaslki LP, Anelli A, Salvajoli JV, Lopes LF. Manual de condutas diagnósticas e terapêuticas em oncologia. $2^{\mathrm{a}}$ ed. São Paulo: Âmbito Editores Ltda; 2002. p.643-44.

Nutrient Database for Standard Reference Release [software na internet]. USDA: US Department of Agriculture, Agricultural Research Service; 2005 
[acesso em setembro de 2005]. Disponível em www.nal.usda.gov/fnic/foodcomp.

NutWin: Programa de apoio à nutrição [software em CD-ROM]. Versão 1.5. São Paulo: UNIFESP - Universidade Federal do Estado de São Paulo; 2002.

Oliveira T, Angelis EC. Terapia nutricional e reabilitação do paciente com câncer de cabeça e pescoço. In: Ikemori EHA, Oliveira T, Serralheiro IFD, Shibuya E, Cotrim TH, Trintin LA et al. Nutrição em oncologia. $1^{a}$ ed. São Paulo: Lemar; 2003. p.83-108.

Organização Mundial da Saúde (OMS). The problem of overweight and obesity. In: Obesity: preventing and managing the global epidemic. Geneva: World Health Organization, 2000. [WHO Technical Report Series, 897].

Organização Mundial da Saúde (OMS). World Health Statistics 2006. Relatório. França; 2006.

Pandey M, Thomas BC, SreeRekha P, Ramdas K, Ratheesan K, Parameswaran S. Mathew BS, Raian B. Quality of life in women with breast cancer undergoing treatment with curative intent. World J Surg Oncol. 2005. $27(3): 63$.

Perez E, Muss HB. Optimizing adjuvant chemotherapy in early-stage breast cancer. Oncology. 2005. 19(14):1759-67. 
Perry MC. The Chemoterapy Sourcebook, $3^{a}$ ed. Philadelphia, Lippincott: Williams \& Wilkins; 2001.

Phillipi ST. Tabela de composição de alimentos: suporte para decisão nutricional. $2^{\mathrm{a}}$ ed. São Paulo: Coronário, 2002.

Piccoli A, Pastori G. BIVA software. Department of Medical and Surgical Sciences, University of Padova, Italy; 2002.

Pinheiro ABV, Lacerda EMA, Benzecry EH et al. Tabela para avaliação de consumo alimentar em medidas caseiras. $4^{a}$ ed. Rio de Janeiro, São Paulo, Belo Horizonte: Atheneu, 2001.

Pinho VFS, Coutinho ESF. Risk factors for breast cancer: a systematic review of studies with female samples among the general population in Brazil. Cad Saúde Pública. 2005; 21(2): 351-360.

Puskas F, Gergely P, Niland B, Banki K, Perl A. Differential regulation of hydrogen peroxide and fas-dependent apoptosis pathways by dehydroascorbate, the oxidized form of vitamin C. Antioxid Redox Signal. 2002; 4:357-69.

Ravasco P. Aspects of taste and compliance in patients with cancer. Eur $\mathrm{J}$ Oncol Nurs. 2005; 9(S): 84-91. 
Reis NT, Bisso ML, Marques CC. Agentes utilizados nas neoplasias malignas e na SIDA. In: REIS NT. Nutrição clínica: interações. $1^{\text {a }}$ ed. Rio de Janeiro: Rubio, 2004. p. 284-319.

Rhodes VA, McDaniel RW. Nausea, vomiting, and retching: complex problems in palliative care. CA: Cancer J Clin. 2001; 51: 232-48.

Rock CL. Diet and breast cancer: can dietary factors influence survival? J Mammary Gland Biol Neoplasia. 2003; 8:119-32.

Rock CL, Demark-Wahnefried W. Nutrition and survival after the diagnosis of breast cancer: a review of the evidence. J Clin Oncol. 2002; 20(15): 3302-16.

Rosenfel RS, Leite C, Rocha RGA. Terapia nutricional no paciente imunodeprimido e no câncer. Programa abbott de especialização em terapia intensiva. Rio de Janeiro: Vero Comunicação Total. 2001; 10:03-12.

Salvajoli JV, Santos EC. Radio-oncologia. In: Kowaslki LP, Anelli A, Salvajoli JV, Lopes LF. Manual de condutas diagnósticas e terapêuticas em oncologia. $2^{\mathrm{a}}$ ed. São Paulo: Âmbito Editores Ltda; 2002. p.92-99.

SAS for DOS [software em CD-ROM]. Versão 9.1.3. Cary, NC: SAS Institute, 2006. http://www.sas.com.

Schwartz MD, Jacobsen PB, Bovbjerg DH. Role of nausea in development of aversion to a beverage paired with chemoyherapy treatment in cancer patients. Physiol Behav. 1996; 59: 659-63.

Schutz HG. A food action rating scale for measuring food acceptance. J Food Sci. 1965; 30:365-74. 
Selberg O, Selberg D. Norms and correlates of bioimpedance phase angle in healthy human subjects, hospitalized patients and patients with liver cirrohsis. Eur J Appl Physiol. 2002; 86: 506-16.

Simonton OC, Matthews-Simonton S, Creighton JL. Com a vida de novo. Trad. Heloísa de MA Costa. São Paulo: Summus Editorial;1987.

Smith JS, Souba WW. Nutritional Support. In: DeVita VTJ, Hellman S, Rosenberg SA. Cancer: principles e practice of oncology. Philadelphia: Lippincott Williams \& Wilkins; 2001. p.3012-3032.

Smith $\mathrm{Tj}$, Desch CE. Neutropenia-wise and pondfoolish: safe and effective chemotherapy in massive obese patients. South Med J. 1991;84:883-885.

SPSS [software em CD-ROM]. Versão 13.0. Chicago: Incorporation. Statistical package for the social science for windows student version; 2000.

Tabela brasileira de composição de alimentos. TACO/NEPA - UNICAMP. Versão 1. Campinas. 2004.

Tangney CC, Young JA, Murtaugh MA, Cobleigh MA, Oleske DM. Selfreported dietary habits, overall dietary quality and symptomatology of breast cancer survivors: a cross-sectional examination. Breast Cancer Res Treat. 2002; 71:113-23. 
TBCAUSP. Tabela de composição de alimentos: projeto integrado de composição de alimentos Brasil foods [on line]. Versão 4.1. Out 2005. [acessado em 19.10.2005] www.fcf.usp.br/tabela.

Thomson CA, Giuliano AR, Shaw JW, Rock CL, Ritenbaugh CK, Hakin IA. Diet and biomarkers of oxidative damage in women previously treated for breast cancer. Nutr Cancer. 2005; 51(2): 146-154.

Tomita LY, Cardoso MA. Relação de medidas caseiras, composição química e receitas de alimentos nipo-brasileiros. $1^{\text {a }}$ ed. São José do Rio Preto: FAMERP, 2000.

Trintin LA. Avaliação Nutricional. In: Ikemori EHA, Oliveira T, Serralheiro IFD, Shibuya E, Cotrim TH, Trintin LA et al. Nutrição em oncologia. 1 ed. São Paulo: Lemar; 2003. p.45-82.

Vacek PM, Winstead-Fry P, Secker-Walker RH, Hooper GJ. Factors influencing quality of life in breast cancer survivors. Qual Life Res. 2003; 12:527-537.

Van Den Brant PA, Dagnelie PC, Von Meyenfeldt MF. Nutrition and cancer: causative, protective and therapeutic aspects. Ned Tijdschr Geneeskd. 1999. 143(27): 1414-20.

Venturini M, Del Mastro L, Aitini E. Dose-dense adjuvant chemotherapy in early breast cancer patients: results from a randomized trial. J Natl Cancer Inst. 2005; 97(23):1724-33. 
Walsh SJ, Begg CB, Carbone PP. Cancer chemotherapy in the eldery. Semin Oncol. 1989;16:66-75

Wapnir IL, Cody RP, Grco RS. Subtle differences in quality of life after breast cancer surgery. Ann Surg Oncol. 1999; 6(4): 359-366.

Wayne SJ, Baumgartner K, Baumgartner RN, Bernstein L, Bowen DJ, Ballard-Barbash R. Diet quality is directly associated with quality of life in breast cancer survivors. Breast Cancer Res Treat. 2006; 96:227-232.

Willet W, Stampfer M. Implications of total energy intake for epidemiologic analyses. In: Willet W. Nutritional epidemiology. $2^{\mathrm{a}}$ ed. New York: Oxford University Press, 1998. 514p.

Winer EP et al. Malignant tumors of the breast. In: DeVita VTJ, Hellman S, Rosenberg SA. Cancer: principles e practice of oncology. Philadelphia: Lippincott Williams \& Wilkins; 2001. p.1651-1716. 


\section{Anexos}

ANEXO 1: Protocolos de Aprovação dos Comitês de Ética da Faculdade de Saúde Pública-USP e do Hospital do Câncer AC Camargo. 


\section{. \\ Universidade de São Paulo \\ Faculdade de Saúde Pública \\ COMITÉ DE ÉTICA - COEP}

Av. Dr. Arnaldo, 715 - Assessoria Acadêmica - CEP 01246-904 - São Paulo-Brasil Telefones: (55-II) 3066-7779 - e-mail: coep a fsp.usp.br

\section{Of.COEP/140/05}

20 de maio de 2005

Pelo presente, informo que o Comitê de Ética em Pesquisa da Faculdade de Saúde Pública da Universidade de São Paulo-COEP aprovou de acordo com os requisitos da Resolução CNS/196/96 e suas complementares, o Protocolo de Pesquisa n. ${ }^{\circ}$ 1315, intitulado: "INFLUÊNCIA DO TRATAMENTO QUIMIOTERÁPICO NA AQUISIÇÃO DE AVERSÕES ALIMENTARES TRANSITÓRIAS E PERMANENTES EM PACIENTES COM NEOPLASIA MAMÁRIA", apresentado pela pesquisadora Nágila Raquel Teixeira Damasceno.

Atenciosamente,

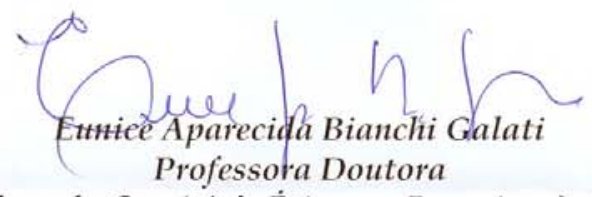

Coordenadora do Comitê de Ética em Pesquisa da FSP-COEP 


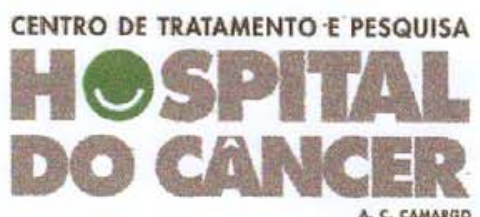

São Paulo, 29 de junho de 2005.

$\dot{A}$ Prof. Dra. Nagila Raquel T. Damasceno

Ref.: Projeto de Pesquisa n. ${ }^{\circ} 687 / 05$

"Influência do tratamento quimioterápico na aquisição de aversöes alimentares transitórias e permanentes em pacientes com neoplasia mamária".

Prezada Doutora:

Seu projeto de pesquisa, acima mencionado, foi apreciado pela Comissão de Ética em Pesquisa (CEP) do Hospital do Câncer em sua última reunião de 28/06/2005. Os membros desta comissão aprovaram a realização deste estudo.

Informações a respeito do andamento do referido projeto deverão ser encaminhados à secretaria do CEP dentro de 12 meses.

Atenciosamente,

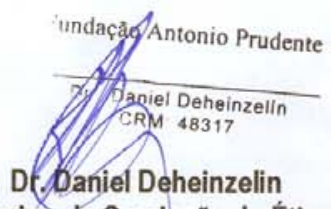

Coordenador Interino da Comissão de Ética em Pesquisa

C.C

Dr. Märio Mourāo Neto/ Dr. Daniel Luiz Gimenes / Sra. Tatiana H. Cotrin/Sra. Sara Maria Moreira de Souza

COMISSÃO DE ÉTICA EM PESQUISA - CEP

Rua Prof. Antônio Prudente, 211 - Liberdade - Såo Paulo - SP CEP 01509-900 PABX(OXX11)3272-5000 ramal 1117 


\section{ANEXO 2 - Índice de performance de Karnofsky.}

\begin{tabular}{ccl}
\hline \multicolumn{2}{c}{ ESCORE } & \multicolumn{1}{c}{ DESCRIÇÃO } \\
\hline$\underline{1}$ & 100 & Normal \\
$\underline{2}$ & 90 & Capaz de realizar atividades normais. Sem sinais ou sintomas de doenças \\
$\underline{3}$ & 80 & Realiza atividades normais com proeza. \\
$\underline{4}$ & 70 & Cuida de si próprio, capaz de realizar atividades normais e trabalhar. \\
$\underline{5}$ & 60 & $\begin{array}{l}\text { Requer assistência ocasional, mas é capaz de cuidar da maioria das suas } \\
\text { próprias atividades. }\end{array}$ \\
$\underline{6}$ & 50 & Requer considerável assistência e cuidados médicos freqüentes \\
$\underline{7}$ & 40 & Incapaz, requer cuidados especiais e assistência. \\
$\underline{8}$ & 30 & Severamente incapaz, indicação de hospitalização em morte iminente. \\
$\underline{9}$ & 20 & Muito doente, hospitalização necessária, necessidade de tratamento de \\
& &
\end{tabular}




\section{ANEXO 3: Termo de consentimento Termo de Consentimento}

$\mathrm{Eu}$,

voluntariamente,

participarei da pesquisa intitulada "Influência do tratamento quimioterápico nas aversões alimentares transitórias ou permanentes em pacientes com neoplasia mamária", sob a responsabilidade da Profa. Dra. Nágila Raquel Teixeira Damasceno. Fui esclarecida que:

- A minha participação será somente na pesquisa descrita acima, portanto essa autorização não pode ser utilizada para outros projetos;

- O objetivo da pesquisa é avaliar as mudanças alimentares que terei durante a quimioterapia e se essas mudanças irão modificar meu estado nutricional;

- A pesquisa será feita antes de começar o tratamento quimioterápico, logo que o tratamento terminar e 2 meses após o final da quimioterapia;

- Nos três momentos:

o Fornecerei informações sobre minha alimentação;

- Responderei a um questionário sobre minha qualidade de vida;

- Serão obtidas medidas de peso e altura e ainda farei o exame para determinação da composição corpórea, todos feitos pela própria pesquisadora e/ ou equipe treinada;

- Esta pesquisa não trará nenhum risco a minha saúde, pois não apresenta nenhum tipo de intervenção;

- Os resultados obtidos serão divulgados para a comunidade científica (médicos, nutricionistas, enfermeiros), com o objetivo de beneficiar o acompanhamento e a orientação nutricional do paciente com câncer;

- Minha identidade ficará em sigilo e sob a responsabilidade do pesquisador-chefe e não será divulgada.

- Tenho a liberdade de não colaborar ou de desistir a qualquer momento ao longo da pesquisa, não tendo este ato, nenhuma conseqüência ao meu tratamento médico;

Em caso de dúvida ou maiores esclarecimentos, fui informada que poderei entrar em contato com a pesquisadora-chefe Profa. Dra. Nágila Raquel Teixeira Damasceno pelos telefones (11) 3066-7701 - R: 220.

Se a pesquisadora não fornecer as informações/ esclarecimentos suficientes poderei entrar em contato com o Coordenador do Comitê de Ética do Hospital co Câncer - SP, pelo telefone 3272-2189, ramais 1113 ou 1117 .

Ciente,

Assinatura do participante

São Paulo, de de 2006 


\section{ANEXO 4 - Protocolo de avaliação sócio-econômica cultural, clínica e antropométrica}

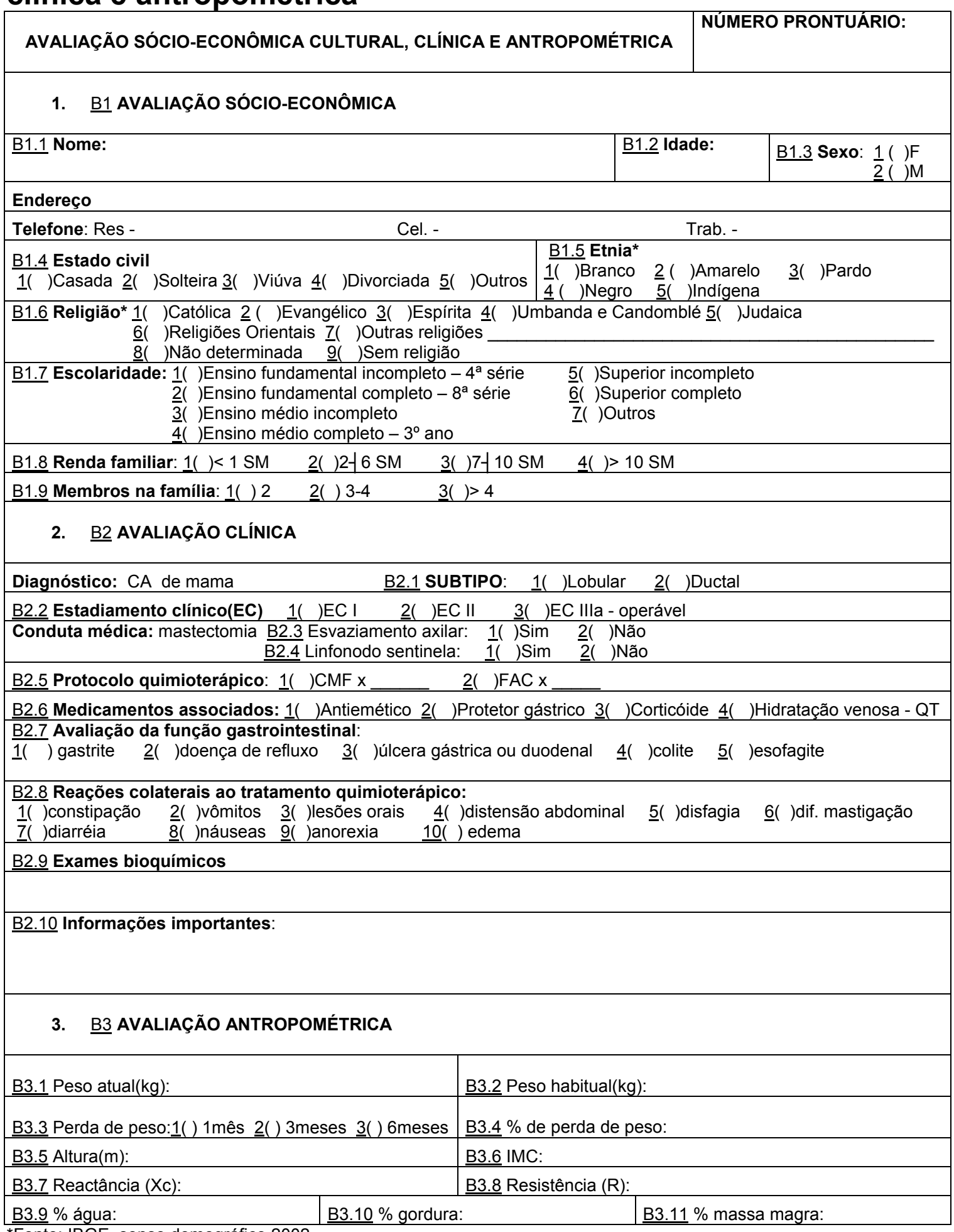

*Fonte: IBGE, senso demográfico 2002 
ANEXO 5 - Recordatório de 24 Horas

NOME:

TEL:( )

DATA DE NASC: $\_l-l$ ENTREVISTA $\_l-1 \_$DIA DA SEMANA:

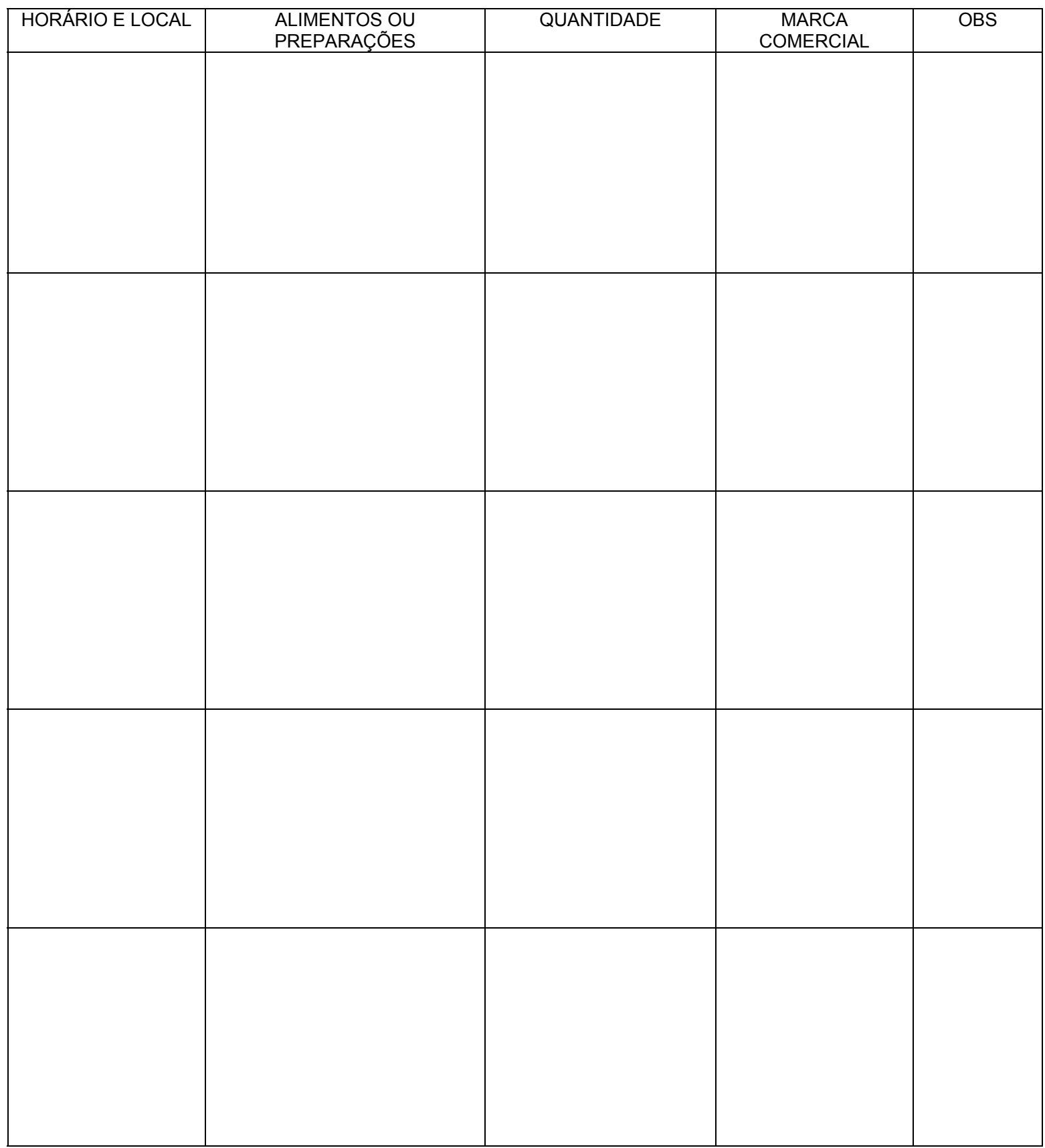

Entrevistador

Tempo da entrevista 


\section{ANEXO 6: Manual do Entrevistador}

Para o sucesso da aplicação do método de inquérito alimentar escolhido, é preciso que o entrevistador atente-se a algumas questões, que serão descritas ao longo deste manual.

\section{Apresentação inicial do entrevistador:}

> É de extrema importância, antes da aplicação do inquérito alimentar, que o entrevistador se apresente, explicando os objetivos da entrevista e informando ao entrevistado a duração média da mesma.

$>$ Esclarecer que todos os dados coletados são de ordem confidencial.

> Expor ao entrevistado o direito à não participação, sem qualquer prejuízo.

\section{Considerações importantes:}

$>$ Os entrevistadores deverão estar treinados e possuir amplo conhecimento dos hábitos e costumes da comunidade em estudo, assim como dos alimentos e modo de prepará-los.

> Para auxiliar na quantificação do tamanho e volume das porções consumidas, será utilizado material de suporte com registros fotográficos e réplicas de alimentos.

> O entrevistador deverá estabelecer um canal de comunicação em que se obtenha a informação por meio de um diálogo agradável, uma vez que a qualidade da informação dependerá da memória e da cooperação do entrevistado.

$>$ Respostas precisas e não tendenciosas exigem respeito e atitude neutra diante de hábitos e consumo de alimentos do entrevistado. Para tanto, o entrevistador deverá evitar expressar sentimentos de surpresa, tristeza ou decepção, o que poderia induzir o entrevistado a subestimar ou superestimar a quantidade de alimentos, dependendo da reação que ele observe.

\section{RECORDATÓRIO DE 24 HORAS}

Definição:

O recordatório de 24 horas é um método de inquérito alimentar realizado mediante uma entrevista pessoal, na qual o entrevistado relata detalhadamente os alimentos consumidos no dia anterior, desde o primeiro alimento ingerido após acordar até a última refeição antes de dormir, incluindo os alimentos consumidos dentro e fora do domicílio.

\section{Metodologia:}

A aplicação do Recordatório de 24 horas deve obedecer a seguinte metodologia: 
Passo 1: Pergunte ao indivíduo:

"A Sra pode, por favor, me dizer tudo o que comeu ou bebeu ontem, desde o momento que acordou até antes de dormir, começando pelo primeiro alimento ou bebida consumido?".

Transcreva tudo o que for dito, sem preocupação com quantidade, por enquanto. Não interrompa a informante.

Passo 2: Pergunte o horário e local da refeição.

"A Sra pode lembrar o horário (mais ou menos) e em que lugar?"

Anote os horários e o local referido.

Passo 3: Volte à descrição dos alimentos e pergunte as quantidades em medidas caseiras consumidas, de cada alimento ou preparação.

a. No caso de alimentos como frutas, pães, biscoitos e ovos, pergunte quantas unidades foram consumidas. Exemplo: 1 fatia de pão de forma, 1 pão francês, 1 pão de queijo, 1 biscoito recheado, etc.

b. Se possível, registre a marca comercial e variedade dos alimentos. Exemplo: banana nanica, prata, maçã.

c. No caso de alimentos compostos, como por exemplo café com leite, mingaus, mamadeiras, vitaminas e sopas, pergunte os ingredientes, quantidades e medidas utilizadas na preparação.

d. Para alimentos como carnes (vaca, frango, porco, peixe) utilize unidades como: fatia (pequena, média, grande), pedaço (pequeno, médio, grande), posta (pequena, média, grande).

e. Registre se a preparação da carne foi frita, assada, à milanesa ou grelhada.

f. No caso de verduras e legumes, pergunte os ingredientes da salada. Legumes (cenoura, abobrinha, berinjela, milho, etc): registre em colheres de sopa ou de servir e pergunte o tipo de preparação (cozidos ou refogados).

g. Para preparações habituais como arroz, feijão e macarrão utilize as medidas caseiras de referência (colher de sopa, de servir, concha, pegador de macarrão).

h. Certifique-se da presença ou não de temperos nas saladas, açúcar/adoçante nas bebidas, manteiga/requeijão/outros no pão/biscoito/ou torrada e suas quantidades.

i. Na faça perguntas tendenciosas. Exemplo: "Você tomou café da manhã? Você come pouco?"

j. Ao longo da entrevista, lembre-se de perguntar se houve sobras e quantificálas.

\section{Revisão do recordatório:}


Ao final da entrevista é importante que o entrevistador dê ao entrevistado a oportunidade para lembrar de algum alimento que porventura tenha consumido, mas esquecido de referir por ocasião da entrevista.

Por fim, é importante anotar o nome do entrevistador e quanto tempo durou a entrevista. 
ANEXO 7 - Escala Food Action (FACT)

\begin{tabular}{|c|c|c|c|c|c|c|c|c|c|c|}
\hline $\begin{array}{l}\frac{\text { C1 }}{\text { ALIMENTOS }} \\
\text { FREQUÊNCIA }\end{array}$ & \multicolumn{2}{|c|}{$\begin{array}{c}\text { C1.1 Sopas } \\
\text { (de legumes, } \\
\text { canja, } \\
\text { cremes, etc.) }\end{array}$} & & $\begin{array}{l}\text { C1.2 } \\
\text { arronada, } \\
\text { sanha }\end{array}$ & \multicolumn{2}{|c|}{$\begin{array}{l}\text { C1.3 Pizza, } \\
\text { empada, } \\
\text { esfiha, pastel, } \\
\text { kibe, coxinha }\end{array}$} & \multicolumn{2}{|c|}{$\begin{array}{c}\text { C1.4 Peixe } \\
\text { cozido, assado } \\
\text { ou grelhado }\end{array}$} & \multicolumn{2}{|c|}{$\begin{array}{l}\underline{\mathrm{C} 1.5} \text { Peixe } \\
\text { frito }\end{array}$} \\
\hline $\begin{array}{l}\text { Sempre que tivesse } \\
\text { oportunidade }\end{array}$ & 1 & 9 & 1 & 9 & 1 & 9 & 1 & 9 & 1 & 9 \\
\hline Muito freqüentemente & $\underline{2}$ & 8 & $\underline{2}$ & 8 & $\underline{2}$ & 8 & $\underline{2}$ & 8 & $\underline{2}$ & 8 \\
\hline Freqüentemente & $\underline{3}$ & 7 & $\underline{3}$ & 7 & $\underline{3}$ & 7 & $\underline{3}$ & 7 & $\underline{3}$ & 7 \\
\hline Agora; gosto muito & $\underline{4}$ & 6 & $\underline{4}$ & 6 & $\underline{4}$ & 6 & $\underline{4}$ & 6 & $\underline{4}$ & 6 \\
\hline Se disponível & $\underline{5}$ & 5 & $\underline{5}$ & 5 & $\underline{5}$ & 5 & $\underline{5}$ & 5 & $\underline{5}$ & 5 \\
\hline $\begin{array}{l}\text { Em uma ocasião; mas } \\
\text { não gosto }\end{array}$ & $\underline{6}$ & 4 & $\underline{6}$ & 4 & $\underline{6}$ & 4 & $\underline{6}$ & 4 & $\underline{6}$ & 4 \\
\hline $\begin{array}{l}\text { Quase nunca } \\
\text { Somente se não }\end{array}$ & $\underline{7}$ & 3 & $\underline{7}$ & 3 & $\underline{7}$ & 3 & $\underline{7}$ & 3 & $\underline{7}$ & 3 \\
\hline $\begin{array}{l}\text { houvesse outras } \\
\text { opções de comida }\end{array}$ & $\underline{8}$ & 2 & $\underline{8}$ & 2 & $\underline{8}$ & 2 & $\underline{8}$ & 2 & $\underline{8}$ & 2 \\
\hline Se fosse forçado & $\underline{9}$ & 1 & $\underline{9}$ & 1 & $\underline{9}$ & 1 & $\underline{9}$ & 1 & $\underline{9}$ & 1 \\
\hline
\end{tabular}

\begin{tabular}{|c|c|c|c|c|c|c|c|c|c|c|}
\hline $\begin{array}{l}\frac{\mathrm{C} 2}{\mathrm{ALIMENTOS}} \\
\text { FREQUÊNCIA }\end{array}$ & \multicolumn{2}{|c|}{$\begin{array}{l}\text { C2.1 Carne de } \\
\text { boi (cozida, } \\
\text { assada, } \\
\text { grelhada ou } \\
\text { churrasco) }\end{array}$} & & Bife & \multicolumn{2}{|c|}{$\begin{array}{c}\text { C2.3 Carne de } \\
\text { charque, carne } \\
\text { de sol }\end{array}$} & \multicolumn{2}{|c|}{$\begin{array}{c}\text { C2.4 Lingüiça, } \\
\text { salsicha, } \\
\text { presunto, } \\
\text { outros frios }\end{array}$} & \multicolumn{2}{|c|}{$\begin{array}{c}\text { C2.5 Frango } \\
\text { frito, à } \\
\text { milanesa, } \\
\text { nuggets }\end{array}$} \\
\hline $\begin{array}{l}\text { Sempre que tivesse } \\
\text { oportunidade }\end{array}$ & 1 & 9 & 1 & 9 & 1 & 9 & 1 & 9 & 1 & 9 \\
\hline Muito freqüentemente & $\underline{2}$ & 8 & $\underline{2}$ & 8 & $\underline{2}$ & 8 & $\underline{2}$ & 8 & $\underline{2}$ & 8 \\
\hline Freqüentemente & $\underline{3}$ & 7 & $\underline{3}$ & 7 & $\underline{3}$ & 7 & $\underline{3}$ & 7 & $\underline{3}$ & 7 \\
\hline Agora; gosto muito & $\underline{4}$ & 6 & $\underline{4}$ & 6 & $\underline{4}$ & 6 & $\underline{4}$ & 6 & $\underline{4}$ & 6 \\
\hline Se disponível & $\underline{5}$ & 5 & $\underline{5}$ & 5 & $\underline{5}$ & 5 & $\underline{5}$ & 5 & $\underline{5}$ & 5 \\
\hline $\begin{array}{l}\text { Em uma ocasião; mas } \\
\text { não gosto }\end{array}$ & $\underline{6}$ & 4 & $\underline{6}$ & 4 & $\underline{6}$ & 4 & $\underline{6}$ & 4 & $\underline{6}$ & 4 \\
\hline $\begin{array}{l}\text { Quase nunca } \\
\text { Somente se não }\end{array}$ & $\underline{7}$ & 3 & $\underline{7}$ & 3 & 7 & 3 & $\underline{7}$ & 3 & $\underline{7}$ & 3 \\
\hline $\begin{array}{l}\text { houvesse outras } \\
\text { opções de comida }\end{array}$ & $\underline{8}$ & 2 & $\underline{8}$ & 2 & $\underline{8}$ & 2 & $\underline{8}$ & 2 & $\underline{8}$ & 2 \\
\hline Se fosse forçado & $\underline{9}$ & 1 & $\underline{9}$ & 1 & $\underline{9}$ & 1 & $\underline{9}$ & 1 & $\underline{9}$ & 1 \\
\hline
\end{tabular}

\begin{tabular}{|c|c|c|c|c|c|c|c|c|c|}
\hline $\begin{array}{l}\frac{\mathrm{C} 3}{\text { ALIMENTOS }} \\
\text { FREQUÊNCIA }\end{array}$ & $\begin{array}{l}\text { C3.1 Frango } \\
\text { guisado, } \\
\text { grelhado, } \\
\text { assado, } \\
\text { espeto }\end{array}$ & & $\begin{array}{l}\text { Miúdos } \\
\text { rango }\end{array}$ & & $\begin{array}{l}3.3 \text { Fígado } \\
\text { bovino }\end{array}$ & & $\begin{array}{l}\text { 3.4 Feijão } \\
\text { ioca, preto, } \\
\text { verde }\end{array}$ & & $\begin{array}{l}\text { ozido, cru, } \\
\text { frito) }\end{array}$ \\
\hline $\begin{array}{l}\text { Sempre que tivesse } \\
\text { oportunidade }\end{array}$ & 9 & 1 & 9 & 1 & 9 & 1 & 9 & 1 & 9 \\
\hline Muito freqüentemente & 8 & $\underline{2}$ & 8 & $\underline{2}$ & 8 & $\underline{2}$ & 8 & $\underline{2}$ & 8 \\
\hline
\end{tabular}




\begin{tabular}{|c|c|c|c|c|c|c|c|c|c|c|}
\hline Freqüentemente & $\underline{3}$ & 7 & $\underline{3}$ & 7 & $\underline{3}$ & 7 & $\underline{3}$ & 7 & $\underline{3}$ & 7 \\
\hline Agora; gosto muito & $\underline{4}$ & 6 & $\underline{4}$ & 6 & $\underline{4}$ & 6 & $\underline{4}$ & 6 & $\underline{4}$ & 6 \\
\hline Se disponível & $\underline{5}$ & 5 & $\underline{5}$ & 5 & $\underline{5}$ & 5 & $\underline{5}$ & 5 & $\underline{5}$ & 5 \\
\hline $\begin{array}{l}\text { Em uma ocasião; mas } \\
\text { não gosto }\end{array}$ & $\underline{6}$ & 4 & $\underline{6}$ & 4 & $\underline{6}$ & 4 & $\underline{6}$ & 4 & $\underline{6}$ & 4 \\
\hline Quase nunca & $\underline{7}$ & 3 & $\underline{7}$ & 3 & $\underline{7}$ & 3 & $\underline{7}$ & 3 & $\underline{7}$ & 3 \\
\hline $\begin{array}{l}\text { Somente se não } \\
\text { houvesse outras } \\
\text { opções de comida }\end{array}$ & $\underline{8}$ & 2 & $\underline{8}$ & 2 & $\underline{8}$ & 2 & $\underline{8}$ & 2 & $\underline{8}$ & 2 \\
\hline Se fosse forçado & $\underline{9}$ & 1 & $\underline{9}$ & 1 & $\underline{9}$ & 1 & $\underline{9}$ & 1 & $\underline{9}$ & 1 \\
\hline
\end{tabular}

\begin{tabular}{|c|c|c|c|c|c|c|c|c|c|c|}
\hline $\begin{array}{l}\frac{\mathrm{C} 4}{\mathrm{ALIMENTOS}} \\
\text { FREQUÊNCIA }\end{array}$ & \multicolumn{2}{|c|}{$\begin{array}{c}\text { C4.1 Milho } \\
\text { verde, ervilha, } \\
\text { vagem } \\
\text { (fresco, } \\
\text { congelado, } \\
\text { enlatado) }\end{array}$} & \multicolumn{2}{|c|}{$\begin{array}{l}\text { C4.2 Arroz } \\
\text { braço cozido } \\
\text { com óleo e } \\
\text { temperos }\end{array}$} & \multicolumn{2}{|c|}{$\frac{\mathrm{C} 4.3}{\text { mandioca frita }}$} & \multicolumn{2}{|c|}{$\begin{array}{c}\text { C4.4 Batata, } \\
\text { mandioca, } \\
\text { inhame - } \\
\text { assado/ cozido }\end{array}$} & \multicolumn{2}{|c|}{$\begin{array}{c}\frac{\mathrm{C} 4.5}{\text { Saloda de }} \\
\text { maionese com } \\
\text { legumes }\end{array}$} \\
\hline $\begin{array}{l}\text { Sempre que tivesse } \\
\text { oportunidade }\end{array}$ & 1 & 9 & 1 & 9 & 1 & 9 & 1 & 9 & 1 & 9 \\
\hline Muito freqüentemente & $\underline{2}$ & 8 & $\underline{2}$ & 8 & $\underline{2}$ & 8 & $\underline{2}$ & 8 & $\underline{2}$ & 8 \\
\hline Freqüentemente & $\underline{3}$ & 7 & $\underline{3}$ & 7 & $\underline{3}$ & 7 & $\underline{3}$ & 7 & $\underline{3}$ & 7 \\
\hline Agora; gosto muito & $\underline{4}$ & 6 & $\underline{4}$ & 6 & $\underline{4}$ & 6 & $\underline{4}$ & 6 & $\underline{4}$ & 6 \\
\hline Se disponível & $\underline{5}$ & 5 & $\underline{5}$ & 5 & $\underline{5}$ & 5 & $\underline{5}$ & 5 & $\underline{5}$ & 5 \\
\hline $\begin{array}{l}\text { Em uma ocasião; mas } \\
\text { não gosto }\end{array}$ & $\underline{6}$ & 4 & $\underline{6}$ & 4 & $\underline{6}$ & 4 & $\underline{6}$ & 4 & $\underline{6}$ & 4 \\
\hline $\begin{array}{l}\text { Quase nunca } \\
\text { Somente se não }\end{array}$ & $\underline{7}$ & 3 & $\underline{7}$ & 3 & $\underline{7}$ & 3 & $\underline{7}$ & 3 & $\underline{7}$ & 3 \\
\hline $\begin{array}{l}\text { houvesse outras } \\
\text { opções de comida }\end{array}$ & $\underline{8}$ & 2 & $\underline{8}$ & 2 & $\underline{8}$ & 2 & $\underline{8}$ & 2 & $\underline{8}$ & 2 \\
\hline Se fosse forçado & $\underline{9}$ & 1 & $\underline{9}$ & 1 & $\underline{9}$ & 1 & $\underline{9}$ & 1 & $\underline{9}$ & 1 \\
\hline
\end{tabular}

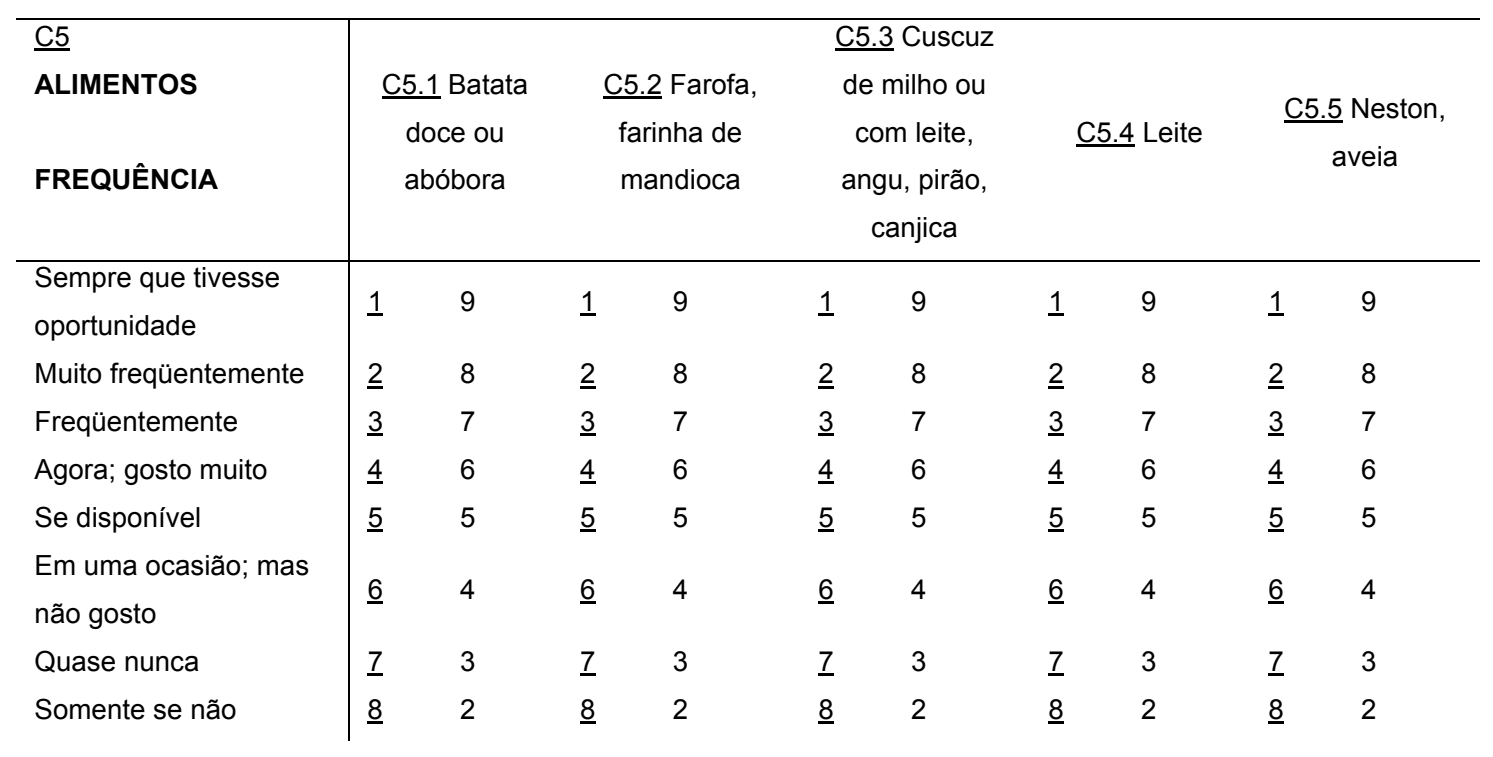




\begin{tabular}{|c|c|c|c|c|c|c|c|c|c|c|}
\hline Se fosse forçado & $\underline{9}$ & 1 & $\underline{9}$ & 1 & $\underline{9}$ & 1 & $\underline{9}$ & 1 & $\underline{9}$ & 1 \\
\hline$\underline{\mathrm{C} 6}$ & \multirow{2}{*}{\multicolumn{2}{|c|}{$\begin{array}{c}\text { C6.1 logurte } \\
\text { ou coalhada - } \\
\text { natural ou } \\
\text { com frutas }\end{array}$}} & \multirow{2}{*}{\multicolumn{2}{|c|}{$\begin{array}{l}\text { C6.2 Vitamina } \\
\text { de leite ou leite } \\
\text { batido com } \\
\text { frutas }\end{array}$}} & \multicolumn{6}{|c|}{ C6.4 Queijo } \\
\hline $\begin{array}{l}\text { ALIMENTOS } \\
\text { FREQUÊNCIA }\end{array}$ & & & & & \multicolumn{2}{|c|}{$\begin{array}{l}\text { C6.3 Queijo } \\
\text { minas ou } \\
\text { ricota, } \\
\text { requeijão light }\end{array}$} & \multicolumn{2}{|c|}{$\begin{array}{c}\text { coalho, } \\
\text { manteiga, prato, } \\
\text { mussarela, } \\
\text { requeijão } \\
\text { cremoso }\end{array}$} & & 6.5 Alface \\
\hline $\begin{array}{l}\text { Sempre que tivesse } \\
\text { oportunidade }\end{array}$ & 1 & 9 & 1 & 9 & 1 & 9 & 1 & 9 & 1 & 9 \\
\hline Muito freqüentemente & $\underline{2}$ & 8 & $\underline{2}$ & 8 & $\underline{2}$ & 8 & $\underline{2}$ & 8 & $\underline{2}$ & 8 \\
\hline Freqüentemente & $\underline{3}$ & 7 & $\underline{3}$ & 7 & $\underline{3}$ & 7 & $\underline{3}$ & 7 & $\underline{3}$ & 7 \\
\hline Agora; gosto muito & $\underline{4}$ & 6 & $\underline{4}$ & 6 & $\underline{4}$ & 6 & $\underline{4}$ & 6 & $\underline{4}$ & 6 \\
\hline Se disponível & $\underline{5}$ & 5 & $\underline{5}$ & 5 & $\underline{5}$ & 5 & $\underline{5}$ & 5 & $\underline{5}$ & 5 \\
\hline $\begin{array}{l}\text { Em uma ocasião; mas } \\
\text { não gosto }\end{array}$ & $\underline{6}$ & 4 & $\underline{6}$ & 4 & $\underline{6}$ & 4 & $\underline{6}$ & 4 & $\underline{6}$ & 4 \\
\hline $\begin{array}{l}\text { Quase nunca } \\
\text { Somente se não }\end{array}$ & $\underline{7}$ & 3 & $\underline{7}$ & 3 & 7 & 3 & $\underline{7}$ & 3 & $\underline{7}$ & 3 \\
\hline $\begin{array}{l}\text { houvesse outras } \\
\text { opções de comida }\end{array}$ & $\underline{8}$ & 2 & $\underline{8}$ & 2 & $\underline{8}$ & 2 & $\underline{8}$ & 2 & $\underline{8}$ & 2 \\
\hline Se fosse forçado & $\underline{9}$ & 1 & $\underline{9}$ & 1 & $\underline{9}$ & 1 & $\underline{9}$ & 1 & $\underline{9}$ & 1 \\
\hline
\end{tabular}

\begin{tabular}{|c|c|c|c|c|c|c|c|c|c|c|}
\hline $\begin{array}{l}\frac{\mathrm{C} 7}{\text { ALIMENTOS }} \\
\text { FREQUÊNCIA } \\
\text { Sempre que tivesse }\end{array}$ & \multicolumn{2}{|c|}{$\begin{array}{c}\text { C7.1 Tomate } \\
\text { cru }\end{array}$} & \multicolumn{2}{|c|}{$\begin{array}{c}\text { C7.2 Couve } \\
\text { espinafre, } \\
\text { escarola }\end{array}$} & \multicolumn{2}{|c|}{$\begin{array}{l}\underline{\mathrm{C} 7.3} \text { Beterraba } \\
\text { crua ou cozida }\end{array}$} & \multicolumn{2}{|c|}{$\begin{array}{l}\text { C7.4 Cenoura } \\
\text { crua ou cozida }\end{array}$} & \multicolumn{2}{|c|}{$\frac{\text { C7.5 Pepino, }}{\text { pimentão }}$} \\
\hline $\begin{array}{l}\text { Sempre que tivesse } \\
\text { oportunidade }\end{array}$ & 1 & 9 & 1 & 9 & 1 & 9 & 1 & 9 & 1 & 9 \\
\hline Muito freqüentemente & $\underline{2}$ & 8 & $\underline{2}$ & 8 & $\underline{2}$ & 8 & $\underline{2}$ & 8 & $\underline{2}$ & 8 \\
\hline Freqüentemente & $\underline{3}$ & 7 & $\underline{3}$ & 7 & $\underline{3}$ & 7 & $\underline{3}$ & 7 & $\underline{3}$ & 7 \\
\hline Agora; gosto muito & $\underline{4}$ & 6 & $\underline{4}$ & 6 & $\underline{4}$ & 6 & $\underline{4}$ & 6 & $\underline{4}$ & 6 \\
\hline Se disponível & $\underline{5}$ & 5 & $\underline{5}$ & 5 & $\underline{5}$ & 5 & $\underline{5}$ & 5 & $\underline{5}$ & 5 \\
\hline $\begin{array}{l}\text { Em uma ocasião; mas } \\
\text { não gosto }\end{array}$ & $\underline{6}$ & 4 & $\underline{6}$ & 4 & $\underline{6}$ & 4 & $\underline{6}$ & 4 & $\underline{6}$ & 4 \\
\hline $\begin{array}{l}\text { Quase nunca } \\
\text { Somente se não }\end{array}$ & $\underline{7}$ & 3 & $\underline{7}$ & 3 & $\underline{7}$ & 3 & $\underline{7}$ & 3 & $\underline{7}$ & 3 \\
\hline $\begin{array}{l}\text { houvesse outras } \\
\text { opções de comida }\end{array}$ & $\underline{8}$ & 2 & $\underline{8}$ & 2 & $\underline{8}$ & 2 & $\underline{8}$ & 2 & $\underline{8}$ & 2 \\
\hline Se fosse forçado & $\underline{9}$ & 1 & $\underline{9}$ & 1 & $\underline{9}$ & 1 & $\underline{9}$ & 1 & $\underline{9}$ & 1 \\
\hline
\end{tabular}

\begin{tabular}{|c|c|c|c|c|c|}
\hline$\frac{\mathrm{C8}}{\mathrm{ALIMENTOS}}$ & $\begin{array}{c}\text { C8.1 Óleo, } \\
\text { azeite ou } \\
\text { vinagrete em }\end{array}$ & $\begin{array}{l}\text { C8.2 Catchup } \\
\text { ou mostarda }\end{array}$ & $\begin{array}{c}\text { C8.3 Maionese } \\
\text { molho rosê }\end{array}$ & $\begin{array}{c}\text { C8.4 Laranja, } \\
\text { mexerica }\end{array}$ & $\underline{\text { C8.5 Banana }}$ \\
\hline
\end{tabular}




\begin{tabular}{|c|c|c|c|c|c|c|c|c|c|c|}
\hline FREQUÊNCIA & & ada & & & & & & & & \\
\hline $\begin{array}{l}\text { Sempre que tivesse } \\
\text { oportunidade }\end{array}$ & 1 & 9 & 1 & 9 & 1 & 9 & 1 & 9 & 1 & 9 \\
\hline Muito freqüentemente & $\underline{2}$ & 8 & $\underline{2}$ & 8 & $\underline{2}$ & 8 & $\underline{2}$ & 8 & $\underline{2}$ & 8 \\
\hline Freqüentemente & $\underline{3}$ & 7 & $\underline{3}$ & 7 & $\underline{3}$ & 7 & $\underline{3}$ & 7 & $\underline{3}$ & 7 \\
\hline Agora; gosto muito & $\underline{4}$ & 6 & $\underline{4}$ & 6 & $\underline{4}$ & 6 & $\underline{4}$ & 6 & $\underline{4}$ & 6 \\
\hline Se disponível & $\underline{5}$ & 5 & $\underline{5}$ & 5 & $\underline{5}$ & 5 & $\underline{5}$ & 5 & $\underline{5}$ & 5 \\
\hline $\begin{array}{l}\text { Em uma ocasião; mas } \\
\text { não gosto }\end{array}$ & $\underline{6}$ & 4 & $\underline{6}$ & 4 & $\underline{6}$ & 4 & $\underline{6}$ & 4 & $\underline{6}$ & 4 \\
\hline $\begin{array}{l}\text { Quase nunca } \\
\text { Somente se não }\end{array}$ & $\underline{7}$ & 3 & $\underline{7}$ & 3 & $\underline{7}$ & 3 & $\underline{7}$ & 3 & $\underline{7}$ & 3 \\
\hline $\begin{array}{l}\text { houvesse outras } \\
\text { opções de comida }\end{array}$ & $\underline{8}$ & 2 & $\underline{8}$ & 2 & $\underline{8}$ & 2 & $\underline{8}$ & 2 & $\underline{8}$ & 2 \\
\hline Se fosse forçado & $\underline{9}$ & 1 & $\underline{9}$ & 1 & $\underline{9}$ & 1 & $\underline{9}$ & 1 & $\underline{9}$ & 1 \\
\hline
\end{tabular}

\begin{tabular}{|c|c|c|c|c|c|c|c|c|c|c|}
\hline $\begin{array}{l}\frac{\text { C9 }}{\text { ALIMENTOS }} \\
\text { FREQUÊNCIA }\end{array}$ & \multicolumn{2}{|c|}{$\underline{\text { C9.1 Mamão }}$} & \multicolumn{2}{|c|}{ C9.2 Maçã } & \multicolumn{2}{|c|}{$\begin{array}{l}\text { C9.3 Melancia, } \\
\text { melão }\end{array}$} & \multicolumn{2}{|c|}{ C9.4 Morango } & \multicolumn{2}{|c|}{ 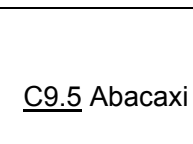 } \\
\hline $\begin{array}{l}\text { Sempre que tivesse } \\
\text { oportunidade }\end{array}$ & 1 & 9 & 1 & 9 & 1 & 9 & 1 & 9 & 1 & 9 \\
\hline Muito freqüentemente & $\underline{2}$ & 8 & $\underline{2}$ & 8 & $\underline{2}$ & 8 & $\underline{2}$ & 8 & $\underline{2}$ & 8 \\
\hline Freqüentemente & $\underline{3}$ & 7 & $\underline{3}$ & 7 & $\underline{3}$ & 7 & $\underline{3}$ & 7 & $\underline{3}$ & 7 \\
\hline Agora; gosto muito & $\underline{4}$ & 6 & $\underline{4}$ & 6 & $\underline{4}$ & 6 & $\underline{4}$ & 6 & $\underline{4}$ & 6 \\
\hline Se disponível & $\underline{5}$ & 5 & $\underline{5}$ & 5 & $\underline{5}$ & 5 & $\underline{5}$ & 5 & $\underline{5}$ & 5 \\
\hline $\begin{array}{l}\text { Em uma ocasião; mas } \\
\text { não gosto }\end{array}$ & $\underline{6}$ & 4 & $\underline{6}$ & 4 & $\underline{6}$ & 4 & $\underline{6}$ & 4 & $\underline{6}$ & 4 \\
\hline $\begin{array}{l}\text { Quase nunca } \\
\text { Somente se não }\end{array}$ & $\underline{7}$ & 3 & $\underline{7}$ & 3 & $\underline{7}$ & 3 & $\underline{7}$ & 3 & $\underline{7}$ & 3 \\
\hline $\begin{array}{l}\text { houvesse outras } \\
\text { opções de comida }\end{array}$ & $\underline{8}$ & 2 & $\underline{8}$ & 2 & $\underline{8}$ & 2 & $\underline{8}$ & 2 & $\underline{8}$ & 2 \\
\hline Se fosse forçado & $\underline{9}$ & 1 & $\underline{9}$ & 1 & $\underline{9}$ & 1 & $\underline{9}$ & 1 & $\underline{9}$ & 1 \\
\hline
\end{tabular}

\begin{tabular}{|c|c|c|c|c|c|c|c|c|c|c|}
\hline \multirow{2}{*}{$\begin{array}{l}\text { FREQUÊNCIA } \\
\text { Sempre que tivesse } \\
\text { oportunidade }\end{array}$} & \multirow{2}{*}{\multicolumn{2}{|c|}{$\begin{array}{c}\frac{\mathrm{C} 10.1}{\text { Ameixa }} \\
9\end{array}$}} & \multicolumn{2}{|c|}{$\frac{\text { C10.2 Suco de }}{\text { laranja }}$} & \multicolumn{2}{|c|}{$\begin{array}{l}\text { C10.3 Suco } \\
\text { natural de } \\
\text { outras frutas }\end{array}$} & \multicolumn{2}{|c|}{$\begin{array}{c}\text { C10.4 Pão } \\
\text { francês, forma, } \\
\text { integral, doce, } \\
\text { torrada }\end{array}$} & \multicolumn{2}{|c|}{$\begin{array}{l}\text { C10.5 Biscoito } \\
\text { salgado, } \\
\text { biscoito doce } \\
\text { sem recheio }\end{array}$} \\
\hline & & & 1 & 9 & 1 & 9 & 1 & 9 & 1 & 9 \\
\hline Muito freqüentemente & $\underline{2}$ & 8 & $\underline{2}$ & 8 & $\underline{2}$ & 8 & $\underline{2}$ & 8 & $\underline{2}$ & 8 \\
\hline Freqüentemente & $\underline{3}$ & 7 & $\underline{3}$ & 7 & $\underline{3}$ & 7 & $\underline{3}$ & 7 & $\underline{3}$ & 7 \\
\hline Agora; gosto muito & $\underline{4}$ & 6 & $\underline{4}$ & 6 & $\underline{4}$ & 6 & $\underline{4}$ & 6 & $\underline{4}$ & 6 \\
\hline Se disponível & $\underline{5}$ & 5 & $\underline{5}$ & 5 & $\underline{5}$ & 5 & $\underline{5}$ & 5 & $\underline{5}$ & 5 \\
\hline $\begin{array}{l}\text { Em uma ocasião; mas } \\
\text { não gosto }\end{array}$ & $\underline{6}$ & 4 & $\underline{6}$ & 4 & $\underline{6}$ & 4 & $\underline{6}$ & 4 & $\underline{6}$ & 4 \\
\hline Quase nunca & $\underline{7}$ & 3 & $\underline{7}$ & 3 & $\underline{7}$ & 3 & $\underline{7}$ & 3 & $\underline{7}$ & 3 \\
\hline Somente se não & $\underline{8}$ & 2 & $\underline{8}$ & 2 & $\underline{8}$ & 2 & $\underline{8}$ & 2 & $\underline{8}$ & 2 \\
\hline
\end{tabular}




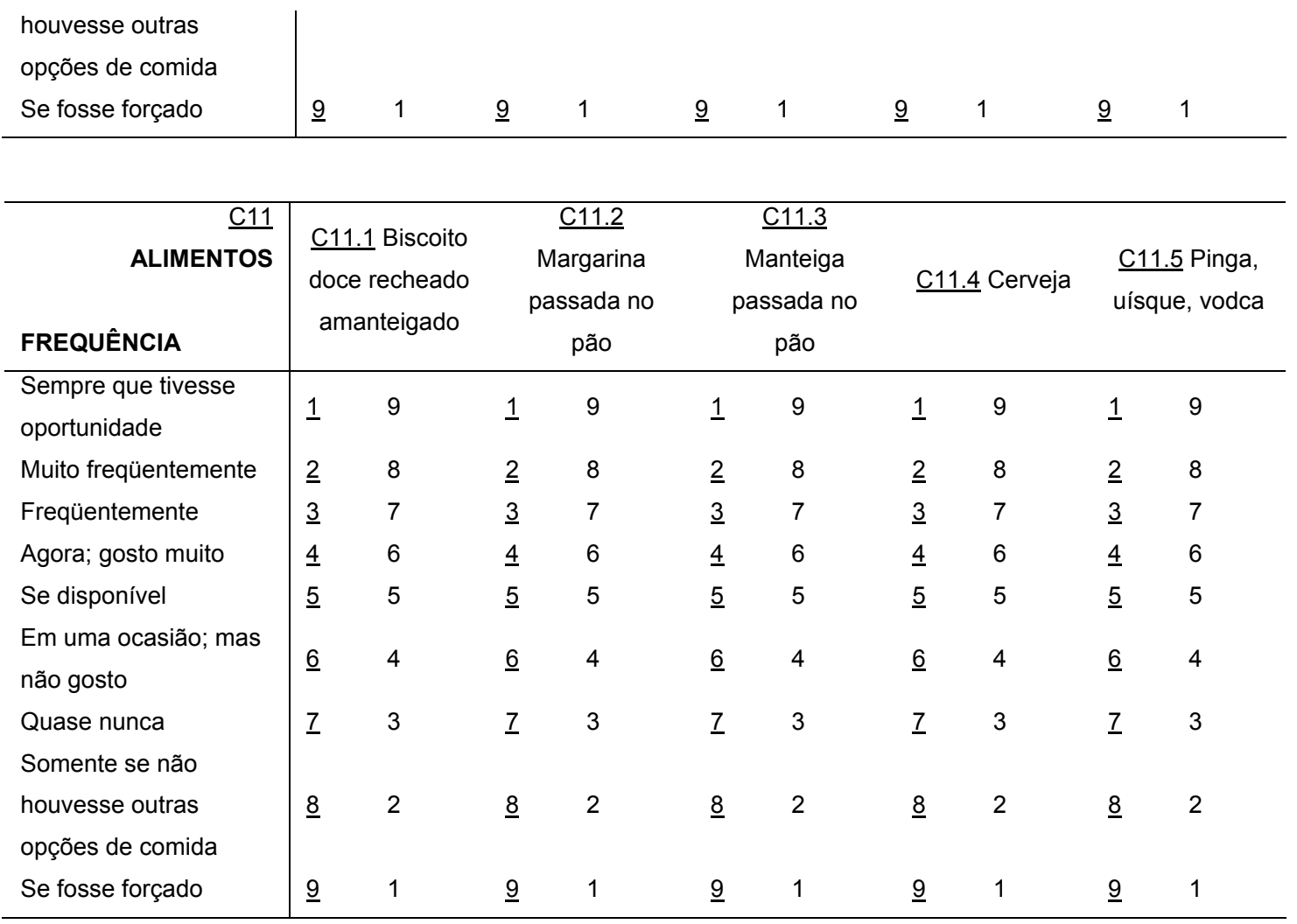

\begin{tabular}{|c|c|c|c|c|c|c|c|c|c|c|}
\hline \multirow{2}{*}{$\begin{array}{l}\text { ALIMENTOS } \\
\text { FREQUÊNCIA } \\
\end{array}$} & \multirow[b]{2}{*}{$\underline{\mathrm{C} 12.1}$} & \multirow[b]{2}{*}{ Vinho } & \multirow{2}{*}{\multicolumn{2}{|c|}{$\begin{array}{c}\underline{\text { C12.2 Café }} \\
\text { com e sem } \\
\text { açúcar }\end{array}$}} & \multicolumn{6}{|c|}{$\underline{\mathrm{C} 12.4}$} \\
\hline & & & & & \multicolumn{2}{|c|}{$\begin{array}{c}\text { C12.3 Adoçante } \\
\text { artificial }\end{array}$} & \multicolumn{2}{|c|}{$\begin{array}{l}\text { Chocolate, } \\
\text { bombons, } \\
\text { brigadeiro }\end{array}$} & \multicolumn{2}{|c|}{$\frac{\text { C12.5 Doce }}{\text { de frutas }}$} \\
\hline $\begin{array}{l}\text { Sempre que tivesse } \\
\text { oportunidade }\end{array}$ & 1 & 9 & 1 & 9 & 1 & 9 & 1 & 9 & 1 & 9 \\
\hline Muito freqüentemente & $\underline{2}$ & 8 & $\underline{2}$ & 8 & $\underline{2}$ & 8 & $\underline{2}$ & 8 & $\underline{2}$ & 8 \\
\hline Freqüentemente & $\underline{3}$ & 7 & $\underline{3}$ & 7 & $\underline{3}$ & 7 & $\underline{3}$ & 7 & $\underline{3}$ & 7 \\
\hline Agora; gosto muito & $\underline{4}$ & 6 & $\underline{4}$ & 6 & $\underline{4}$ & 6 & $\underline{4}$ & 6 & $\underline{4}$ & 6 \\
\hline Se disponível & $\underline{5}$ & 5 & $\underline{5}$ & 5 & $\underline{5}$ & 5 & $\underline{5}$ & 5 & $\underline{5}$ & 5 \\
\hline $\begin{array}{l}\text { Em uma ocasião; mas } \\
\text { não gosto }\end{array}$ & $\underline{6}$ & 4 & $\underline{6}$ & 4 & $\underline{6}$ & 4 & $\underline{6}$ & 4 & $\underline{6}$ & 4 \\
\hline $\begin{array}{l}\text { Quase nunca } \\
\text { Somente se não }\end{array}$ & $\underline{7}$ & 3 & $\underline{7}$ & 3 & $\underline{7}$ & 3 & $\underline{7}$ & 3 & $\underline{7}$ & 3 \\
\hline $\begin{array}{l}\text { houvesse outras } \\
\text { opções de comida }\end{array}$ & $\underline{8}$ & 2 & $\underline{8}$ & 2 & $\underline{8}$ & 2 & $\underline{8}$ & 2 & $\underline{8}$ & 2 \\
\hline Se fosse forçado & $\underline{9}$ & 1 & $\underline{9}$ & 1 & $\underline{9}$ & 1 & $\underline{9}$ & 1 & $\underline{9}$ & 1 \\
\hline
\end{tabular}

\begin{tabular}{|c|c|c|c|}
\hline $\begin{array}{l}\frac{\mathrm{C} 13}{\text { ALIMENTOS }} \\
\text { FREOUÊNCIA }\end{array}$ & $\frac{\text { C13.1 Bolos }}{\text { e tortas }}$ & $\underline{\text { C13.2 Sorvete }}$ & $\begin{array}{c}\frac{\mathrm{C} 13.3}{\text { Refrigerantes }} \\
\text { Rent }\end{array}$ \\
\hline $\begin{array}{l}\text { Sempre que tivesse } \\
\text { oportunidade }\end{array}$ & 1 & 1 & 1 \\
\hline
\end{tabular}




\begin{tabular}{|c|c|c|c|c|c|}
\hline Muito freqüentemente & $\underline{2}$ & 8 & $\underline{2}$ & 8 & $\underline{2}$ \\
\hline Freqüentemente & $\underline{3}$ & 7 & $\underline{3}$ & 7 & $\underline{3}$ \\
\hline Agora; gosto muito & $\underline{4}$ & 6 & $\underline{4}$ & 6 & $\underline{4}$ \\
\hline Se disponível & $\underline{5}$ & 5 & $\underline{5}$ & 5 & $\underline{5}$ \\
\hline $\begin{array}{l}\text { Em uma ocasião; mas } \\
\text { não gosto }\end{array}$ & $\underline{6}$ & 4 & $\underline{6}$ & 4 & $\underline{6}$ \\
\hline $\begin{array}{l}\text { Quase nunca } \\
\text { Somente se não }\end{array}$ & $\underline{7}$ & 3 & $\underline{7}$ & 3 & $\underline{7}$ \\
\hline $\begin{array}{l}\text { houvesse outras } \\
\text { opções de comida }\end{array}$ & $\underline{8}$ & 2 & $\underline{8}$ & 2 & $\underline{8}$ \\
\hline Se fosse forçado & $\underline{9}$ & 1 & $\underline{9}$ & 1 & $\underline{9}$ \\
\hline
\end{tabular}

Há algum alimento que você não gosta e que comê-lo ou pensar nele faz você sentirse desconfortável?

Não

Sim. Qual? 
ANEXO 8 - Respostas para Escala de Aversão Alimentar (FACT)

$\checkmark$ Sempre que tenho oportunidade

$\checkmark$ Quase sempre

$\checkmark$ Frequentemente

$\checkmark$ Gosto muito e como de vez em quando

$\checkmark$ Como se estiver disponível, mas não deixo o que estou fazendo por causa desse alimento

$\checkmark$ Não gosto muito, mas como ocasionalmente

$\checkmark$ Quase nunca como

$\checkmark$ Somente se não houver outras opções de comida

$\checkmark$ Só como se for forçada 


\section{ANEXO 9 - Escala Functional Assessment Cancer Treatment -Breast Cancer (FACT-B)}

\section{D1 Bem-estar físico}

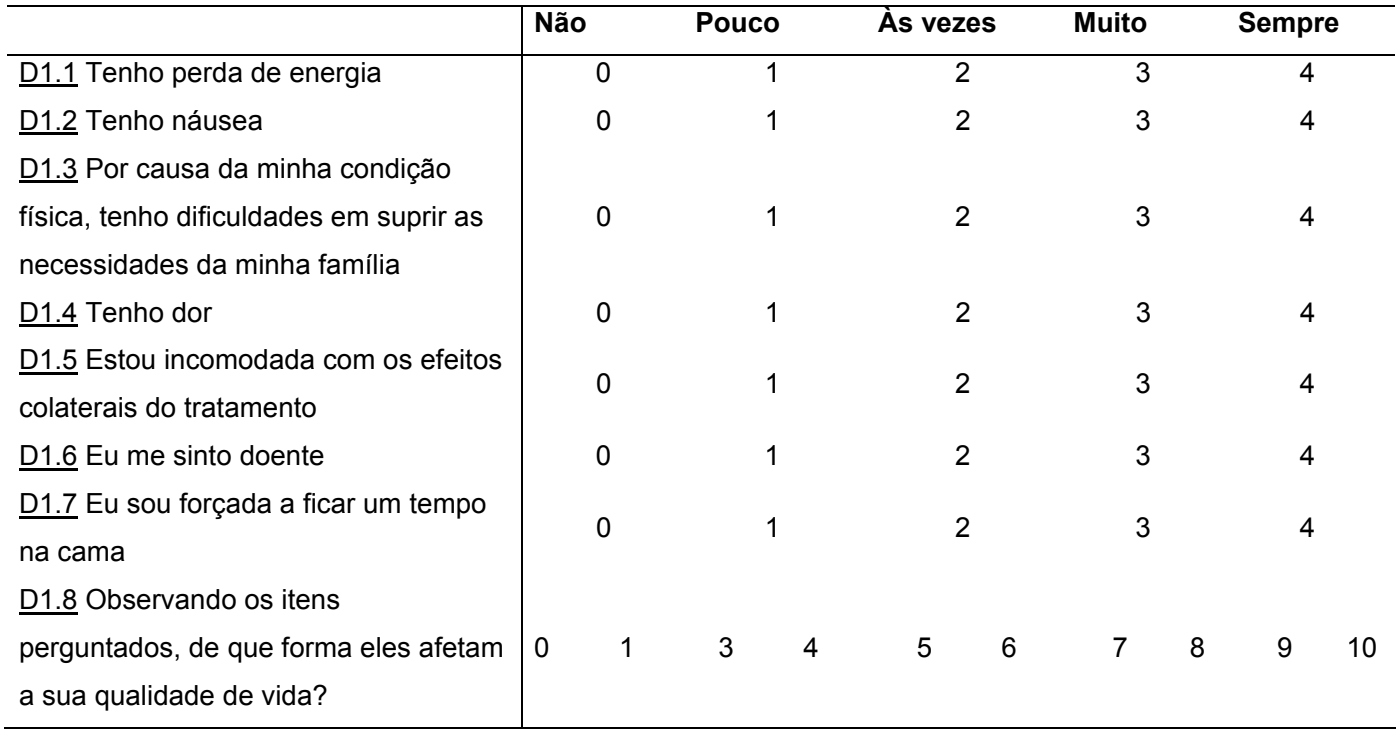

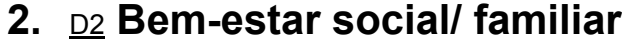

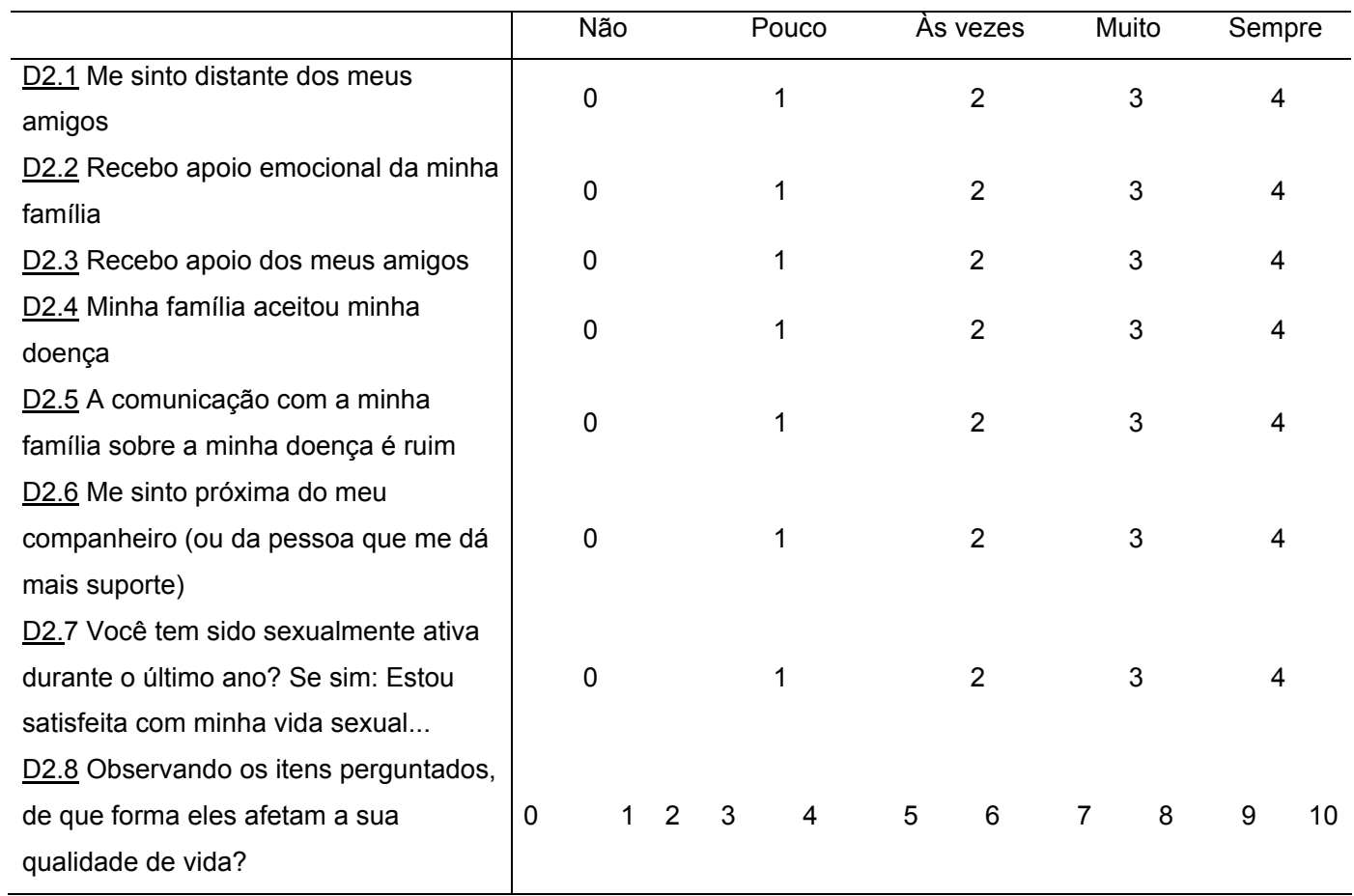

\section{D3 Relacionamento com o médico}

\begin{tabular}{|c|c|c|c|c|c|}
\hline & Não & Pouco & Às vezes & Muito & Sempre \\
\hline D3.1 Tenho confiança no meu médico & 0 & 1 & 2 & 3 & 4 \\
\hline $\begin{array}{l}\text { D3.2 Meu médico está disponível para } \\
\text { responder minhas dúvidas }\end{array}$ & 0 & 1 & 2 & 3 & 4 \\
\hline
\end{tabular}


D3.3 Observando os itens

perguntados, de que forma eles afetam

a sua qualidade de vida?

\section{4. $\underline{\mathrm{D}}$ Bem-estar emocional}

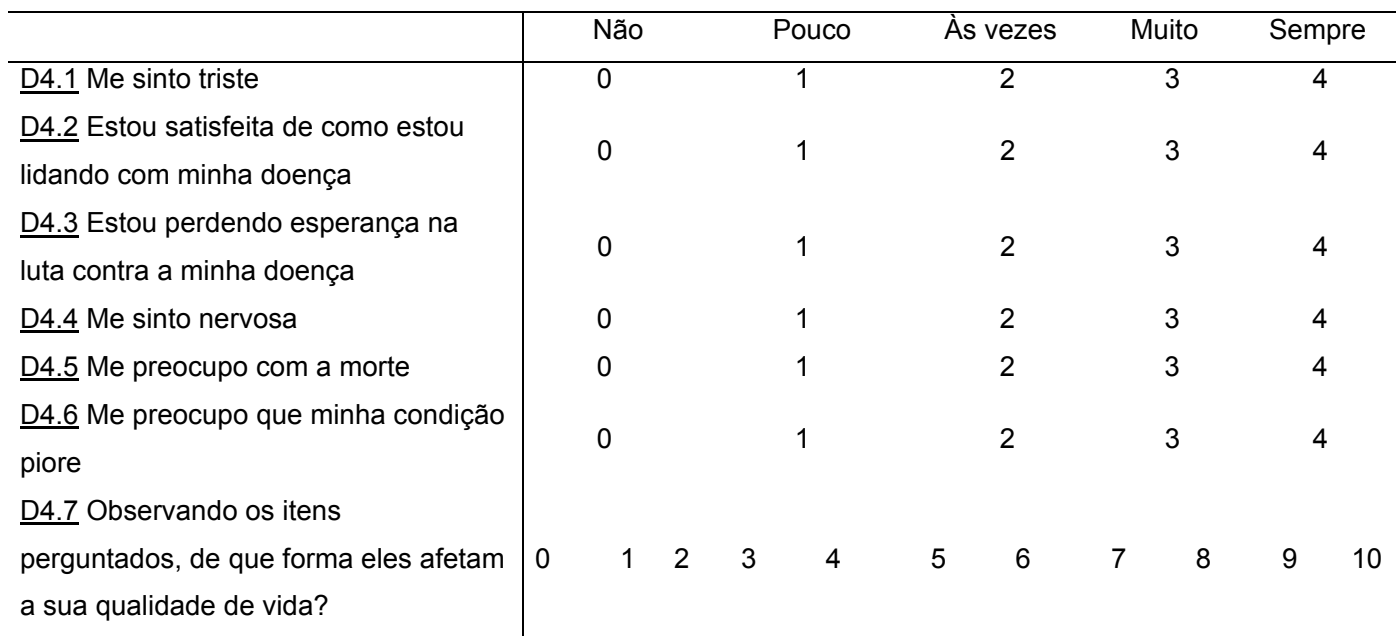

\section{D5 Bem-estar funcional}

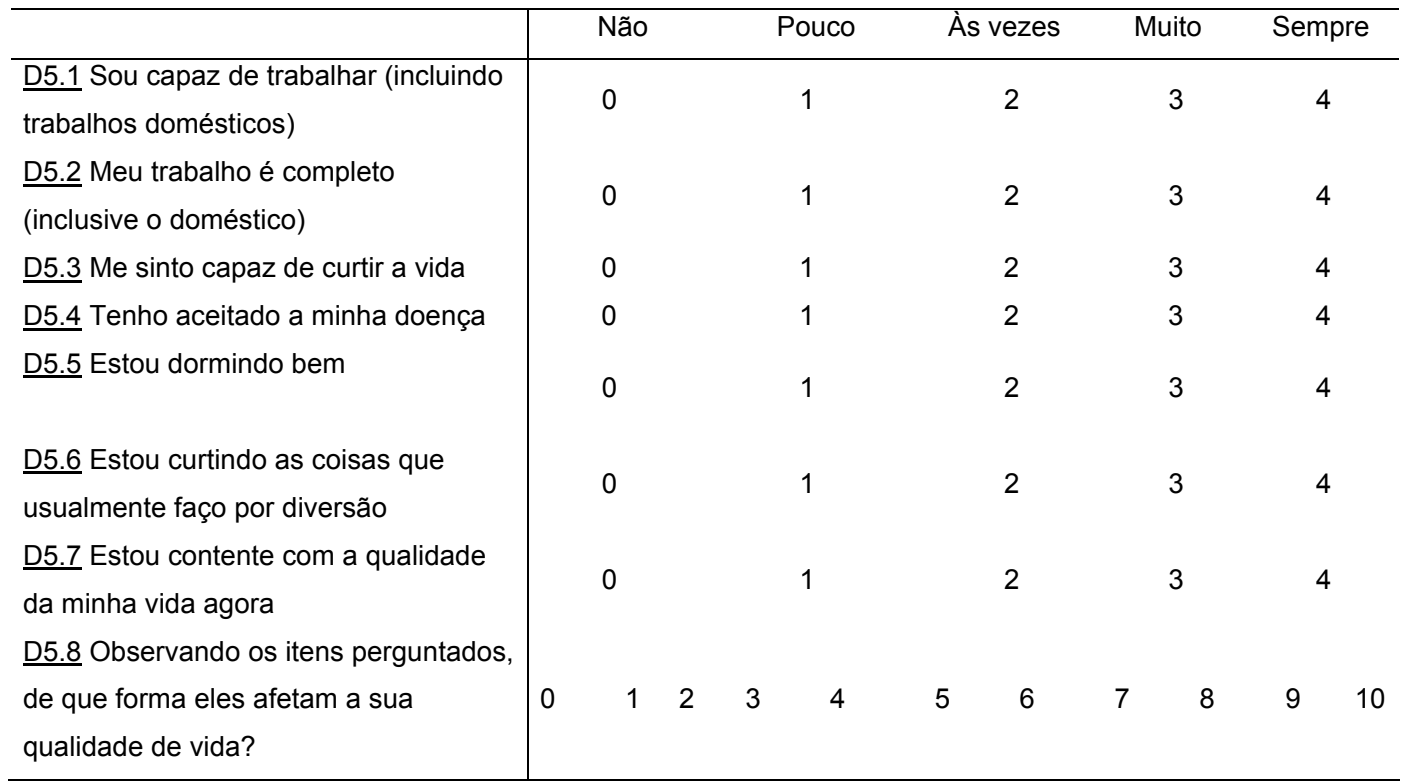

\section{D6 Questões de interesse adicional}

\begin{tabular}{|c|c|c|c|c|c|}
\hline & Não & Pouco & Às vezes & Muito & Sempre \\
\hline D6.1 Tenho tido falta de ar & 0 & 1 & 2 & 3 & 4 \\
\hline $\begin{array}{l}\text { D6.2 Me sinto desconfortável em } \\
\text { relação à forma como se veste }\end{array}$ & 0 & 1 & 2 & 3 & 4 \\
\hline $\begin{array}{l}\text { D6.3 Um ou ambos os meus braços } \\
\text { estão inchados ou tensos }\end{array}$ & 0 & 1 & 2 & 3 & 4 \\
\hline D6.4 Me sinto sexualmente atraente & 0 & 1 & 2 & 3 & 4 \\
\hline D6.5 Estou incomodada pela queda de & 0 & 1 & 2 & 3 & 4 \\
\hline
\end{tabular}




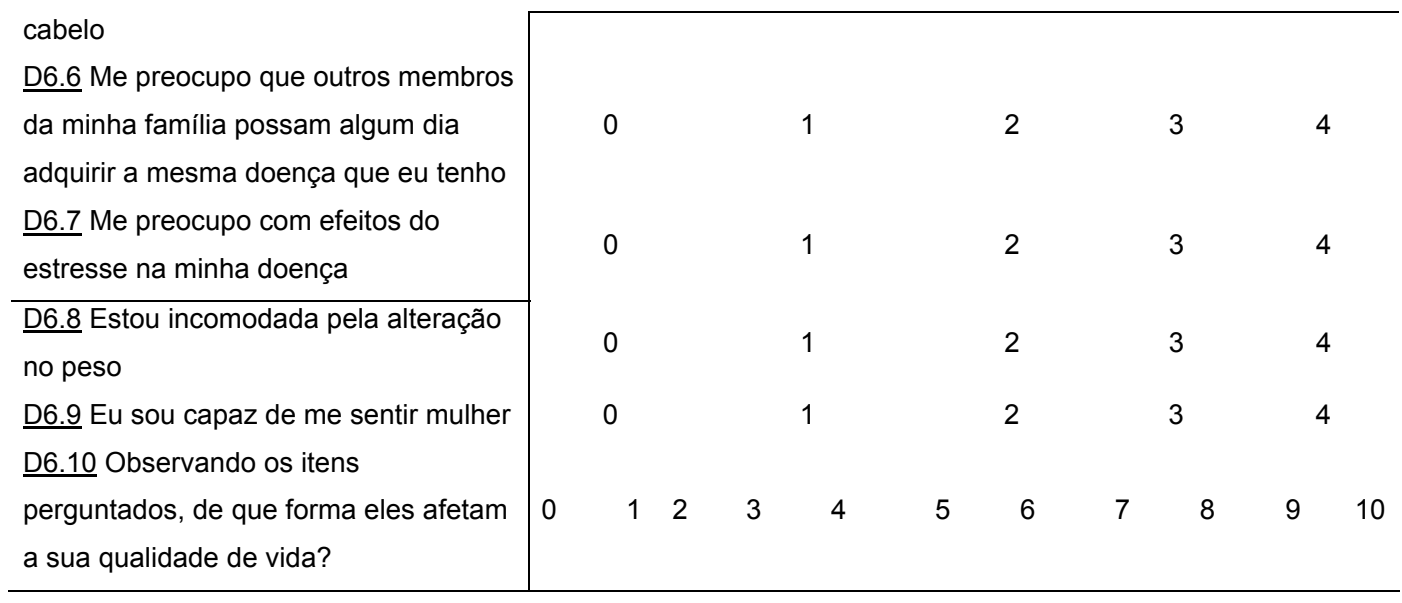

